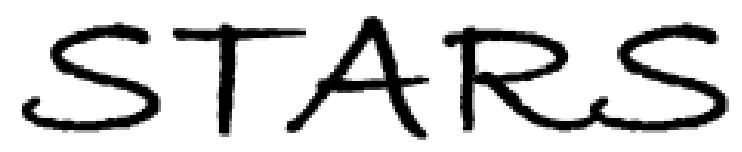

University of Central Florida

STARS

$9-1-2016$

\title{
Flexible Residential Test Facility: Impact Of Infiltration And Ventilation On Measured Cooling Season Energy And Moisture Levels (2016)
}

Florida Solar Energy Center

Danny Parker

Florida Solar Energy Center, dparker@fsec.ucf.edu

Part of the Energy Systems Commons

Find similar works at: https://stars.library.ucf.edu/fsec

University of Central Florida Libraries http://library.ucf.edu

This Contract Report is brought to you for free and open access by STARS. It has been accepted for inclusion in FSEC Energy Research Center ${ }^{\circledR}$ by an authorized administrator of STARS. For more information, please contact

STARS@ucf.edu.

\section{STARS Citation}

Florida Solar Energy Center and Parker, Danny, "Flexible Residential Test Facility: Impact Of Infiltration And Ventilation On Measured Cooling Season Energy And Moisture Levels (2016)" (2016). FSEC Energy Research Center®. 108.

https://stars.library.ucf.edu/fsec/108

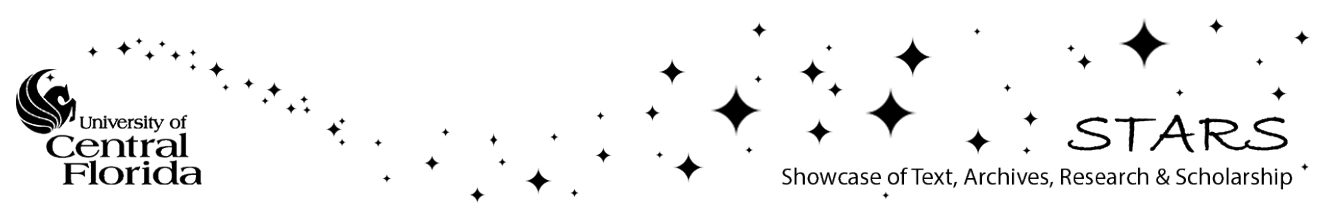




\section{FLORIDA SOLAR ENERGY CENTER \\ Creating Energy Independence}

\section{Flexible Residential Test Facility: Impact of Infiltration and Ventilation on Measured Cooling Season Energy and Moisture Levels}

FSEC-CR-2038-16

Final Report

September 2016

\section{Authors}

Danny Parker

James Cummings

Robin Vieira

Philip Fairey III

John Sherwin

Charles Withers Jr.

David Hoak

David Beal

(C)2016 University of Central Florida.

All Rights Reserved.

\section{Clearlake Road}

Cocoa, Florida 32922, USA

(321) 638-1000

www.floridaenergycenter.org 


\section{Disclaimer}

The Florida Solar Energy Center/University of Central Florida nor any agency thereof, nor any of their employees, makes any warranty, express or implied, or assumes any legal liability or responsibility for the accuracy, completeness, or usefulness of any information, apparatus, product, or process disclosed, or represents that its use would not infringe privately owned rights. Reference herein to any specific commercial product, process, or service by trade name, trademark, manufacturer, or otherwise does not necessarily constitute or imply its endorsement, recommendation, or favoring by the Florida Solar Energy Center/University of Central Florida or any agency thereof. The views and opinions of authors expressed herein do not necessarily state or reflect those of the Florida Solar Energy Center/University of Central Florida or any agency thereof. 


\section{Flexible Residential Test Facility:} Impact of Infiltration and Ventilation on Measured Cooling Season Energy and Moisture Levels

D. Parker, J. Cummings, R. Vieira, P. Fairey III, J. Sherwin, C. Withers Jr., D. Hoak, and D. Beal BA-PIRC 


\section{NOTICE}

This report was prepared as an account of work sponsored by an agency of the United States government. Neither the United States government nor any agency thereof, nor any of their employees, subcontractors, or affiliated partners makes any warranty, express or implied, or assumes any legal liability or responsibility for the accuracy, completeness, or usefulness of any information, apparatus, product, or process disclosed, or represents that its use would not infringe privately owned rights. Reference herein to any specific commercial product, process, or service by trade name, trademark, manufacturer, or otherwise does not necessarily constitute or imply its endorsement, recommendation, or favoring by the United States government or any agency thereof. The views and opinions of authors expressed herein do not necessarily state or reflect those of the United States government or any agency thereof.

Available electronically at SciTech Connect http:/www.osti.gov/scitech

Available for a processing fee to U.S. Department of Energy

and its contractors, in paper, from:

U.S. Department of Energy

Office of Scientific and Technical Information

P.O. Box 62

Oak Ridge, TN 37831-0062

OSTI http://www.osti.gov

Phone: 865.576.8401

Fax: 865.576.5728

Email: reports@osti.gov

Available for sale to the public, in paper, from:

U.S. Department of Commerce

National Technical Information Service

5301 Shawnee Road

Alexandria, VA 22312

NTIS http://www.ntis.gov

Phone: 800.553 .6847 or 703.605 .6000

Fax: 703.605.6900

Email: orders@ntis.gov 


\title{
Flexible Residential Test Facility: Impact of Infiltration and Ventilation on Measured Cooling Season Energy and Moisture Levels
}

\author{
Prepared for: \\ The National Renewable Energy Laboratory \\ On behalf of the U.S. Department of Energy's Building America Program \\ Office of Energy Efficiency and Renewable Energy \\ 15013 Denver West Parkway \\ Golden, CO 80401 \\ NREL Contract No. DE-AC36-08GO28308
}

Prepared by:

Danny S. Parker, Jamie E. Cummings, Robin K. Vieira, Philip W. Fairey III, John S. Sherwin, Charles Withers Jr., David Hoak, and David Beal

BA-PIRC/Florida Solar Energy Center

1679 Clearlake Road

Cocoa, FL 32922

NREL Technical Monitor: Stacey Rothgeb

Prepared under Subcontract No. KNDJ-0-40339-03

September 2016 
The work presented in this report does not represent performance of any product relative to regulated minimum efficiency requirements.

The laboratory and/or field sites used for this work are not certified rating test facilities. The conditions and methods under which products were characterized for this work differ from standard rating conditions, as described.

Because the methods and conditions differ, the reported results are not comparable to rated product performance and should only be used to estimate performance under the measured conditions. 


\section{Contents}

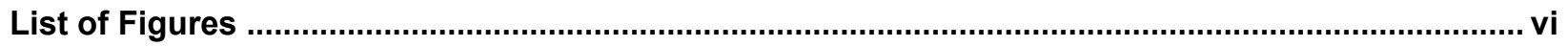

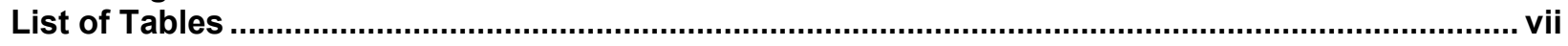

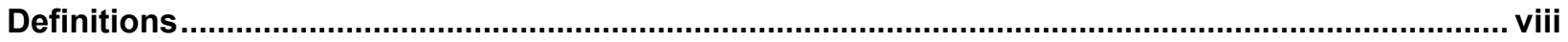

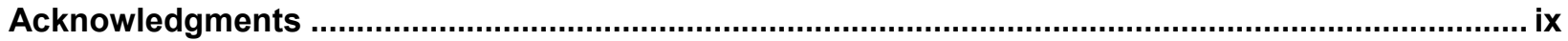

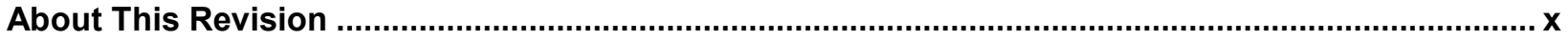

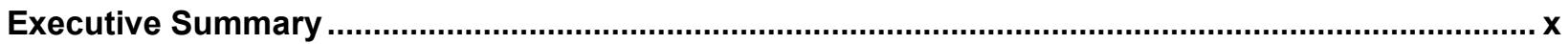

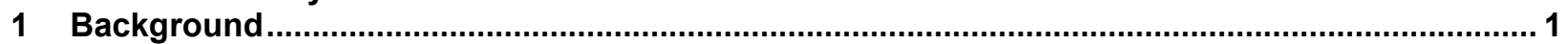

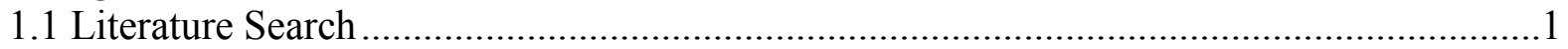

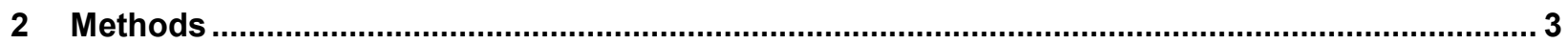

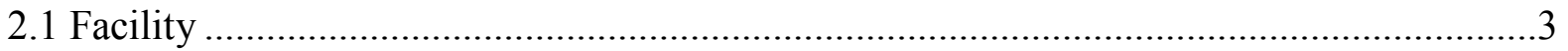

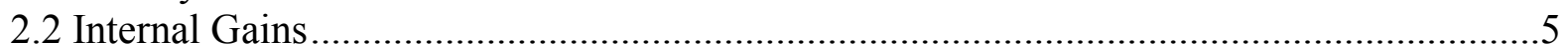

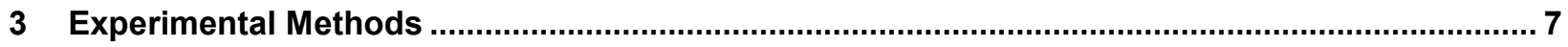

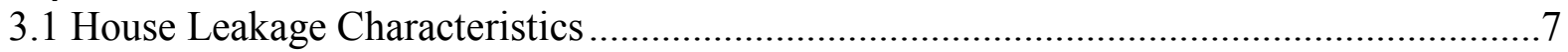

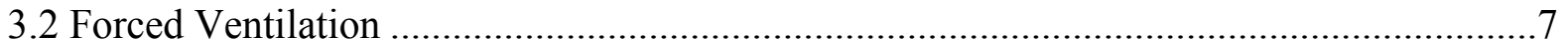

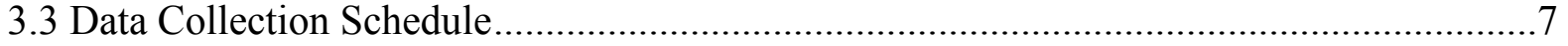

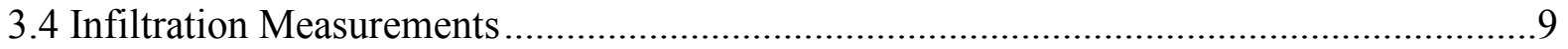

3.5 Temperature, Relative Humidity, and Power Measurements ..........................................

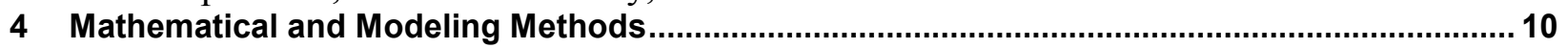

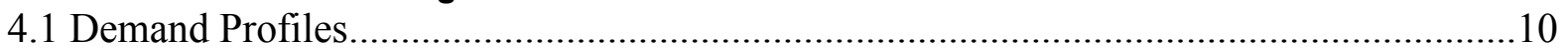

4.2 Tracer Gas Infiltration Measurements ...................................................................... 10

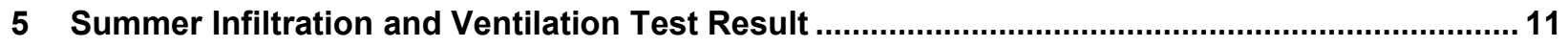

5.1 Measured Outdoor and Indoor Temperature and Moisture Conditions............................11

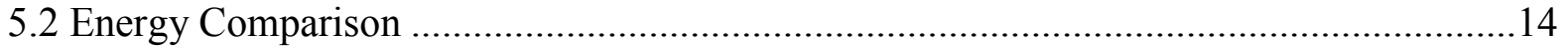

5.3 Evaluation During Individual Test Periods................................................................. 15

5.3.1 Test Period I: May 10 to June 21, 2012 ........................................................... 15

5.3.2 Test Period II: June 23 to July 31, 2012 ........................................................ 18

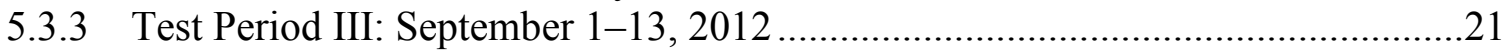

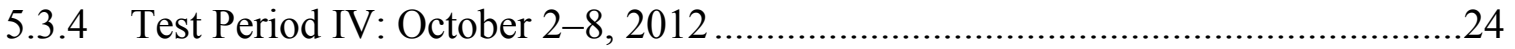

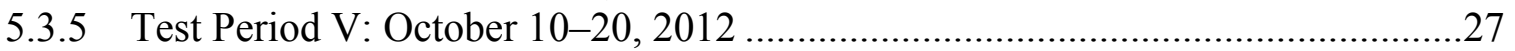

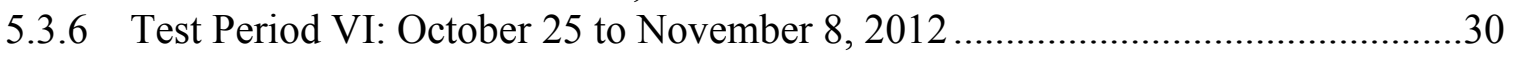

5.4 Tracer Gas Testing of Real-Time Building Infiltration and Ventilation Rates .................32

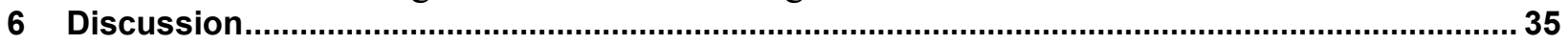

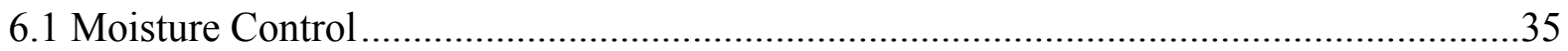

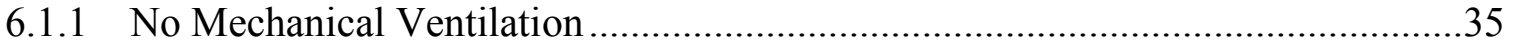

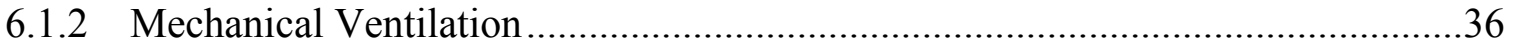

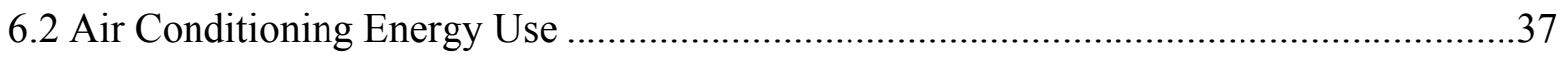

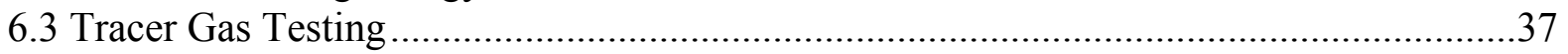

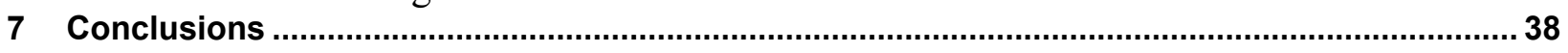

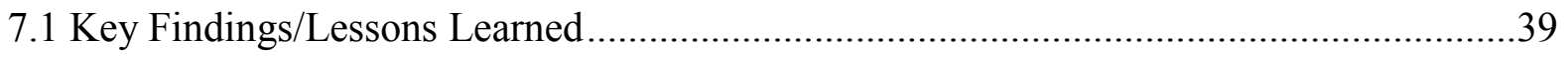

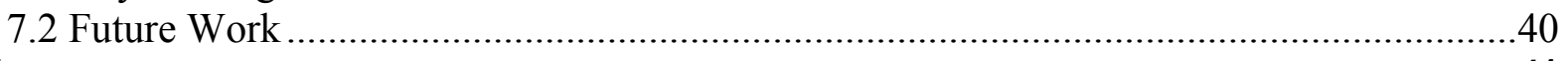

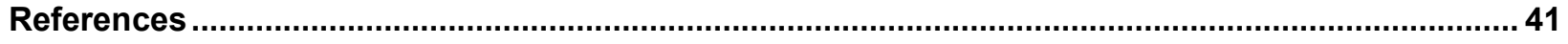




\section{List of Figures}

Figure 1. Completed flexible residential test structures on FSEC campus ...................................... 3

Figure 2. Ceiling penetration for planned leakage (left); attic view of hole that diffuses airflow (right)

Figure 4. Daily load schedule for both homes

Figure 5. Outdoor ambient air temperature and interior temperature by the interior thermostat in the two test buildings during the entire summer

Figure 6. Measured indoor RH by the thermostat in the two test buildings during the entire summer...

Figure 7. Measured indoor and outdoor dew point temperatures in the two test buildings during

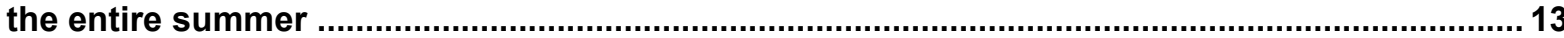

Figure 8. Measured air conditioner condensate in the two test buildings during the entire summer

Figure 9. Measured air conditioner and ventilation system power in the two test buildings over the entire summer

Figure 10. AC energy use, May 10 to June 21, 2012: natural infiltration, low moisture release ....... 16

Figure 11. Comparative RH, May 10 to June 21, 2012: natural infiltration, low moisture release .... 17

Figure 12. Comparative dew point temperatures, May 10 to June 21, 2012: natural infiltration, low

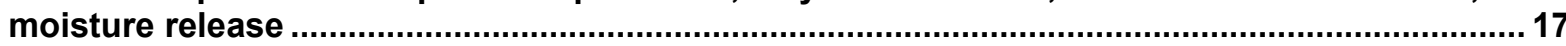

Figure 13. Comparative condensate removal, May 10 to June 21, 2012: natural infiltration, low

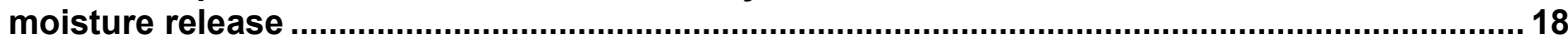

Figure 14. AC energy use, June 23 to July 31, 2012: natural infiltration, standard moisture release

Figure 15. Comparative RH, June 23 to July 31, 2012: natural infiltration, standard moisture release

Figure 16. Comparative dew point temperatures, June 23 to July 31, 2012: natural infiltration, standard moisture release.

Figure 17. Comparative condensate removal, June 23 to July 31, 2012: natural infiltration, standard moisture release.

Figure 18. AC energy use, September 1-13, 2012: west ventilated .................................................22

Figure 19. Comparative RH, September 1-13, 2012: west ventilated ........................................... 23

Figure 20. Comparative dew point temperatures, September 1-13, 2012: west ventilated .............. 23

Figure 21. Comparative condensate removal, September 1-13, 2012: west ventilated .................... 24

Figure 22. AC energy use, October 2-8, 2012: no ventilation, east building goes to high leakage 25

Figure 23. Comparative RH, October 2-8, 2012: no ventilation, east building goes to high leakage.

Figure 24. Comparative dew point temperatures, October 2-8, 2012: no ventilation, east building

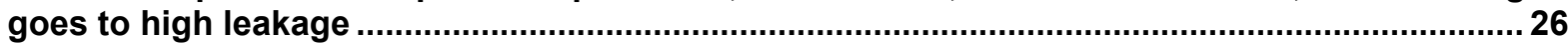

Figure 25. Comparative condensate removal, October 2-8, 2012: no ventilation, east building goes to high leakage..

Figure 26. AC energy use, October 10-20, 2012: west unit vented ................................................ 28

Figure 27. Comparative RH, October 10-20, 2012: west unit vented ............................................... 28

Figure 28. Comparative dew point temperatures, October 10-20, 2012: west unit vented............... 29

Figure 29. Comparative condensate removal, October 10-20, 2012: west unit vented.....................29

Figure 30. AC energy use, October 25 to November 8, 2012: no ventilation .................................... 30

Figure 31. Comparative RH, October 25 to November 8, 2012: no ventilation ................................ 31

Figure 32. Comparative dew point temperatures, October 25 to November 8, 2012: no ventilation 31

Figure 33. Comparative condensate removal, October 25 to November 8, 2012: no ventilation ..... 32

Figure 34. Measured infiltration rate by $\mathrm{CO}_{2}$ tracer, mechanical ventilation in west building.......... 33

Figure 35. Measured infiltration rate by $\mathrm{CO}_{2}$ tracer, infiltration only in both buildings.................... 34

Unless otherwise noted, all figures were created by BA-PIRC. 


\section{List of Tables}

Table 1. Building Tightness Comparison of Tight House Configuration (Tight Duct System) .......... 5

Table 2. Building Tightness Comparison of Leaky House Configuration (Tight Duct System) ......... 5

Table 3. Leakage Measurements in FRTF for Experiment .............................................................. 7

Table 4. Summer 2012 Infiltration/Ventilation Testing Schedule ................................................... 8

Table 5. May 10 to June 21, 2012 (Natural Air Infiltration, Low Moisture Generation)...................... 16

Table 6. June 23 to July 31, 2012 (Natural Air Infiltration, Standard Moisture Generation) .............. 19

Table 7. September 1-13, 2012 (West Unit Vented) ........................................................................ 22

Table 8. October 2-8, 2012 (No Ventilation, East Building Goes to High Leakage) ........................... 25

Table 9. October 10-20, 2012 (West Unit Vented) ............................................................................ 27

Table 10. October 25 to November 8, 2012 (No Ventilation) .......................................................... 30

Unless otherwise noted, all tables were created by BA-PIRC. 


\section{Definitions}

$\mathrm{AC}$

ACH50

$\mathrm{C}$

CFM

$\mathrm{CO}_{2}$

ELA

EqLa

FRTF

FSEC

$\mathrm{n}$

Qn

$\mathrm{RH}$
Air conditioning

Air changes per hour (at 50 Pascals between inside and outside)

Air leakage coefficient

Cubic feet per minute

Carbon dioxide

Effective leakage area

Equivalent leakage area

Flexible Residential Test Facility

Florida Solar Energy Center

the exponent in the building leakage curve defined by the equation: $\mathrm{Q}=\mathrm{C} \times \mathrm{P}^{\mathrm{n}}$ where $\mathrm{Q}$ is airflow into the building (in CFM), $\mathrm{C}$ is the Coefficient, and $\mathrm{P}$ is the pressure difference between inside and outside

Normalized air distribution system leakage

Relative humidity 


\section{Acknowledgments}

The authors gratefully acknowledge the U.S. Department of Energy, Office of Energy Efficiency and Renewable Energy, which sponsored this work under the Building America Program.

Thanks for the kind review from Eric Martin at the Florida Solar Energy Center. Wanda Dutton helped prepare the original manuscript, and Danielle Daniel provided careful review and edit. 


\section{About This Revision}

Originally published in January 2014, this revision of the report clarifies and corrects references to Standard 62.2 as the 2013 version (62.2-2013), and it corrects the total CFM requirement for the subject buildings under the standard. Further, two plots have been updated to distinguish between the mechanical CFM and the total CFM required for the subject buildings under Standard 62.2-2013.

\section{Executive Summary}

Air infiltration and ventilation in residential buildings are a very large part of the heating loads, but empirical data regarding the impact on space cooling have been lacking. Moreover, there have been few data on how building tightness might relate to building interior moisture levels in homes in a hot-humid climate. To address this need, Building America has conducted research in two identical laboratory homes in Central Florida to measure specific impacts.

To assess the moisture and cooling load impacts of airtightness and mechanical ventilation in homes in hot-humid climates over the summer, two identical laboratory homes designed to model existing Florida building stock were sealed and tested to 2.2 ACH50. One lab was made leaky with leakage through the attic and windows to a tested value of approximately 8 ACH50. The other lab was held tight and equipped with a mechanical ventilation system to meet minimum ventilation airflow rates recommended for the ASHRAE Standard 62.2-2013. Testing was conducted over the summer of 2012 to evaluate the energy and moisture effects of differing building leakage rates. The testing also examined the impact of mechanical ventilation according to ASHRAE Standard 62.2-2013 in the tighter building by alternating 2-week periods of mechanical ventilation and no ventilation in the tight home for a portion of the summer.

The comparative summer testing showed that tighter buildings, exemplified by the west structure, had little if any air conditioning (AC) energy savings and only modest differences in moisture content under natural infiltration. The lack of energy savings in the tighter home was largely because the outdoor temperature was nearly as often below as above the desired thermostat set point. Thus, increased air infiltration during nighttime hours when the temperature outside is lower than the desired cooling set point actually reduces the AC load. The less airtight east house showed only a mild increase in moisture levels in the home, likely due to increasing AC runtime that quickly removed any excess moisture from increased infiltration. This occurs because vapor compression $\mathrm{AC}$ equipment removes more moisture as runtime increases. There is also an impact on the machine sensible heat ratio; as the internal level of absolute moisture increases (the wet bulb), the operating machine sensible heat ratio drops.

Unlike natural infiltration, mechanical supply ventilation revealed much more significant changes to energy use and moisture levels when added to the tight home. Cooling energy increased by $20 \%-38 \%$ or about $4 \mathrm{kWh} /$ day. Part of this increase resulted from the mechanical ventilation system fan itself, which added $1.8 \mathrm{kWh} /$ day of energy use to the cooling system energy use. ${ }^{1}$ The power use of the ventilation equipment was approximately 75 Watts. While this

\footnotetext{
${ }^{1}$ Given equipment coefficient of performance, we would estimate that cooling energy would likely be increased by

$\sim 0.5 \mathrm{kWh} /$ day from the heat of added fan energy.
} 
is a commercially available unit, there is equipment that might have system power that is less than half of this level and thus has a more modest impact on fan energy use. The mechanical ventilation system also contributed measurable increases to the building moisture levelsinterior relative humidities (RHs) were modestly increased by $2 \%-5 \%$.

The interior moisture data collected suggest that leaky residential buildings (as exemplified by the loose building) will not result in as large an increase in moisture levels as when ASHRAE Standard 62.2-2013 levels of ventilation are provided in a tight building in Central Florida without enthalpy recovery. In the leaky building, average RH usually did not exceed $50 \%$, except toward the end of the season when the sensible cooling load declined. However, even with mechanical ventilation during periods with high cooling loads, interior RH usually stayed below $60 \%$. This means that while interior moisture levels were increased by mechanical supply ventilation, they were generally in an acceptable range. They did, however, considerably increase cooling energy use.

However, moisture-related results in winter were quite different. The 2011-2012 winter infiltration study found significant moisture problems in an older Florida home with a very tight envelope at 2.2 ACH50 (Vieira and Sherwin 2012). This study provides additional evidence that many of the moisture problems in residences in Central Florida likely occur during winter when there are no sensible cooling loads and no humidity removal.

Later in the test period, we used a carbon dioxide tracer gas technique to examine the evenness and sufficiency of airflows into the two buildings relative to ASHRAE Standard 62.2-2013. Without mechanical ventilation, the tighter building showed much lower than recommended effective ventilation rates - where average observed air change rate was only $0.04 \mathrm{ACH}$. However, even the leaky building (with $0.27 \mathrm{ACH}$ ) experienced long periods when the ventilation rate was half that recommended by Standard 62.2-2013.

The summer 2012 testing at the Flexible Residential Testing Facility (FRTF) suggests that further experimentation should be done in 2013 to examine likely interactions with duct system leakage as well as the potential of enthalpy recovery ventilation systems, which may help address moisture issues while providing comparable energy performance.

By providing specific data on infiltration and ventilation impacts in a hot and humid climate, this study reveals the impact on AC energy and interior moisture levels. While building airtightness was found to only slightly influence space cooling and interior moisture levels, mechanical ventilation had a much more pronounced impact, suggesting that enthalpy recovery ventilation systems will be valuable. The results of this study, combined with further infiltration research at the FRTF, provide important input to designers, homeowners, utilities, and policy makers when determining cost-effective and comfortable energy efficiency improvements for homes in hothumid climates. 


\section{Background}

\subsection{Literature Search}

Early assessments of the impacts of air infiltration in buildings have estimated that air leakage was responsible for a third of heating and cooling loads (Sherman et al. 1980; Hekmat et al. 1986). However, these studies largely concentrated on heating loads, which are known to strongly depend on building air leakage. Very few studies have attempted to measure the impact of air infiltration or ventilation on cooling loads alone. Another very detailed simulation study of office buildings in climates around the United States (Emmerich et al. 2005) found that while air infiltration and ventilation were responsible for $33 \%$ of the heating loads, they actually reduced cooling loads by 3.3\%. Although these were commercial buildings and not residences, this finding was true even in cooling-dominated climates such as Savannah, Georgia and Tucson, Arizona. Part of this stems from the fact that nighttime temperatures are often lower than the cooling thermostat set point - an attribute sometimes advocated to reduce cooling by the use of forced ventilation (an economizer cycle) during these periods (Blondeau et al. 1997).

Data from Japan suggest that occupants can have a large influence on building ventilation rates due to opening of windows during nighttime hours (Iwashita and Akasaka 1997). In Central Florida, Cummings and Tooley (1989) used simulation to show that an increase in the infiltration rate from 0.10 to $0.90 \mathrm{ACH}$ could increase space cooling by $31 \%$, but without data to know what the realistic range of air change rates prevailing in homes might be. In the same study, the authors also found that space heating was much more sensitive to infiltration rate, increasing by $127 \%$ over the same range.

Studies of the impact of the American Society of Heating, Refrigerating, and Air-Conditioning Engineers (ASHRAE) Standard 62.2 (ASHRAE 2013) and associated mechanical ventilation in homes on cooling loads are even more limited. Wray et al. (2000) estimated impacts via simulation, showing the largest impacts of mechanical ventilation in extreme climates, which included humid ones. Although indicated energy penalties were small and were based on simulation, not measurement, they were not inconsequential, and the indicated benefits relied on base building infiltration rates that were not verified. Other relevant simulation estimates were made by Robertson et al. (1998), who found that, depending on the strategy used for compliance, heating and cooling loads in Houston, Texas could be increased by up to four times that of the most effective strategy (balanced enthalpy recovery). No specific empirical studies could be located in our literature search, nor those of earlier investigators (Barley 2001).

One concern of added ventilation in humid climates is the increase of interior moisture levels. As such, it is useful to examine work that investigates how increased relative humidity $(\mathrm{RH})$ may influence occupant health. For instance, Arundel et al. (1986) and Fisk et al. (2010) show that higher interior RH is associated with the incidence of allergies, prevalence of dust mites, and upper respiratory infections. Moreover, Baughmann and Arens (1996) suggest the same as well, indicating that problems with non-biotic agents such as formaldehyde were adversely increased. Most of the studies identify levels exceeding $60 \% \mathrm{RH}$ as being problematic.

There are also some questions about the existing calculation methods to estimate the impact of infiltration or ventilation. Infiltration is customarily assumed to increase the heating and cooling loads of a building by an amount equal to the mass flow rate of the infiltration times the enthalpy 
difference between the inside and outside air, with the latent portion of the enthalpy difference sometimes neglected. However, the situation in real buildings may be more complex. Some research has suggested that natural air infiltration in buildings can behave very differently from mechanical ventilation, where the building may function as a heat exchanger. For instance, Claridge and Bhattacharyya (1990) conducted calorimetric measurements on a small test cell with measured amounts of infiltration introduced under a variety of conditions. The measurements showed that infiltration can lead to a much smaller change in the energy load than is customarily calculated; changes as small as $20 \%$ of the calculated value have been measured in the cell. The data also suggest that the phenomenon occurs in full-sized houses. However, other work on this same phenomenon was done by Walker and Sherman (2003), who showed that the effect was only about $1 \%$ for well-insulated buildings, although potentially much larger for poorly-insulated structures. In any case, the impact of natural air infiltration may be somewhat different from the impact of mechanical ventilation air of a similar quantity.

The summer Flexible Residential Test Facility (FRTF) study on infiltration and mechanical ventilation focused on the following research questions:

- How does the airtightness of a home affect its moisture levels, temperature, and air conditioning $(\mathrm{AC})$ loads during the cooling season?

- How does supply mechanical ventilation, meeting ASHRAE Standard 62.2-2013, affect a home's moisture levels, temperature, and AC loads during the cooling season?

- How does air infiltration from natural infiltration compare to the ASHRAE Standard 62.2-2013 ventilation requirements?

Additionally, the following research question was developed during the study:

- How does the level of moisture generation within a home affect its moisture levels and AC loads? 


\section{Methods}

\subsection{Facility}

The state of Florida provided funding for the design and construction of two reconfigurable, geometrically identical, full-scale, side-by-side residential building energy research facilities at the Florida Solar Energy Center (FSEC), as shown in Figure 1. The Building America Partnership for Improved Residential Construction has instrumented these flexible research homes and monitors them to conduct research on advanced building energy efficiency technologies under controlled conditions.

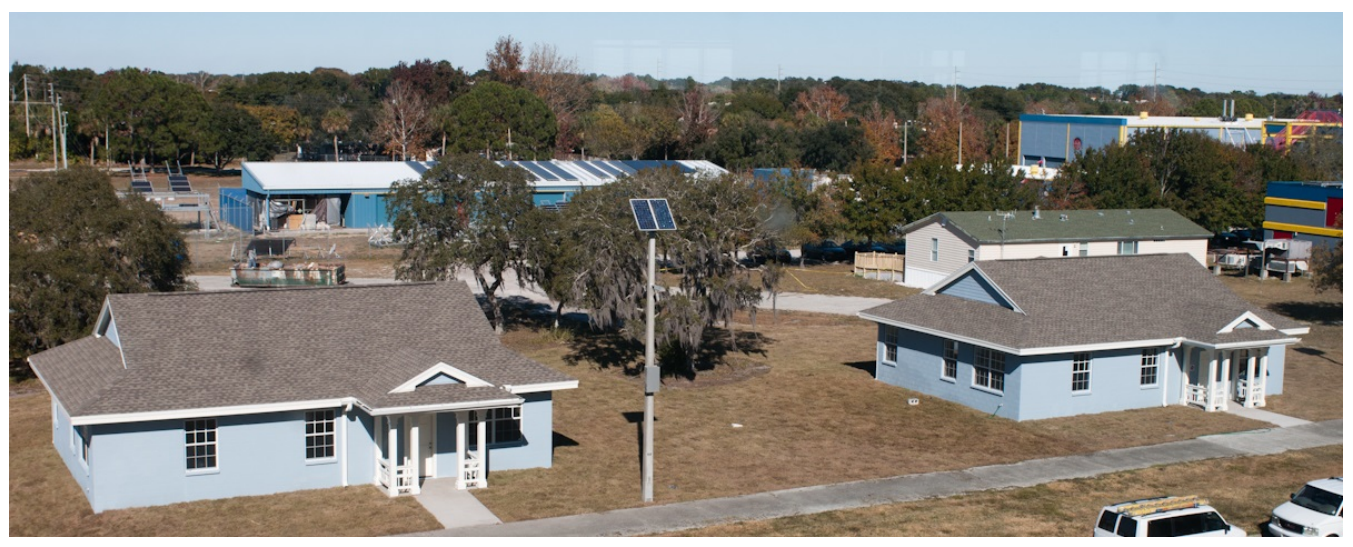

Figure 1. Completed flexible residential test structures on FSEC campus

The purpose of the FRTF is to provide a controlled research environment that serves two main purposes. First, it is used to research and evaluate advanced energy-efficiency technologies and operational strategies. Second, it serves as a venue to help validate building simulation programs and algorithms. Details of the $1,536-\mathrm{ft}^{2}$ single-story buildings (volume $=13,050 \mathrm{ft}^{3}$ ) and their instrumentation are provided in the "Flexible Residential Test Facility Instrumentation Plan" (Vieira and Sherwin 2012).

Of particular significance to this report is the substantial effort that went into creating equal air leakiness in the buildings. Initial construction created reasonably tight buildings (3.62 and 3.82 ACH50), but FSEC staff further sealed leakage points until they were each able to achieve 2.2 ACH50. The air distribution systems were very tight: $1.3 \mathrm{CFM} 25 / 100 \mathrm{ft}^{2}(\mathrm{Qn}=0.013)$ in each home. Each home was then configured with controllable duct leakage and air leakage. The air leakage was designed to create the type of distribution and diffusion of air leakage represented in a number of Southern slab-on-grade homes:

- Both homes were configured with four controllable ceiling leakage sites providing $\sim 70 \%$ of leakage area needed to achieve $\sim 8$ ACH50 (see Figure 2). Seventy percent through the ceiling was able to be verified using calibrated flow hood to measure air through ceiling leak sites when the house was at -50 Pascals with reference to outside.

- The remaining $30 \%$ of leakage area was achieved using metal shims at all windows (Figure 3). 


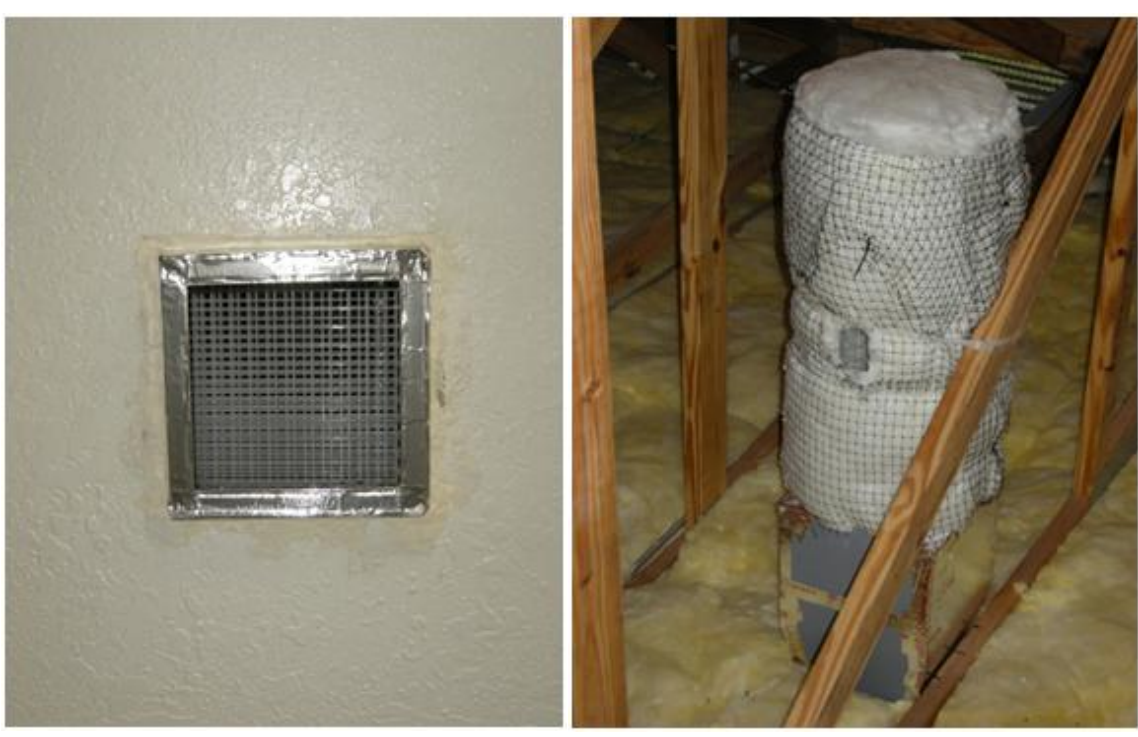

Figure 2. Ceiling penetration for planned leakage (left); attic view of hole that diffuses airflow (right)

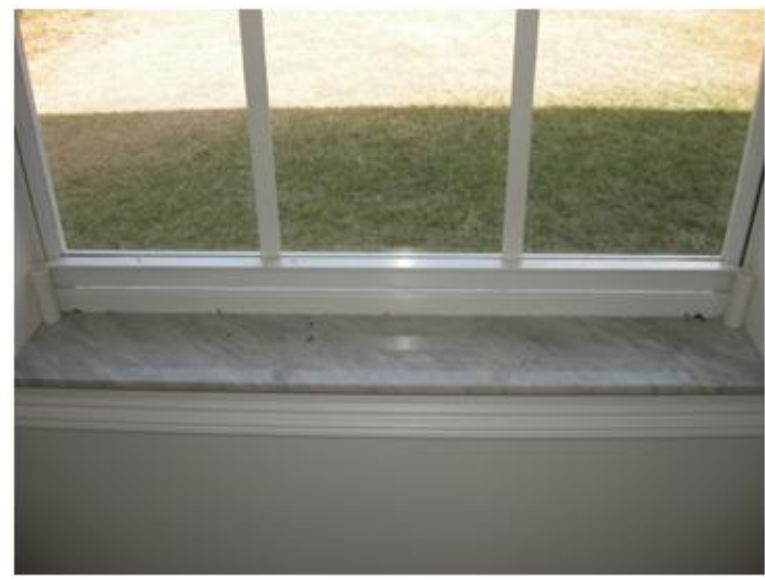

Figure 3. Metal stand-off shims used to add vertical plane leakage to the east building

FSEC staff experimented with different configurations of holes and air pathway restrictions until we were able to achieve an " $n$ " or flow exponent value in a range from 0.6 to 0.7 while bringing in $30 \%$ of the air through the windows and obtaining an ACH50 value near 8 . An "n" value between 0.6 and 0.7 was established because this is the typical range found in measurements in homes across the United States (Sherman et al. 1986). Once the air leakage design was established in the first home, the same design was copied in the second home to obtain matched leakage results.

Airtightness testing was repeated on both homes in the tightest house envelope configuration and in the leakiest house envelope configuration at $9 \mathrm{ACH} 50$. The detailed test results are summarized in Table 1 and Table 2 . These tests were done with a very tight duct system having only Qn $=0.013$ (1.3 CFM25 leakage to outside/100 $\mathrm{ft}^{2}$ of conditioned space). 
It is noted that having leakage concentrated in the ceiling plane can have large influences on the resulting infiltration dynamics because the building is shielded from most wind-related effects (Walker and Wilson 1998). However, the authors believe this arrangement is very typical of homes in the Southeast where slab-on-grade floors have no leakage and windows and doors are relatively well-sealed, but ceiling penetrations for recessed light cans and bathroom and kitchen fans make the ceiling a major site for building leakage.

Table 1. Building Tightness Comparison of Tight House Configuration (Tight Duct System)

\begin{tabular}{l|c|c|c|c|c|c}
\hline & ACH50 & CFM50 & C & n & EqLa & ELA \\
\hline East Lab & \multirow{2}{*}{2.26} & 540 & 36.0 & 0.692 & 55.8 & 29.6 \\
Tight & & $( \pm 0.7 \%)$ & $( \pm 8.6 \%)$ & $( \pm 0.023)$ & $( \pm 3.5 \%)$ & $( \pm 5.5 \%)$ \\
$\begin{array}{l}\text { West Lab } \\
\text { Tight }\end{array}$ & 2.18 & $\begin{array}{c}520 \\
( \pm 0.6 \%)\end{array}$ & $\begin{array}{c}36.0 \\
( \pm 8.9 \%)\end{array}$ & $\begin{array}{c}0.683 \\
( \pm 0.023)\end{array}$ & $\begin{array}{c}53.7 \\
( \pm 3.7 \%)\end{array}$ & $\begin{array}{c}28.5 \\
( \pm 5.8 \%)\end{array}$ \\
\hline
\end{tabular}

Notes: Values in parentheses are the $95 \%$ confidence limits on the estimates; C, air leakage coefficient; $\mathrm{n}$, exponent in the building leakage curve defined by the equation: $\mathrm{Q}=\mathrm{C} \times \mathrm{Pn}$; EqLa, equivalent leakage area

Table 2. Building Tightness Comparison of Leaky House Configuration (Tight Duct System)

\begin{tabular}{l|c|c|c|c|c|c}
\hline & ACH50 & CFM50 & C & n & EqLa & ELA \\
\hline $\begin{array}{l}\text { East Lab } \\
\text { Leaky }\end{array}$ & 7.99 & $\begin{array}{c}1909 \\
( \pm 1.8 \%)\end{array}$ & $\begin{array}{c}177.3 \\
( \pm 15.4 \%)\end{array}$ & $\begin{array}{c}0.607 \\
( \pm 0.047)\end{array}$ & $\begin{array}{c}197.1 \\
( \pm 5.9 \%)\end{array}$ & $\begin{array}{c}104.8 \\
( \pm 9.6 \%)\end{array}$ \\
$\begin{array}{l}\text { West Lab } \\
\text { Leaky }\end{array}$ & 8.06 & $\begin{array}{c}1926 \\
( \pm 1.1 \%)\end{array}$ & $\begin{array}{c}182.3 \\
( \pm 11.3 \%)\end{array}$ & $\begin{array}{c}0.603 \\
( \pm 0.031)\end{array}$ & $\begin{array}{c}198.8 \\
( \pm 4.3 \%)\end{array}$ & $\begin{array}{c}105.7 \\
( \pm 7.1 \%)\end{array}$ \\
\hline
\end{tabular}

Notes: Values in parentheses are the $95 \%$ confidence limits on the estimates.

During the tests, the west lab building was in the tight configuration (2.18 ACH50), and the east building was nominally in the leaky configuration (7.99 ACH50). However, it is important to note that because of miscommunication, the window shims that create the vertical plane leakage in the building were not in place during the majority of the cooling season. In this configuration, the building had a tested leakage of $6.01 \mathrm{ACH} 50$, although with $94 \%$ of its leakage in the ceiling plane. ${ }^{2}$ On October 1, 2012, the window shims were reinstalled, and the east building reverted to the original intention of $7.99 \mathrm{ACH} 50$ for the duration of the experiment.

\subsection{Internal Gains}

Due to the shoulder months of the extended cooling season in Central Florida, internal gains substantially increase cooling loads during periods when the outside conditions are otherwise moderate. This is particularly true in newer, tighter homes. Furthermore, internal moisture generation in a tight home without ventilation will lead to high moisture levels. The laboratories have automated (computer controlled) heat and moisture loads scheduled by time of day based on the Residential Energy Services Network lighting, appliance, and miscellaneous energy usage amendment schedule (Lighting, Appliance and Miscellaneous Energy Usage Profile Amendment 2011). The schedules approximate Building America benchmark hourly schedules (Fang et al. 2011) as shown in Figure 4.

\footnotetext{
${ }^{2}$ This has the likely effect of generally reducing the experienced building infiltration rate for a given absolute leakage. However, this configuration is not unlikely in the real world where much of the leakage in Florida buildings is concentrated in the ceiling plane from recessed can lights and bathroom and kitchen fans.
} 


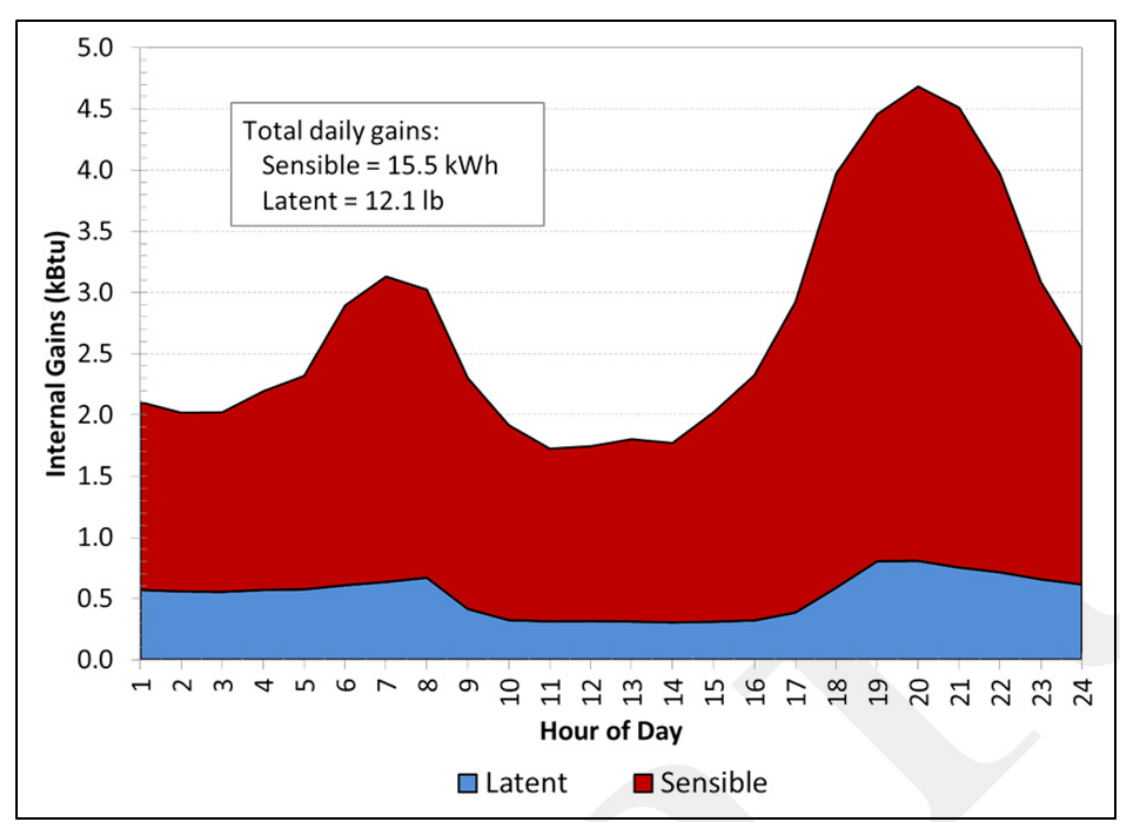

Figure 4. Daily load schedule for both homes

For the first phase of this experiment, beginning on May 10, the latent load was lowered to 6.05 $\mathrm{lb} /$ day of moisture, half the latent load used during other phases. As internal moisture generation rate in real homes is uncertain, this was done as a parametric exercise to see how internal moisture generation level might influence results. However, beginning on June 22, the moisture level was brought back to $11 \mathrm{lb} /$ day in accordance with the Building America Benchmarkcomputed level for moisture generation in a home of this size and configuration.

Some of the internal sensible heat gains were produced by the house's oven. Due to variability in stove elements, the west home oven produced more heat from the same automation schedule, resulting in slightly higher internal loads. 


\section{Experimental Methods}

\subsection{House Leakage Characteristics}

For the infiltration test, the west laboratory home served as the tight home and had the leakage sealed off at the ceiling plane. The leaky east laboratory home used the ceiling penetrations and window shims to obtain the results shown in Table 3.

Table 3. Leakage Measurements in FRTF for Experiment

\begin{tabular}{c|c|c}
\hline Leakage Parameter & Leaky Home East & Tight Home West \\
\hline CFM50 & 1909 & 520 \\
ACH50 & 7.99 & 2.18 \\
C & 177.3 & 36.0 \\
n & 0.607 & 0.683 \\
ELA* $^{\text {(in. }}{ }^{2}$ ) & 104.8 & 28.5 \\
\hline Specific Leakage Area & 0.00053 & 0.000119 \\
\hline
\end{tabular}

*effective leakage area

The west home served as the tight home, with a tested ACH50 of 2.2. The west home alternated every 2 weeks between having no mechanical ventilation and having mechanical ventilation in order to compare the energy savings and moisture impact of a tight home with and without ventilation.

\subsection{Forced Ventilation}

Forced ventilation was also evaluated as an option for providing adequate air turnover in tight homes. In mid-August, an energy recovery ventilation system (Honeywell ER-200) was installed in the west building, allowing the west home to have whole-house ventilation. However, the enthalpy recovery section of the unit was deactivated, and it operated as a supply fan only. The exhaust fan was not operated, so the system was supply only and unbalanced.

When in use, the system provides $63( \pm 3)$ CFM of outdoor air into the space continuously, which was verified using a calibrated flow measurement setup. Measured power use of the ventilation system was $74( \pm 2)$ Watts continuous or $1.77 \mathrm{kWh} /$ day. After installation, the west home alternated between continuous ventilation from the whole-house ventilation system and no ventilation.

\subsection{Data Collection Schedule}

Temperatures and RHs inside the laboratory buildings were extensively monitored. Condensate removed by the air conditioner was also monitored. Power uses of both the air handling unit and compressor were also recorded. During October, carbon dioxide $\left(\mathrm{CO}_{2}\right)$ was released and monitored inside the homes to estimate infiltration rates.

The summer 2012 infiltration and ventilation testing was divided into several test periods, as summarized in Table 4. 
Table 4. Summer 2012 Infiltration/Ventilation Testing Schedule

\begin{tabular}{|c|c|c|c|c|c|c|c|}
\hline \multirow[b]{2}{*}{ Period } & \multirow[b]{2}{*}{ Dates } & \multicolumn{2}{|c|}{ West } & \multicolumn{2}{|c|}{ East } & \multirow{2}{*}{$\begin{array}{l}\text { Moisture } \\
\text { Loading } \\
\text { Level }\end{array}$} & \multirow{2}{*}{$\begin{array}{c}\text { Good } \\
\text { Data } \\
\text { Quality? }\end{array}$} \\
\hline & & Infiltration & $\begin{array}{l}\text { Mechanical } \\
\text { Ventilation? }\end{array}$ & Infiltration & $\begin{array}{l}\text { Mechanical } \\
\text { Ventilation? }\end{array}$ & & \\
\hline I & $5 / 10-6 / 21$ & Tight & No & Moderate $^{3}$ & No & Low & Yes \\
\hline II & $6 / 23-7 / 31$ & Tight & No & Moderate & No & Normal & Yes \\
\hline- & $8 / 16-8 / 31$ & Tight & Yes & Moderate & No & Normal & No \\
\hline III & 9/1-9/13 & Tight & Yes & Moderate & No & Normal & Yes \\
\hline- & $9 / 14-9 / 30$ & Tight & Yes & Moderate & No & Normal & No \\
\hline IV & $10 / 2-10 / 8$ & Tight & No & Normal & No & Normal & Yes \\
\hline $\mathbf{V}$ & $\begin{array}{c}10 / 10- \\
10 / 20\end{array}$ & Tight & Yes & Normal & No & Normal & Yes \\
\hline VI & $\begin{array}{c}10 / 25- \\
11 / 8\end{array}$ & Tight & No & Normal & No & Normal & Yes \\
\hline
\end{tabular}

The homes began cooling-related testing on April 17, 2012, when the AC systems were both set to $77^{\circ} \mathrm{F}$. However, official data collection did not start until May 10, after thermostat calibrations were performed, key measurement thermocouples were installed, and a condensate collection system was installed.

From May 10 to August 15, the buildings were operated with no supplemental ventilation. During period I, from May 10 to June 21, the internal moisture release level was half that estimated ( $6 \mathrm{lb} /$ day released) to examine how reduced internal moisture gain would influence cooling season performance.

During period II, June 23 to July 31 , the released moisture level was increased back to the normal level of $11 \mathrm{lb} /$ day. As the exact level of internal moisture in Florida residential buildings remains uncertain, this variation likely spans the possible variation in moisture generation due to lower occupancy.

Beginning August 16, the tighter west building began an alternating schedule of forced ventilation and no ventilation. However, installation and debugging of the ventilation system and the $\mathrm{CO}_{2}$ tracer gas dosing systems caused the August data to be unreliable.

During period III, September 1-13, the west building operated with continuous forced ventilation. During the second half of September, it was intended for the west building to operate without ventilation. However, the ventilation system was somehow triggered on for 4 days inadvertently during this period, making the data from this period largely unusable.

On October 1, the error with the vertical plane leakage rate in the east building was altered to the intended configuration with the leakage in the vertical sides of the building restored. This had a large impact in the resulting building air leakage and air change rate.

\footnotetext{
${ }^{3}$ Moderate leakage is 6.8 ACH50 $(1,436$ CFM50; $\mathrm{n}=0.621)$ with $94 \%$ of the leakage located in the ceiling plane; Normal leakage for the east unit is 8.0 ACH50 $(1,909$ CFM50; $\mathrm{n}=0.607)$ with $71 \%$ of the leakage located in the ceiling.
} 
During periods IV and VI, October 2-8 and October 25 to November 8, the west home was unvented. During period V, October 10-20, the west home operated with forced ventilation.

\subsection{Infiltration Measurements}

$\mathrm{CO}_{2}$ dosing and measurement equipment was installed during August to measure infiltration in the two homes. The dosing equipment (Dakota Instruments, INC model 6AGC1AL5-09CA2) consisted of two parallel $\mathrm{CO}_{2}$ tanks located in the garage and precisely metered on their release by digital flow meters that are recorded by instrumentation (the calibrated accuracy of the dosing equipment was $0.4 \%$ ). Measurements came from Velaire $\mathrm{CO}_{2}$ transmitters (Ventostat 8000) with a stated full-range accuracy of $\pm 7 \%$. However, a secondary calibration was performed with the result that the instrument was responding within an accuracy of $\pm 2 \%$. A single interior transmitter was located at the center of each building.

Ambient outdoor $\mathrm{CO}_{2}$ sensors were also installed. Because the buildings are unoccupied, it is possible to measure the building infiltration rate using a known $\mathrm{CO}_{2}$ gas emission rate as a tracer gas. The rise in the concentration of indoor $\mathrm{CO}_{2}$ can be used to then estimate the building infiltration and ventilation rates with outdoor air based on calculated dilution to produce the observed concentration. An initial problem with this setup was experienced when it became apparent that the outdoor $\mathrm{CO}_{2}$ sensor had to be quite remote from the homes to prevent the effluent $\mathrm{CO}_{2}$ from the leaking buildings from corrupting the reference outdoor $\mathrm{CO}_{2}$ measurement. This was corrected by moving the sensor $20 \mathrm{ft}$ away at a height of $10 \mathrm{ft}$.

The dosing and monitoring equipment was installed during August, and because of issues with the monitoring and ventilation equipment, reliable $\mathrm{CO}_{2}$ data were not available until October 1 .

\subsection{Temperature, Relative Humidity, and Power Measurements}

Type-T copper-constantan thermocouples are used to measure temperatures against a platinum reference junction on the Campbell data logger. Full range accuracy of the differential measurements is $+0.2^{\circ} \mathrm{F}$. Humidity measurements are made using Vaisala HMP50 transmitters with a stated accuracy of $+3 \%$ from $0 \%-90 \%$ RH. Power is measured by WattNode WNB-3D$240 \mathrm{P}$ Watt hour transmitters using revenue-grade current transducers with an accuracy of $0.5 \%$. Texas Instruments TR-525i tipping buckets are utilized to introduce interior moisture as well as to measure air conditioner condensate with a $1 \%$ volumetric accuracy. Instruments were scanned each $10 \mathrm{~s}$ with integrated averages obtained every 15 minutes. 


\section{Mathematical and Modeling Methods}

\subsection{Demand Profiles}

A key method of analyzing data in this study uses demand profiles of the performance indices, such as temperature or energy use. To create a demand profile, the average value for each hour is compiled for a data period. For example, the thermostat temperature each day at 10:00 a.m. is recorded and calculated to obtain an average value for 10:00 a.m. This process produces a $24-\mathrm{h}$ profile of the data measured, allowing trends in the data to be identified.

\subsection{Tracer Gas Infiltration Measurements}

Starting in October, $\mathrm{CO}_{2}$ tracer gas dosing began in the two homes, allowing for the estimation of infiltration into the homes. The building infiltration is calculated using the following relation, which comes from ASTM Standard E741-11 (American Society of Testing and Materials 2011):

Where:

$$
\text { building infiltration }[\mathrm{cfm}]=\dot{m}_{\mathrm{CO}_{2}, \text { release }} * 28.31684 * \frac{C_{\mathrm{CO}_{2} \text {,indoor }}-10^{6}}{C_{\mathrm{CO}_{2}, \text { outdoor }}-C_{\mathrm{CO}_{2} \text {,indoor }}}
$$

$$
\begin{array}{lll}
\dot{m}_{\mathrm{CO}_{2} \text {,release }}= & \text { release rate }[\mathrm{L} / \mathrm{min}] \\
C_{\mathrm{CO}_{2} \text {,indoor }}= & \text { measured indoor } \mathrm{CO}_{2} \text { concentration }[\mathrm{ppm}] \\
\mathrm{C}_{\mathrm{CO}_{2} \text {,outdoor }}= & \text { measured outdoor ambient } \mathrm{CO}_{2} \text { concentration }[\mathrm{ppm}]
\end{array}
$$

The net $\mathrm{ACH}$ can then be calculated using the building's net interior volume of $13,100 \mathrm{ft}^{3}$ :

$$
A C H=\frac{\text { building infiltration }[\mathrm{cfm}] * 60}{\text { building volume }\left[\mathrm{ft}^{3}\right]}
$$




\section{Summer Infiltration and Ventilation Test Result}

\subsection{Measured Outdoor and Indoor Temperature and Moisture Conditions}

Figure 5 through Figure 9 show the time series data of the hourly observations taken at the FRTF during the entire summer. Dashed vertical lines divide the period into the various test periods that are summarized in greater detail below.

Figure 5 shows the hourly dry bulb outdoor temperatures superimposed against the measured interior temperatures at the thermostat in each building. The $\mathrm{x}$-axis is the Julian date during the period stretching from day 131 (May 10) to 313 (November 8). Note that the temperatures maintained at the thermostat remained very close to the target of $78^{\circ} \mathrm{F}$ with the exception of the cooler period at the end of the summer period in early November. It is also noteworthy that even during the hottest part of summer, the ambient air temperature is often lower than the thermostat set point temperature during evening hours - a fact with ramifications for the impact of infiltration and ventilation in Florida's climate.

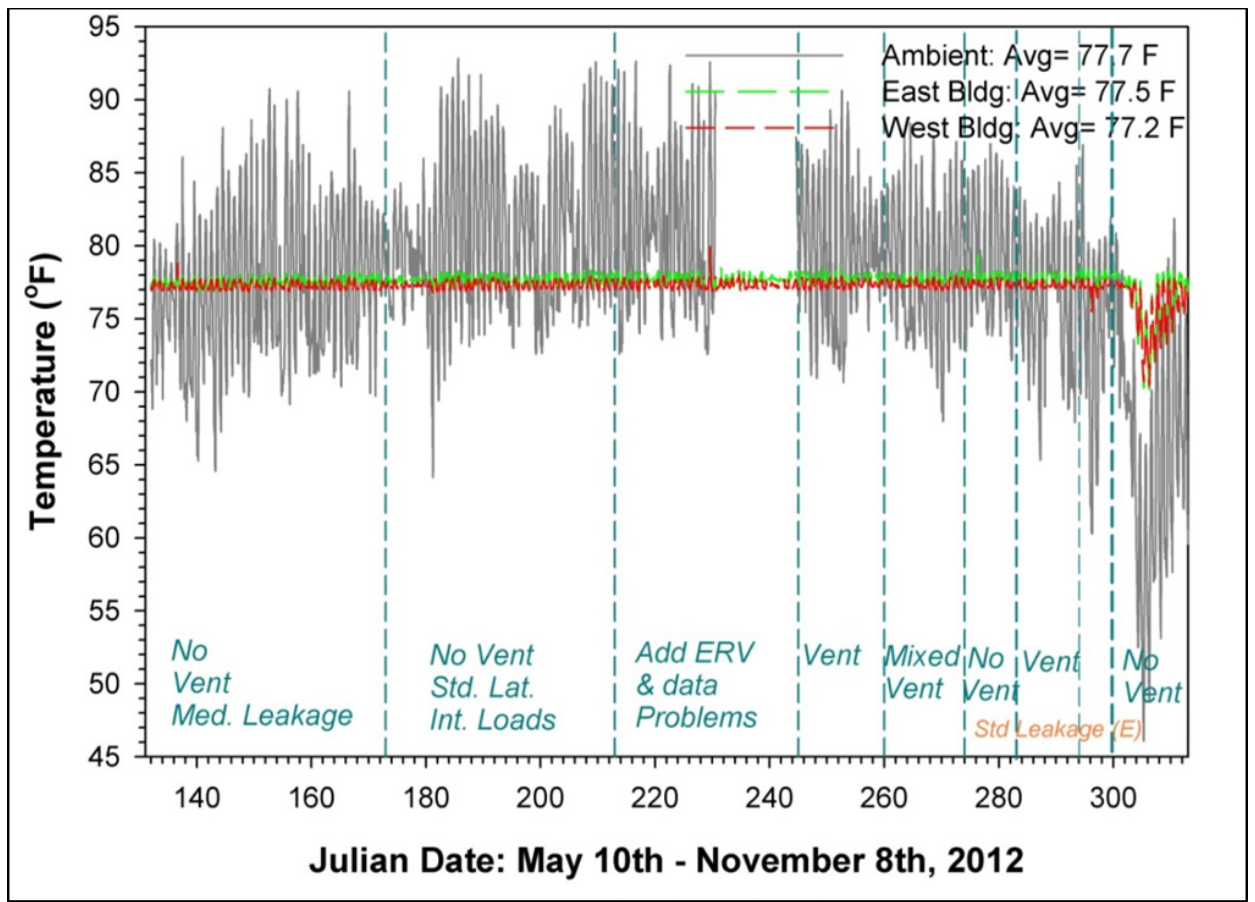

Figure 5. Outdoor ambient air temperature and interior temperature by the interior thermostat in the two test buildings during the entire summer

Figure 6 shows the same description of the summer period, but indicates the indoor $\mathrm{RH}$ in the two test buildings. It is readily seen that the indoor RH with ongoing $\mathrm{AC}$ of the buildings was typically $38 \%-51 \%$ during the time before forced ventilation was added. However, it is clear from the data that the indoor RH approached $60 \%$ beginning in August in the west building when 63 CFM of outdoor air was introduced. The RH becomes much higher in early November $(65 \%$ or more) when the need for $\mathrm{AC}$ ends. 


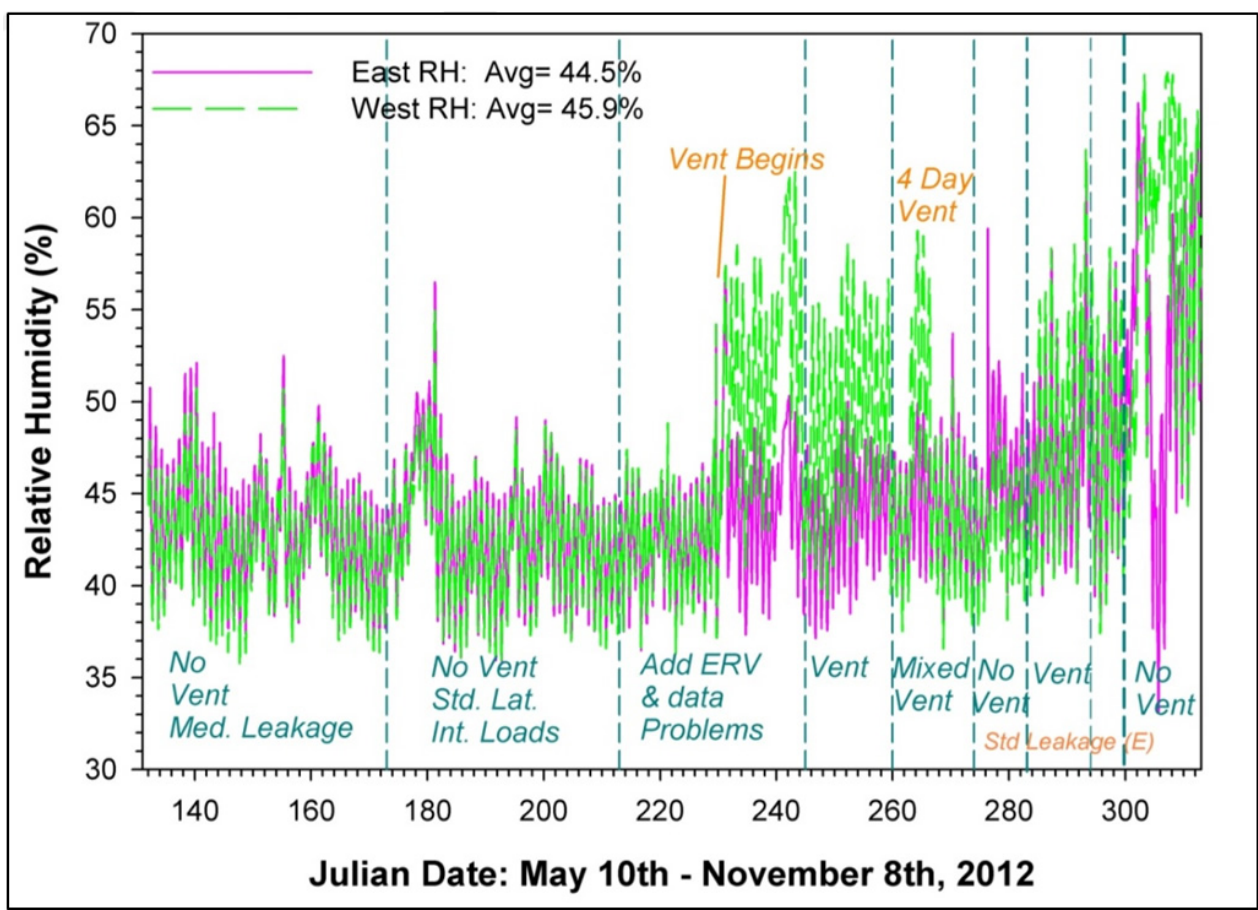

Figure 6. Measured indoor RH by the thermostat in the two test buildings during the entire summer

Figure 7 shows the dew point temperature outdoors and indoors in the two buildings during the summer monitoring period. Unlike the RH values shown in Figure 6, the dew point temperatures indicate the absolute moisture content of the air. As before, we see little influence of the lower or standard interior moisture loads on the achieved interior dew points, which are demonstrably much lower in moisture content than that seen outdoors. This is because the vapor compression AC system largely removes the additional moisture, as shown in Figure 8 where condensate flow rates were considerably elevated at the higher internal moisture release rate. Thus, the interior air and cooling machine characteristics reach equilibrium with the interior absolute moisture level by operating longer with slightly longer runtimes. This is consistent with published research on the operation characteristics of unitary air conditioners (Henderson and Rengarahan 1996). 


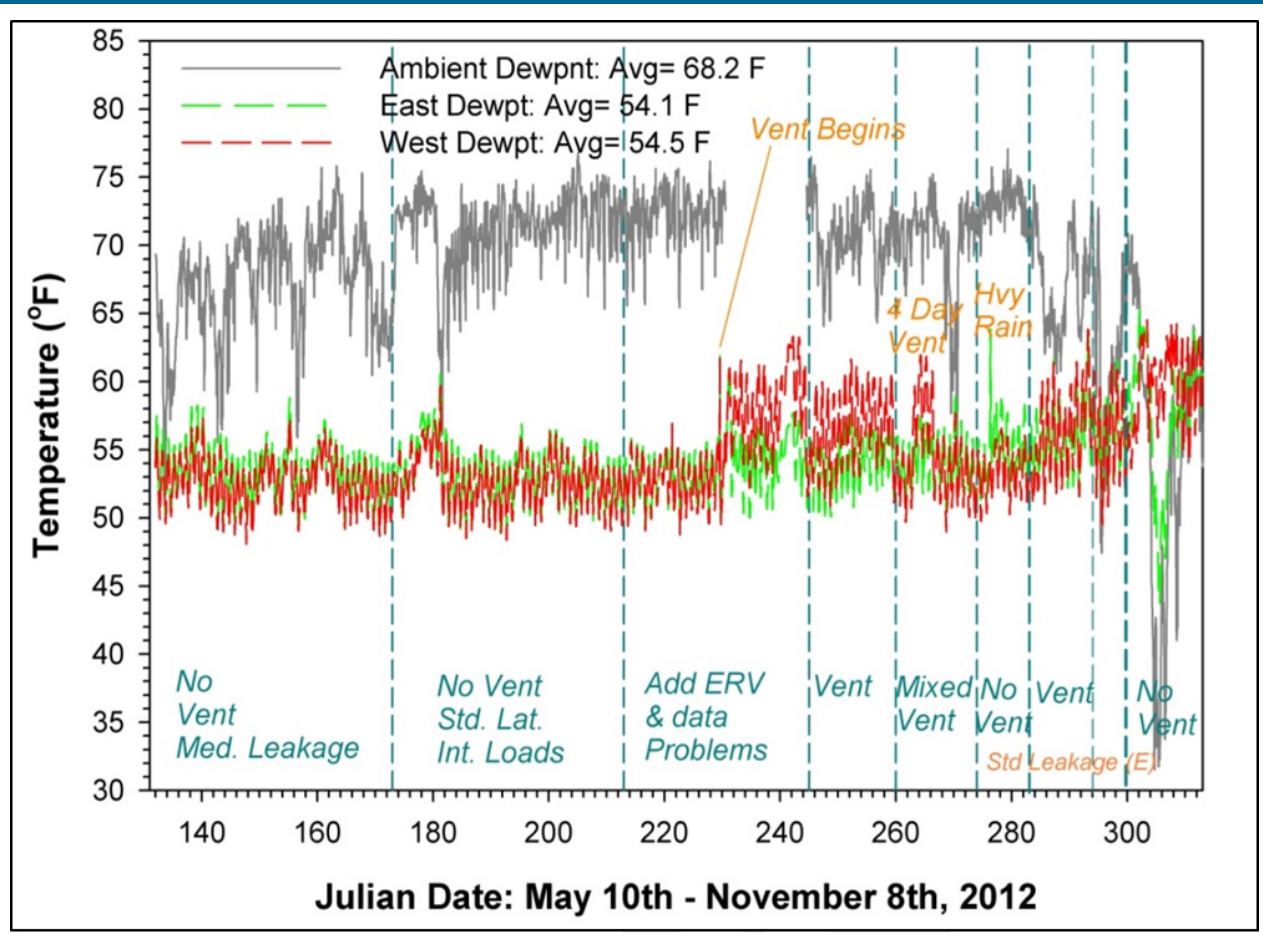

Figure 7. Measured indoor and outdoor dew point temperatures in the two test buildings during the entire summer

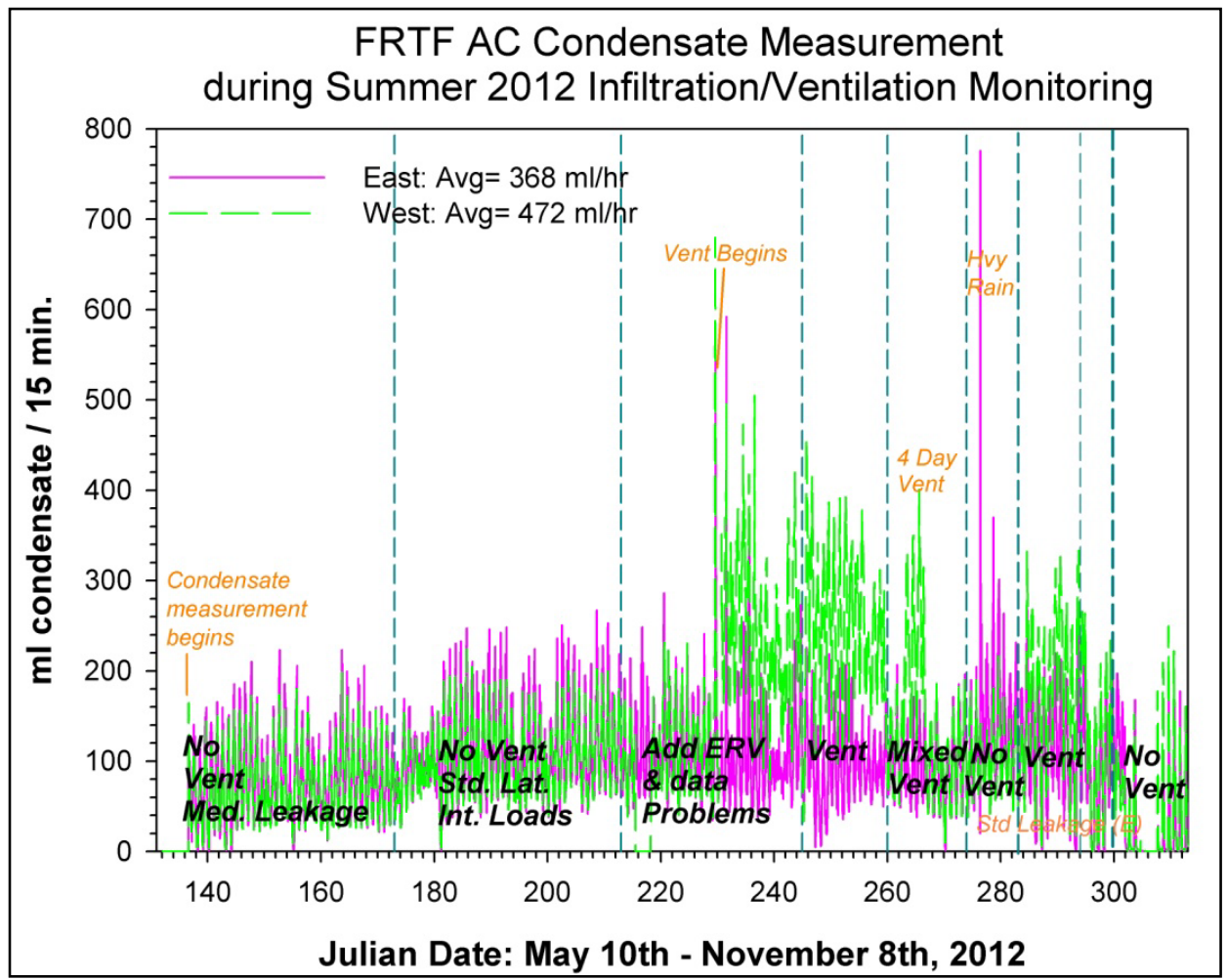

Figure 8. Measured air conditioner condensate in the two test buildings during the entire summer 
However, we also see a pronounced impact from the addition of forced ventilation in the west building beginning in mid-August. The interior dew points are typically elevated by $3^{\circ} \mathrm{F}$ or more. Later in October, we can see that during a no-vent period, the tighter west building has lower interior moisture than the east home during a period with heavy rainfall. On the other hand, at the end of the monitoring period in early November, when the outdoor dew points are much lower than those indoors and there is no longer much need for $\mathrm{AC}$, the leakier east test building achieves lower interior moisture levels by its greater air infiltration during this period.

Figure 8 shows the measured air conditioner condensate volume measured each hour during the monitoring period. Here, we can see that when the internal moisture level is raised to $11 \mathrm{lb} /$ day in late June, both air conditioners remove more moisture, which largely explains the fact that the measured interior dew points in Figure 7 were largely stable. However, we do clearly see that when forced ventilation begins in the west building in August, the measured condensate that is collected increases significantly. Further, during the non-ventilation period from October 2-8, when there were heavy rains, we see the leakier east building with greater removed condensate. Finally, we see the collected condensate drop dramatically in both buildings in the final test period at the end of the Central Florida cooling season in early November 2012.

\subsection{Energy Comparison}

The measured air conditioner and air handling unit compressor power was continuously measured during the test period to evaluate how measured cooling energy use was influenced by building air leakage and mechanical ventilation. Average summer AC from May 1 to September 30 averaged $23.4 \mathrm{kWh} /$ day in the east building and $24.4 \mathrm{kWh} /$ day in the west building.

The final time series plots in Figure 9 show the measured hourly AC during the summer. The power consumption of the 74 Watt ventilation fan is plotted separately in blue. The nature of the "on-off" power consumption data of the single-speed air conditioner during this time makes it impossible to discern trends other than the fact that the needed cooling energy drops rapidly towards the end of summer. However, as shown in the tabular and graphical data summaries that follow for the various periods, it is possible to see some influences when the data are summarized as power demand profiles over the 24-hour time domain during each test period. 


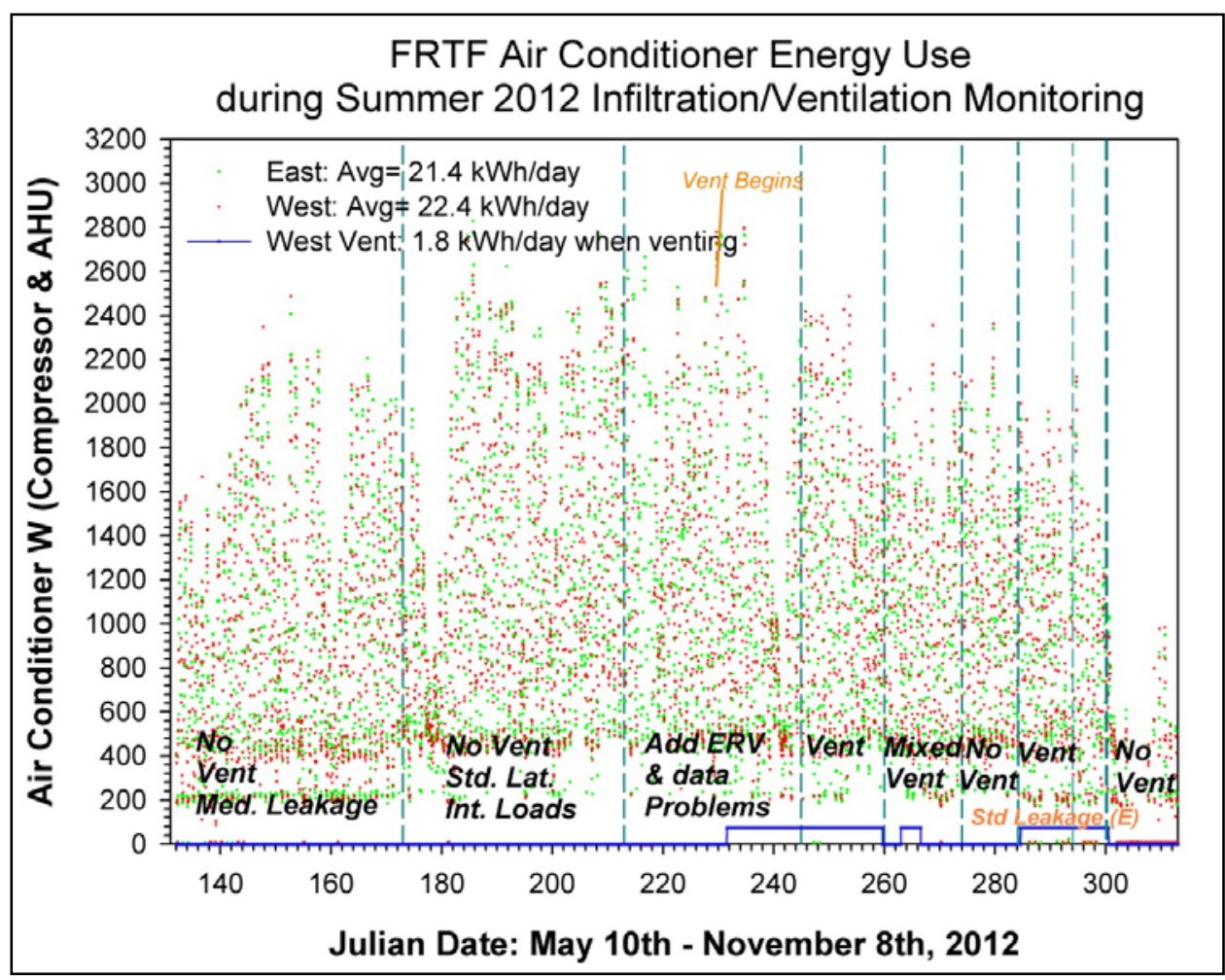

Figure 9. Measured air conditioner and ventilation system power in the two test buildings over the entire summer

\subsection{Evaluation During Individual Test Periods}

From April 17 to August 16, and periodically from August 16 to October 24, the west home was operated with no mechanical ventilation to compare the performance of a very tight home to a leaky home.

Beginning August 16 (roughly every other 2-3 weeks), the west home was ventilated using an energy recovery ventilation system to evaluate the energy and moisture impacts of forced ventilation in a tight home. However, due to a variety of issues $\left(\mathrm{a} \mathrm{CO}_{2}\right.$ tracer gas system was being installed in the building during August), the first consistently operated ventilation period was from September 1-13, 2012. The second valid period with ventilation was during the cooler period from October 9-23. The contrasting non-ventilated period was from October 25 to November 13, at which point the cooling season experiments were declared over.

\subsubsection{Test Period I: May 10 to June 21, 2012}

Test data were taken during the first evaluation period of the summer (Table 5) with a lower internal moisture release rate of $6 \mathrm{lb} / \mathrm{day}$. As internal moisture rates are uncertain, this lower rate would represent the lowest rate of moisture generations associated with human respiration, bathing, and cooking. There was little difference observed between the east building with moderate leakage and the much tighter west building. Air conditioner power was very similar in the two buildings, as were the interior moisture indicators: $\mathrm{RH}$ averaged $42 \%-43 \%$ with interior dew points of about $53^{\circ} \mathrm{F}$. The various summarized performance indices are shown in Figure 10 through Figure 13. 
Table 5. May 10 to June 21, 2012 (Natural Air Infiltration, Low Moisture Generation)

\begin{tabular}{|c|c|c|c|c|}
\hline & East & West & $\Delta$ & $\%$ \\
\hline Thermostat Temperature $\left({ }^{\circ} \mathbf{F}\right)$ & $77.5^{\circ}$ & $77.3^{\circ}$ & -0.2 & -0.4 \\
\hline RH $(\%)$ & $43.0 \%$ & $42.4 \%$ & -0.6 & -1.4 \\
\hline Dew Point ( $\left.{ }^{\circ} \mathrm{F}\right)$ & $53.3^{\circ}$ & $52.6^{\circ}$ & -0.7 & -1.3 \\
\hline Condensate (L/day) & 6.81 & 6.25 & -0.56 & -8.2 \\
\hline \multirow[t]{2}{*}{ Air Conditioner Power (kWh/day) } & 19.70 & 21.00 & +1.34 & +6.8 \\
\hline & Average & Minimum & Maximum & \\
\hline Ambient Temperature $\left({ }^{\circ} \mathbf{F}\right)$ & $77.4^{\circ}$ & $64.6^{\circ}$ & $90.7^{\circ}$ & - \\
\hline Ambient RH (\%) & $72.9 \%$ & $36.6 \%$ & $95.0 \%$ & - \\
\hline Ambient Dew Point $\left({ }^{\circ} \mathrm{F}\right)$ & $67.3^{\circ}$ & $52.0^{\circ}$ & $75.8^{\circ}$ & - \\
\hline
\end{tabular}

Generally, the data showed that when AC is consistent, with the distribution of leakage in our test buildings, building tightness does not appear a large factor influencing either cooling energy use or interior moisture levels. This is not surprising, for as shown in Figure 10, the temperature outside in the May-June time frame is as often lower outside as it is higher for much of the day. This influence is seen graphically in Figure 10 where the energy use in the tighter west building is lower during the hottest part of the day, but higher during the cooler nighttime hours. Thus, greater building leakage is not likely a large factor in energy use. The only seen influence was that the interior $\mathrm{RH}$ in the looser east building was about $0.5 \%$ higher (statistically insignificant at the accuracy of the measurement), with about an $8.2 \%$ increase in the $\mathrm{AC}$ condensate collection during the period.

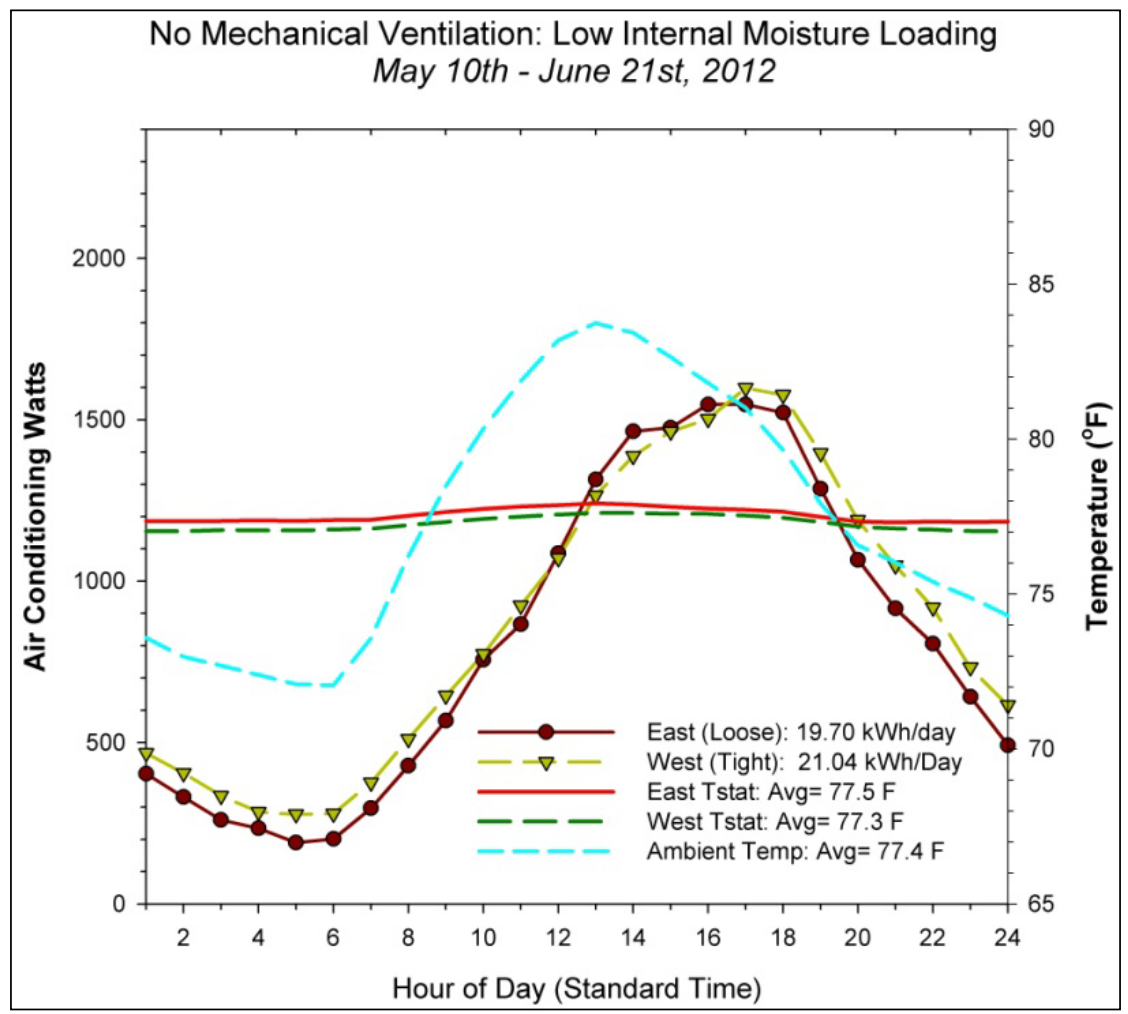

Figure 10. AC energy use, May 10 to June 21, 2012: natural infiltration, low moisture release 


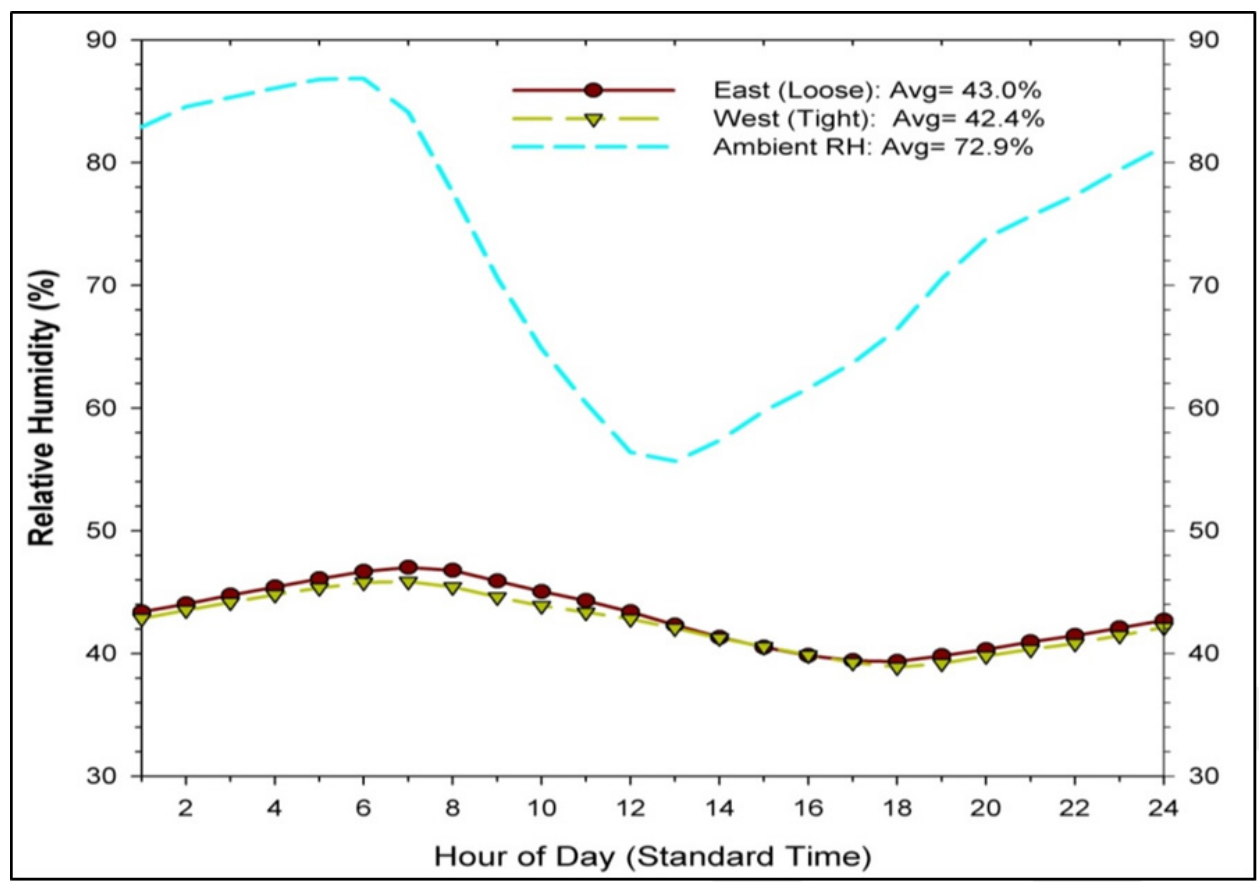

Figure 11. Comparative $\mathrm{RH}$, May 10 to June 21, 2012: natural infiltration, low moisture release

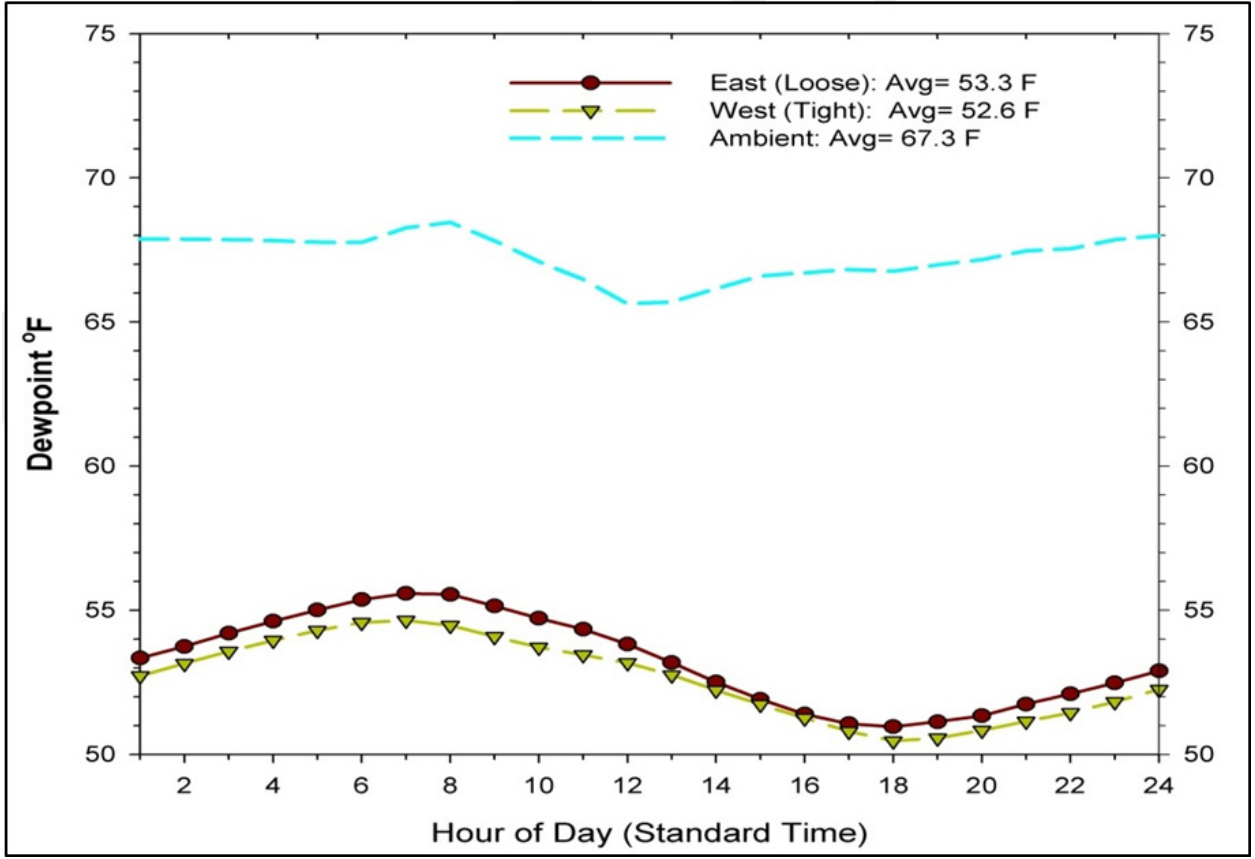

Figure 12. Comparative dew point temperatures, May 10 to June 21, 2012: natural infiltration, low moisture release 


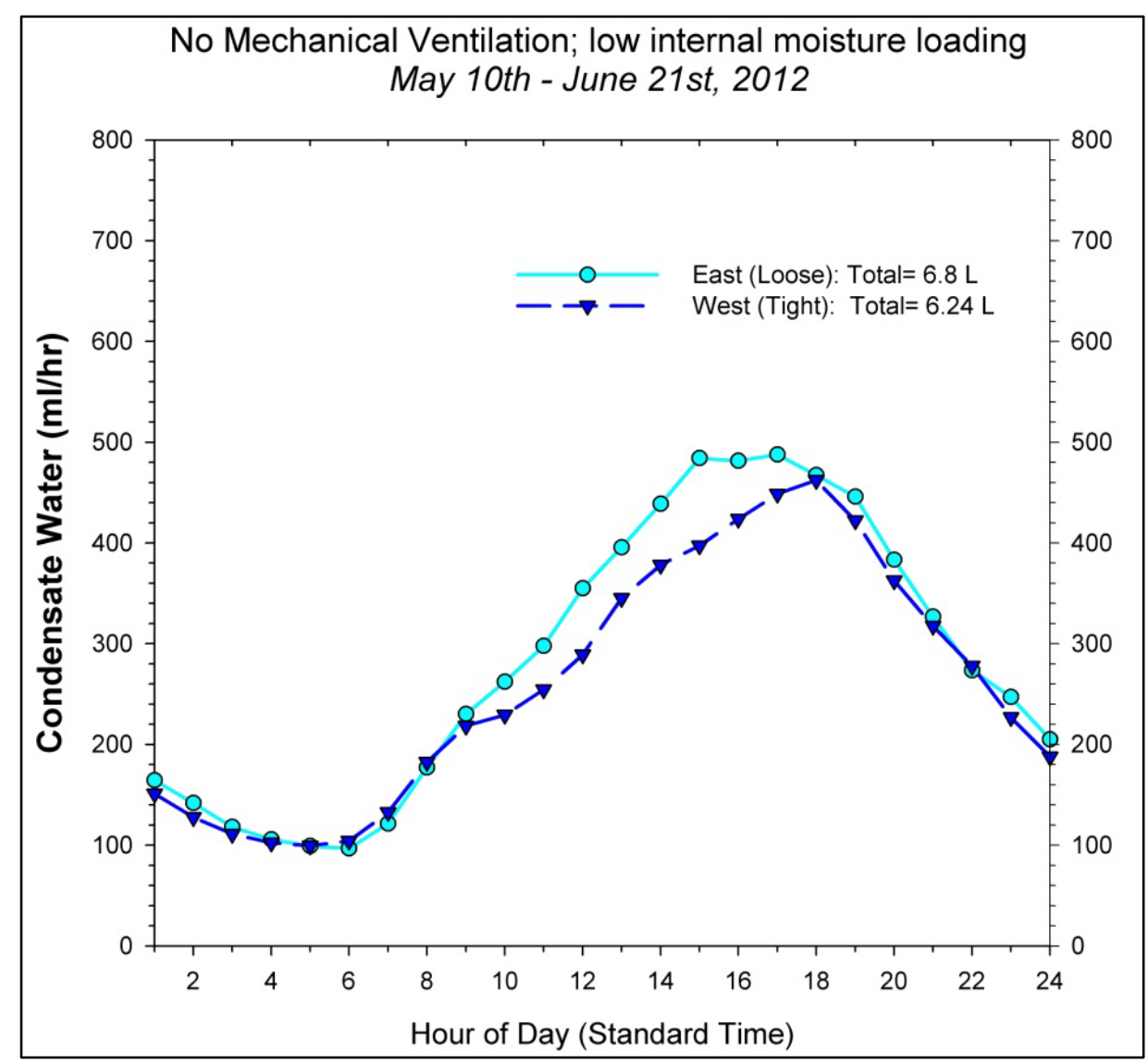

Figure 13. Comparative condensate removal, May 10 to June 21, 2012: natural infiltration, low moisture release

\subsubsection{Test Period II: June 23 to July 31, 2012}

The period from June 23 to July 31 (Table 6) included a higher internal moisture generation level for the two test buildings than the first test period $(11 \mathrm{lb} /$ day of moisture versus $6 \mathrm{lb} /$ day in May). This rate is in general agreement with the recommended levels within the Building America field test protocol (Fang et al. 2011), although considerably lower than the design levels suggested by the ASHRAE 160 Standard (ASHRAE 2009). Even with the higher moisture loading, the data showed similar interior temperatures, RHs, and dew points in the two test buildings. Collected condensate was also similar in the two structures, but considerably higher than the earlier May period by about $4 \mathrm{~L} /$ day. Air conditioner power use was also very similar in the structures with no significant differences within the period. 
Table 6. June 23 to July 31, 2012 (Natural Air Infiltration, Standard Moisture Generation)

\begin{tabular}{c|c|c|c|c}
\hline & East & West & $\Delta$ & $\%$ \\
\hline Thermostat Temperature ( $\left.{ }^{\circ} \mathbf{F}\right)$ & $77.7^{\circ}$ & $77.3^{\circ}$ & -0.4 & -0.5 \\
\hline RH (\%) & $42.8 \%$ & $42.6 \%$ & -0.2 & -0.4 \\
Dew Point $\left({ }^{\circ} \mathbf{F}\right)$ & $53.2^{\circ}$ & $52.7^{\circ}$ & -0.5 & -0.9 \\
\hline Condensate (L/day) & 10.62 & 10.35 & -0.27 & -2.5 \\
\hline Air Conditioner Power (kWh/day) & 27.64 & 28.30 & +0.66 & +2.4 \\
\hline Ambient Temperature $\left({ }^{\circ} \mathbf{F}\right)$ & Average & Minimum & Maximum & \\
Ambient RH (\%) & $80.7^{\circ}$ & $64.1^{\circ}$ & $92.8^{\circ}$ & \\
Ambient Dew Point $\left({ }^{\circ} \mathbf{F}\right)$ & $71.6^{\circ}$ & $36.7^{\circ}$ & $94.2^{\circ} \%$ & \\
\hline
\end{tabular}

The key differences from the May test period were higher collected condensate and much higher air conditioner power - about $7 \mathrm{kWh}(+40 \%$ and $+35 \%$ in the east and west structures, respectively). A portion of the increase was due to the higher latent loads (approximately 9,000 Btu/day), but most was due to the naturally increasing sensible loads during the hottest weather during test period II. The fact that the interior RHs and dew points did not change appreciably is coincidental and due to the approximately $40 \%$ longer runtimes seen during the latter period, which removed much more moisture as evidenced by the condensate differences. The various summarized performance indices are shown in Figure 14 through Figure 17.

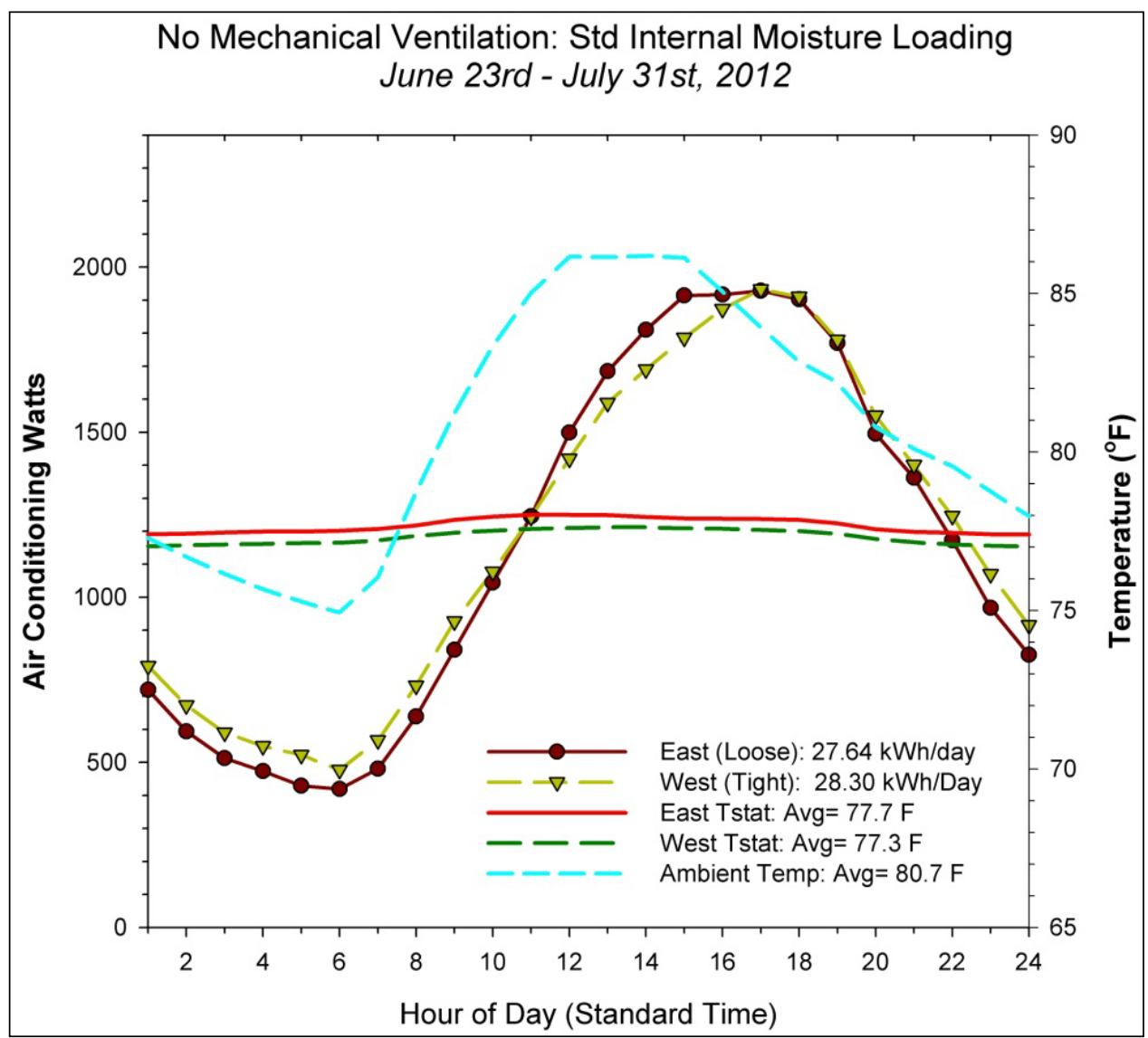

Figure 14. AC energy use, June 23 to July 31, 2012: natural infiltration, standard moisture release 


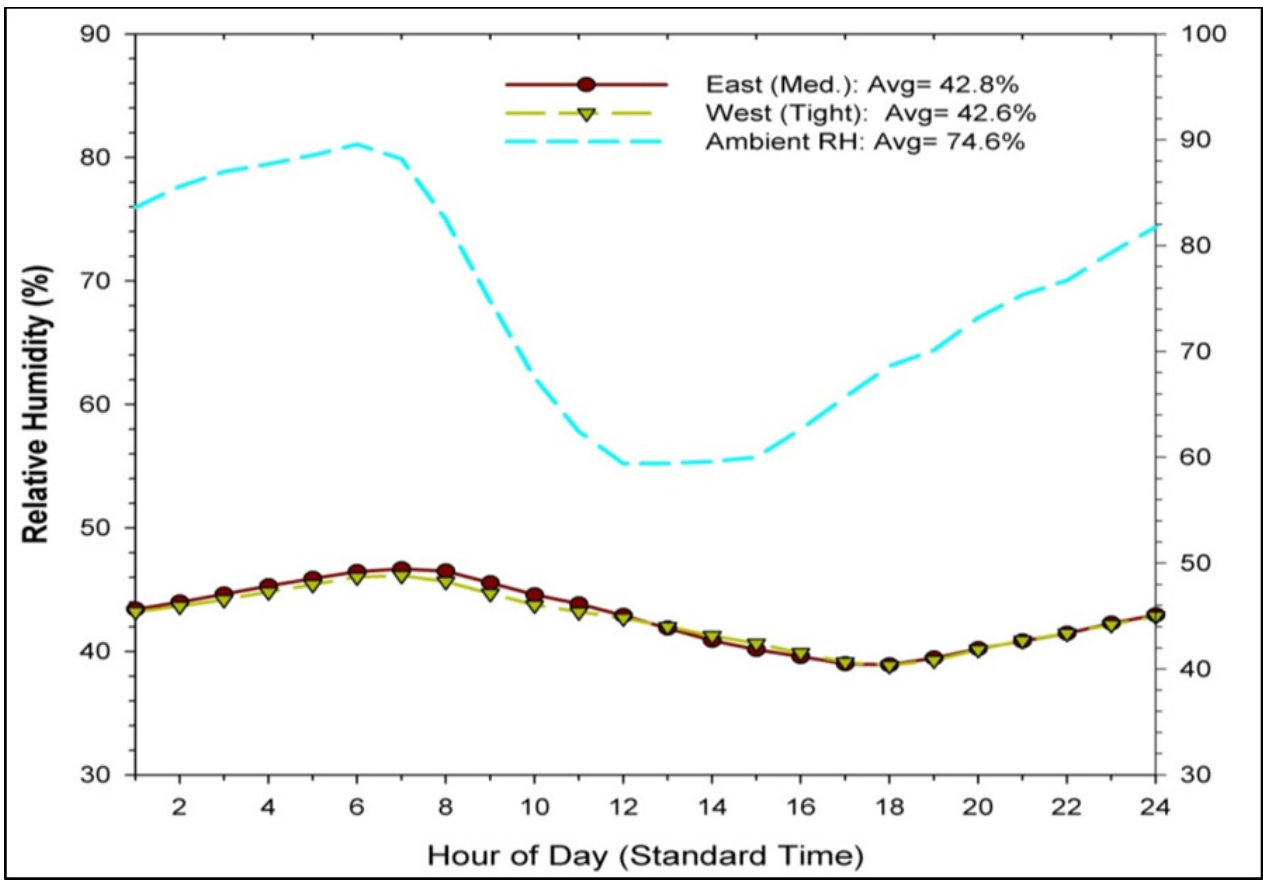

Figure 15. Comparative RH, June 23 to July 31, 2012: natural infiltration, standard moisture release

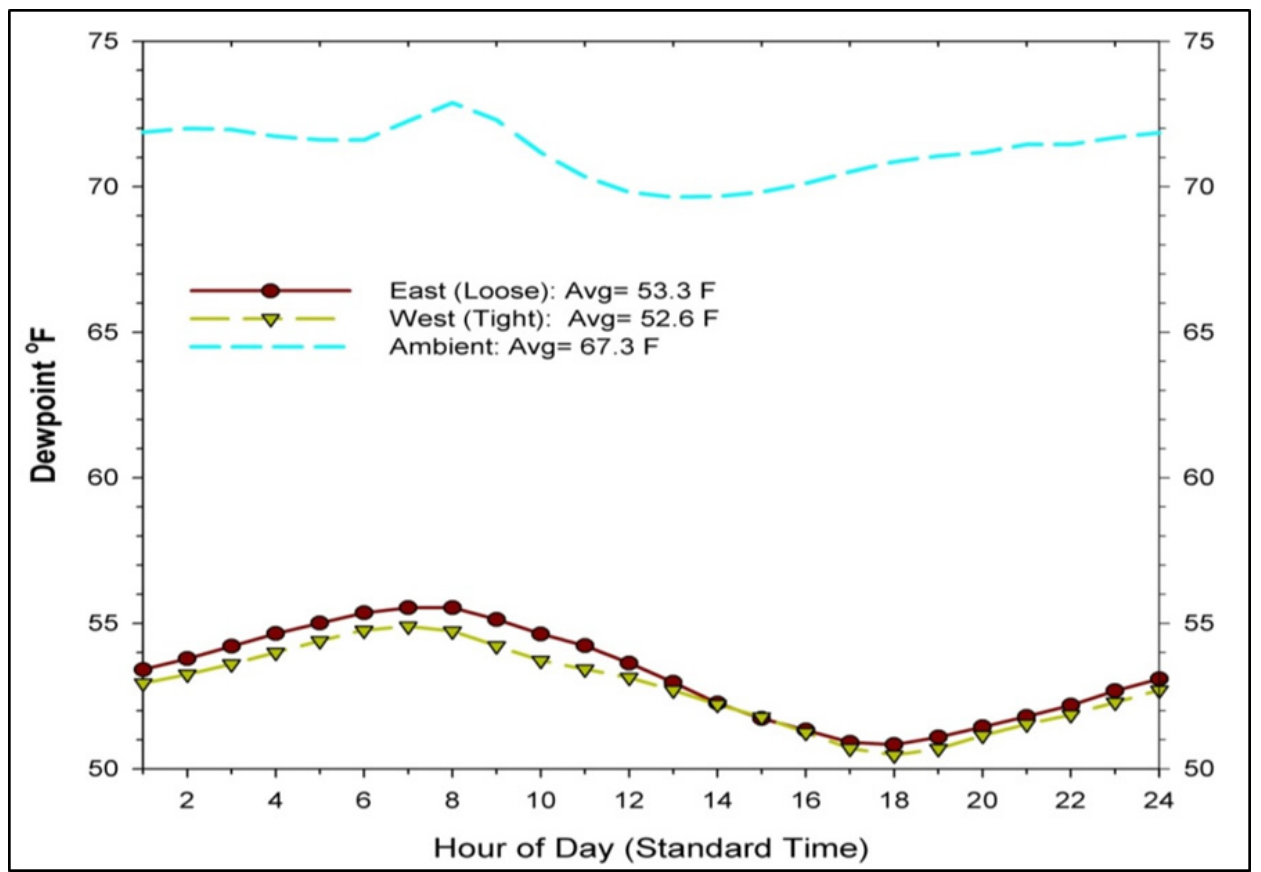

Figure 16. Comparative dew point temperatures, June 23 to July 31, 2012: natural infiltration, standard moisture release 


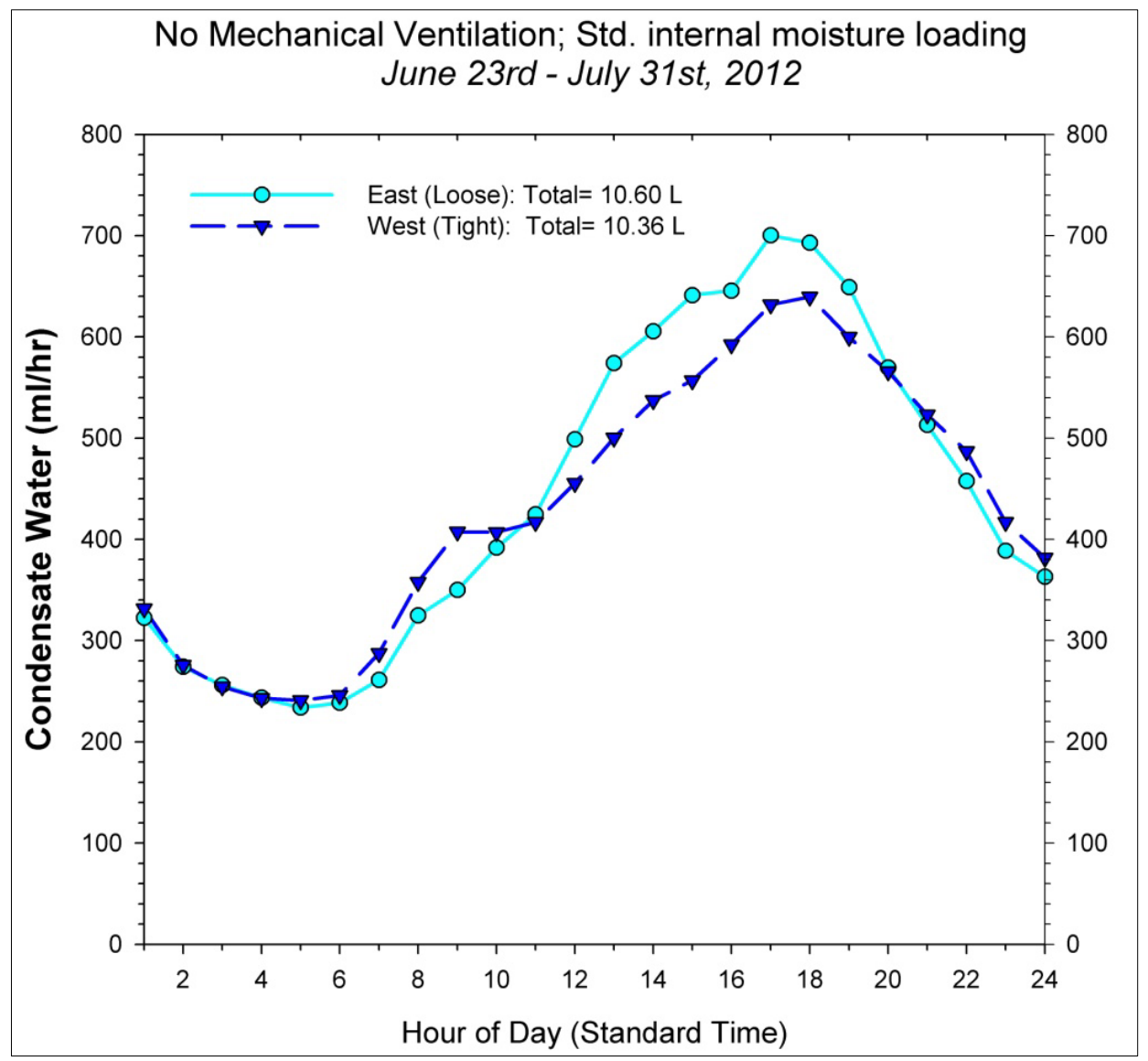

Figure 17. Comparative condensate removal, June 23 to July 31, 2012: natural infiltration, standard moisture release

\subsubsection{Test Period III: September 1-13, 2012}

The period from September 1-13 (Table 7) featured the first valid data collection period when the ventilation system was active in the tighter west building. While temperature conditions by the thermostat were similar, the ventilated west building experienced higher interior moisture levels. This was evidenced by the interior RH, which averaged nearly $6 \%$ higher during the test period, and an interior dew point that was elevated by $3^{\circ} \mathrm{F}$. The collected condensate moisture during the test was more than doubled in the ventilated building: 8.9 versus $24 \mathrm{~L} /$ day. This represents a latent heat of approximately $50,200 \mathrm{Btu} /$ day or about $4.9 \mathrm{kWh} /$ day at a coefficient of performance of 3.0. Closely mirroring these approximations, the air conditioner power was increased by $23 \%(5.2 \mathrm{kWh} /$ day $)$ and by $30 \%(7.0 \mathrm{kWh} /$ day $)$ when the power of the ventilation fan was included. This result is not surprising as simulation research on the moisture impacts of ASHRAE Standard 62-2004 (Walker and Sherman 2007) indicated that compliant mechanical ventilation systems would increase interior humidity levels by $5 \%-10 \%$ in homes in humid climates. Further, empirical research by Rudd and Henderson (2007) found that homes with mechanical ventilation in humid climates without supplement dehumidification experienced higher interior moisture levels. The various summarized performance indices are shown in Figure 18 through Figure 21. 
Table 7. September 1-13, 2012 (West Unit Vented)

\begin{tabular}{|c|c|c|c|c|}
\hline & East & West & $\Delta$ & $\%$ \\
\hline Thermostat Temperature $\left({ }^{\circ} \mathbf{F}\right)$ & $77.8^{\circ}$ & $77.4^{\circ}$ & -0.4 & -1.8 \\
\hline RH $(\%)$ & $43.5 \%$ & $49.2 \%$ & +5.7 & +13.1 \\
\hline Dew Point $\left({ }^{\circ} \mathbf{F}\right)$ & $53.8^{\circ}$ & $56.8^{\circ}$ & +3.0 & +5.6 \\
\hline Condensate $(\mathrm{L} /$ day $)$ & 8.94 & 23.99 & +15.06 & +168.4 \\
\hline \multirow[t]{2}{*}{ Air Conditioner Power (kWh/day) } & $22.90 \mathrm{kWh}$ & $29.88 \mathrm{kWh}$ & +7.00 & +30.5 \\
\hline & Average & Minimum & Maximum & \\
\hline Ambient Temperature $\left({ }^{\circ} \mathrm{F}\right)$ & $79.5^{\circ}$ & $70.6^{\circ}$ & $90.6^{\circ}$ & \\
\hline Ambient RH (\%) & $74.9 \%$ & $47.3 \%$ & $94.5 \%$ & \\
\hline Ambient Dew Point $\left({ }^{\circ} \mathrm{F}\right)$ & $70.3^{\circ}$ & $64.0^{\circ}$ & $75.6^{\circ}$ & \\
\hline
\end{tabular}

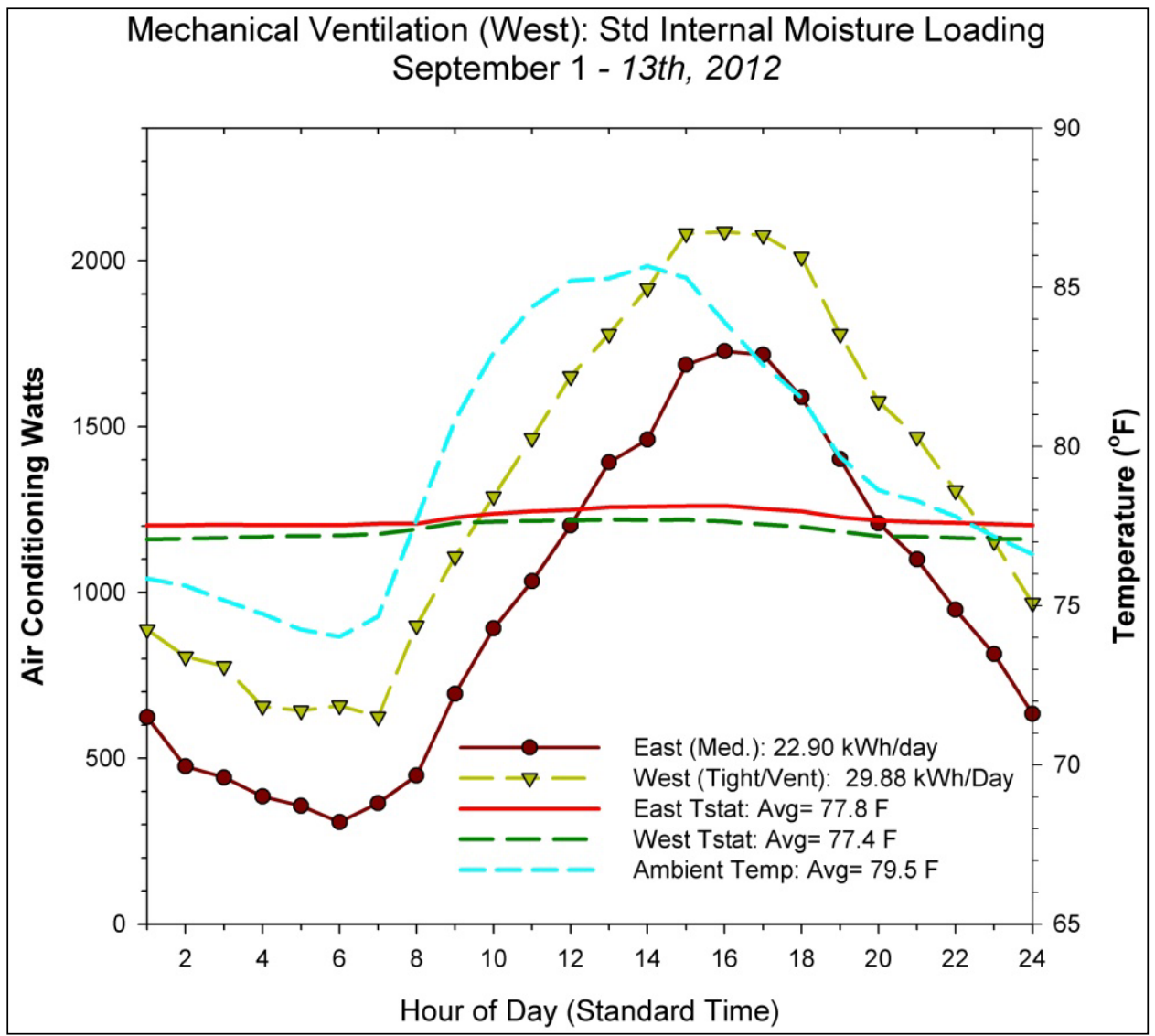

Figure 18. AC energy use, September 1-13, 2012: west ventilated 


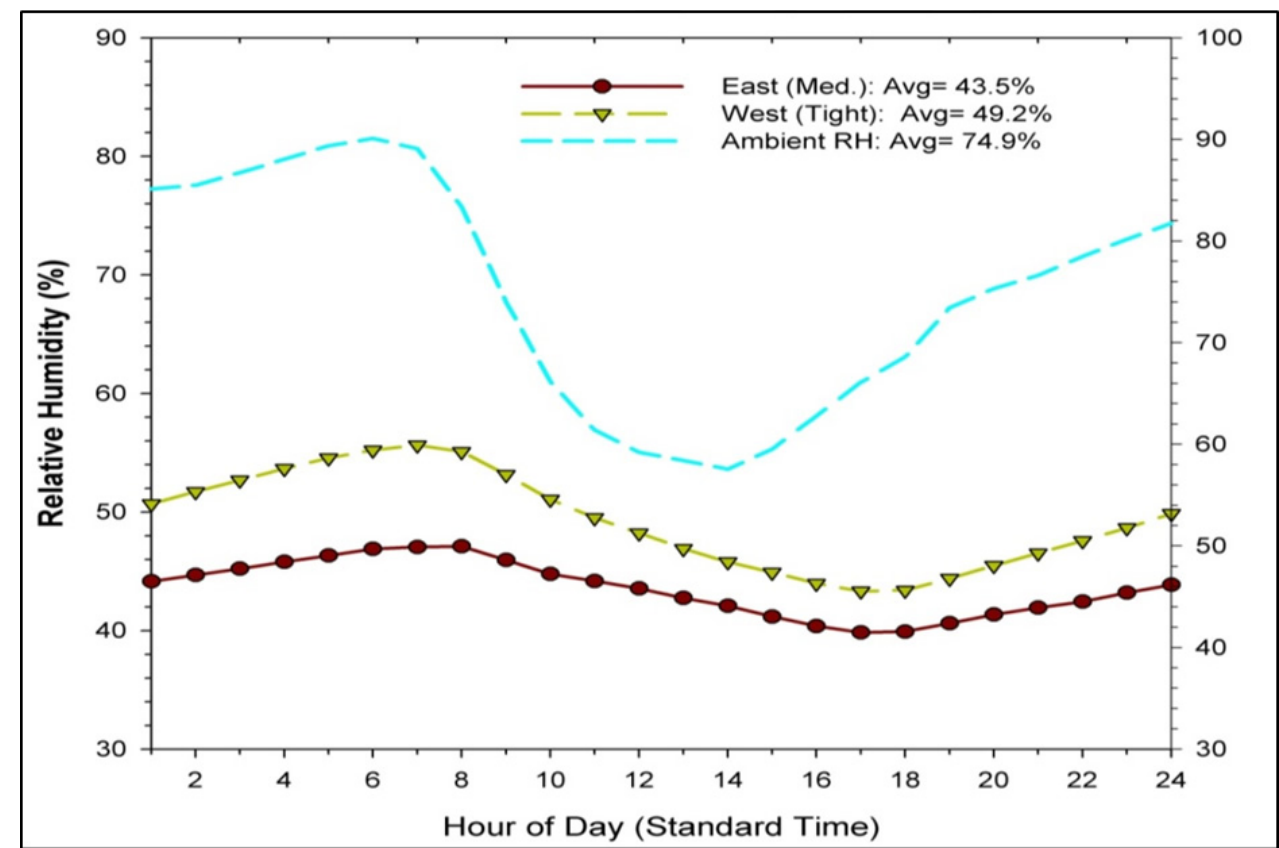

Figure 19. Comparative RH, September 1-13, 2012: west ventilated

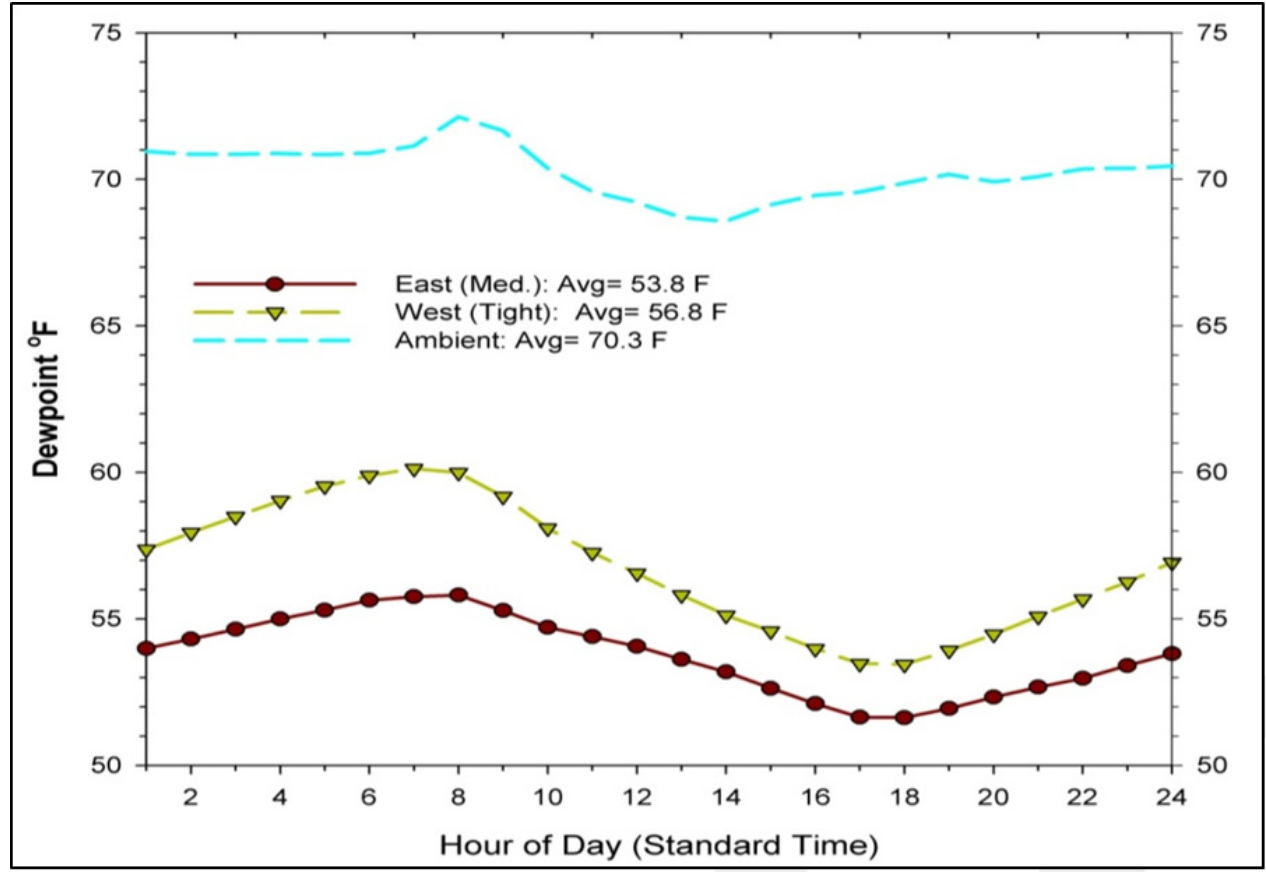

Figure 20. Comparative dew point temperatures, September 1-13, 2012: west ventilated 


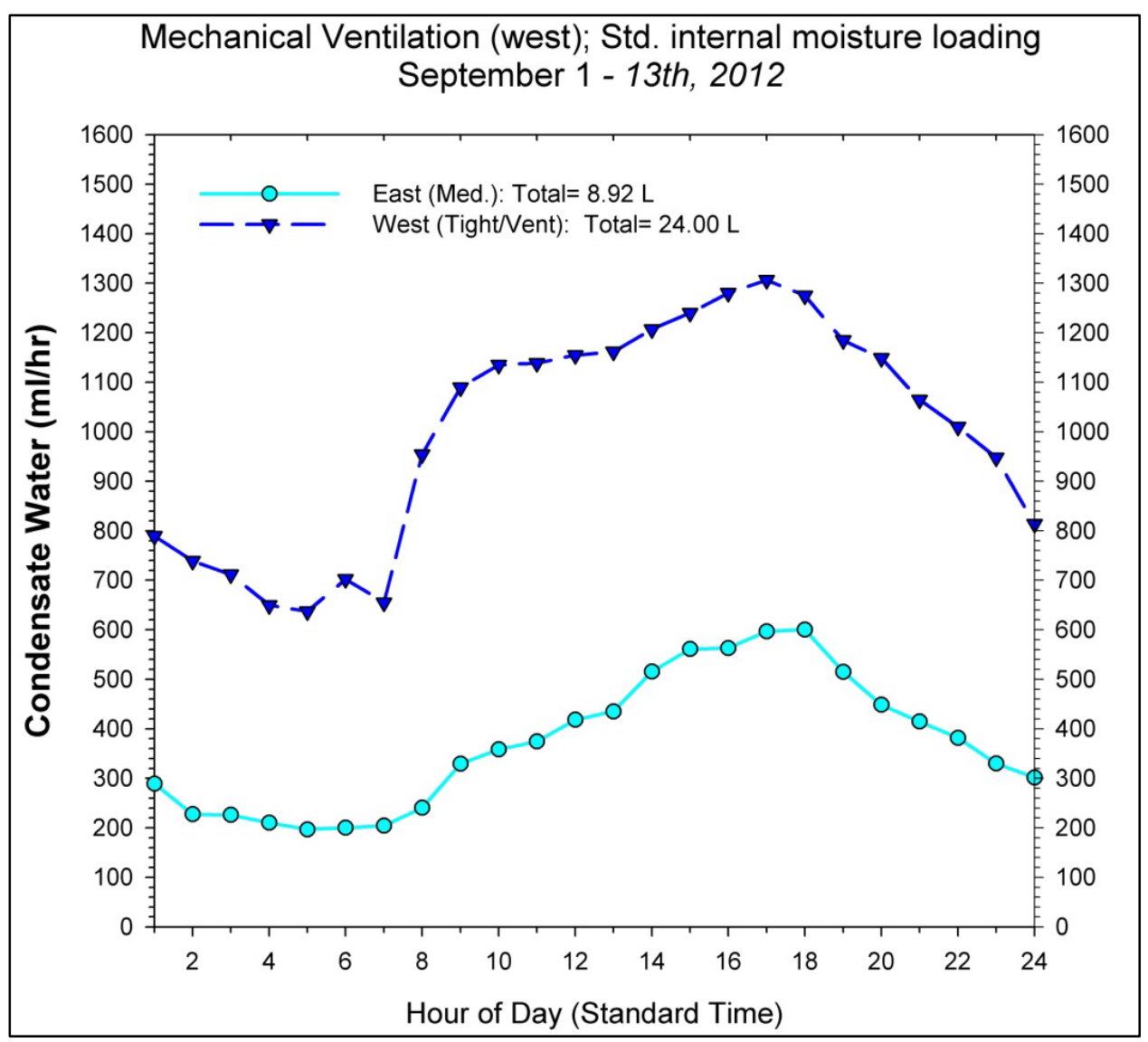

Figure 21. Comparative condensate removal, September 1-13, 2012: west ventilated

\subsubsection{Test Period IV: October 2-8, 2012}

The test period the first week in October (Table 8) included the change back to the leaky configuration in the east test building, although with no forced ventilation in the tighter west building. The weather during this period was characterized by such heavy rainfall that the leakier east building actually had higher interior moisture, as indicated by RH, interior dew point, and collected condensate. Air conditioner power was nearly identical in the two buildings. The various summarized performance indices are shown in Figure 22 through Figure 25.

\footnotetext{
${ }^{4}$ The prior test period from September 15-30 was intended to be a period when no forced ventilation was used. Unfortunately, the ventilation system was inadvertently activated for 4 days during this period, making it unsuitable for further analysis.
} 
Table 8. October 2-8, 2012 (No Ventilation, East Building Goes to High Leakage)

\begin{tabular}{c|c|c|c|c}
\hline & East & West & $\Delta$ & \% \\
\hline Thermostat Temperature $\left({ }^{\circ} \mathbf{F}\right)$ & $77.8^{\circ}$ & $77.3^{\circ}$ & 0.5 & -0.6 \\
RH (\%) & $46.3 \%$ & $43.8 \%$ & -2.5 & -5.3 \\
Dew Point $\left({ }^{\circ} \mathbf{F}\right)$ & $55.5^{\circ}$ & $53.6^{\circ}$ & -1.9 & -3.4 \\
\hline Condensate (L/day) & 13.68 & 10.09 & -3.59 & -26.2 \\
\hline Air Conditioner Power (kWh/day) & 22.22 & 23.28 & +1.06 & +4.7 \\
\hline Ambient Temperature ( $\left.{ }^{\circ} \mathbf{F}\right)$ & Average & Minimum & Maximum & \\
Ambient RH (\%) & $79.0^{\circ}$ & $72.1^{\circ}$ & $87.0^{\circ}$ & \\
Ambient Dew Point $\left({ }^{\circ} \mathbf{F}\right)$ & $82.6^{\circ} \%$ & $60.1 \%$ & $95.1 \%$ & \\
\hline
\end{tabular}

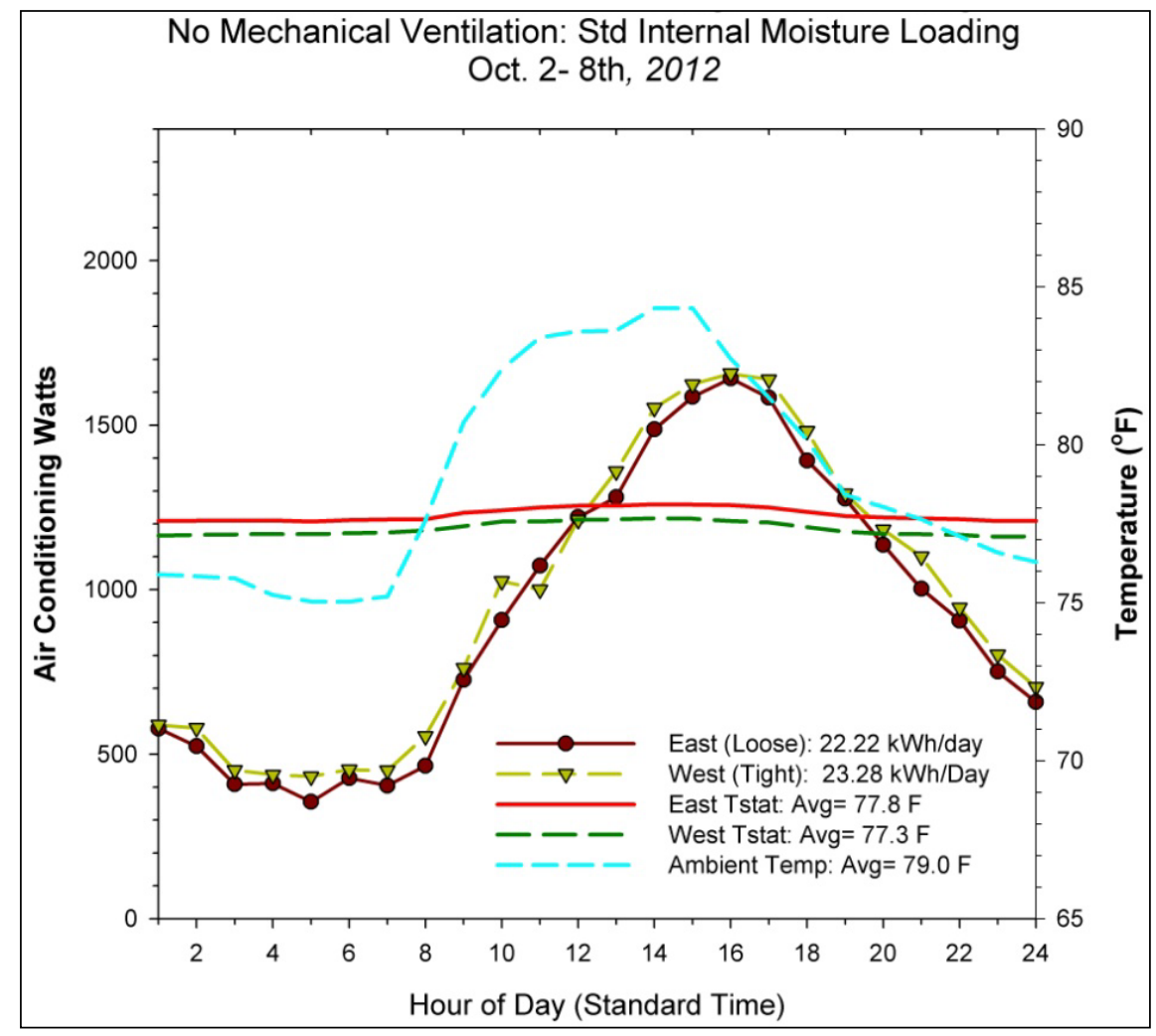

Figure 22. AC energy use, October 2-8, 2012: no ventilation, east building goes to high leakage 


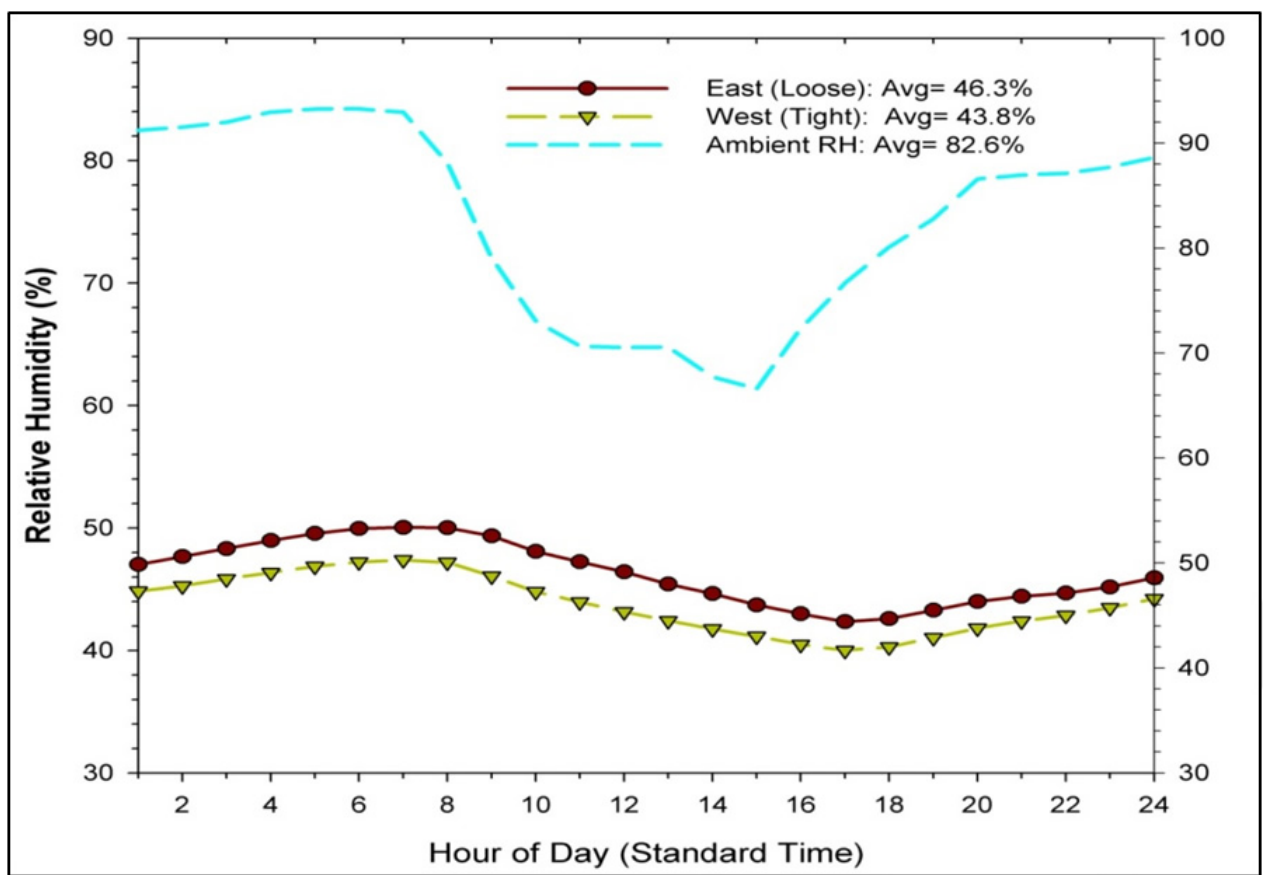

Figure 23. Comparative $\mathrm{RH}$, October 2-8, 2012: no ventilation, east building goes to high leakage

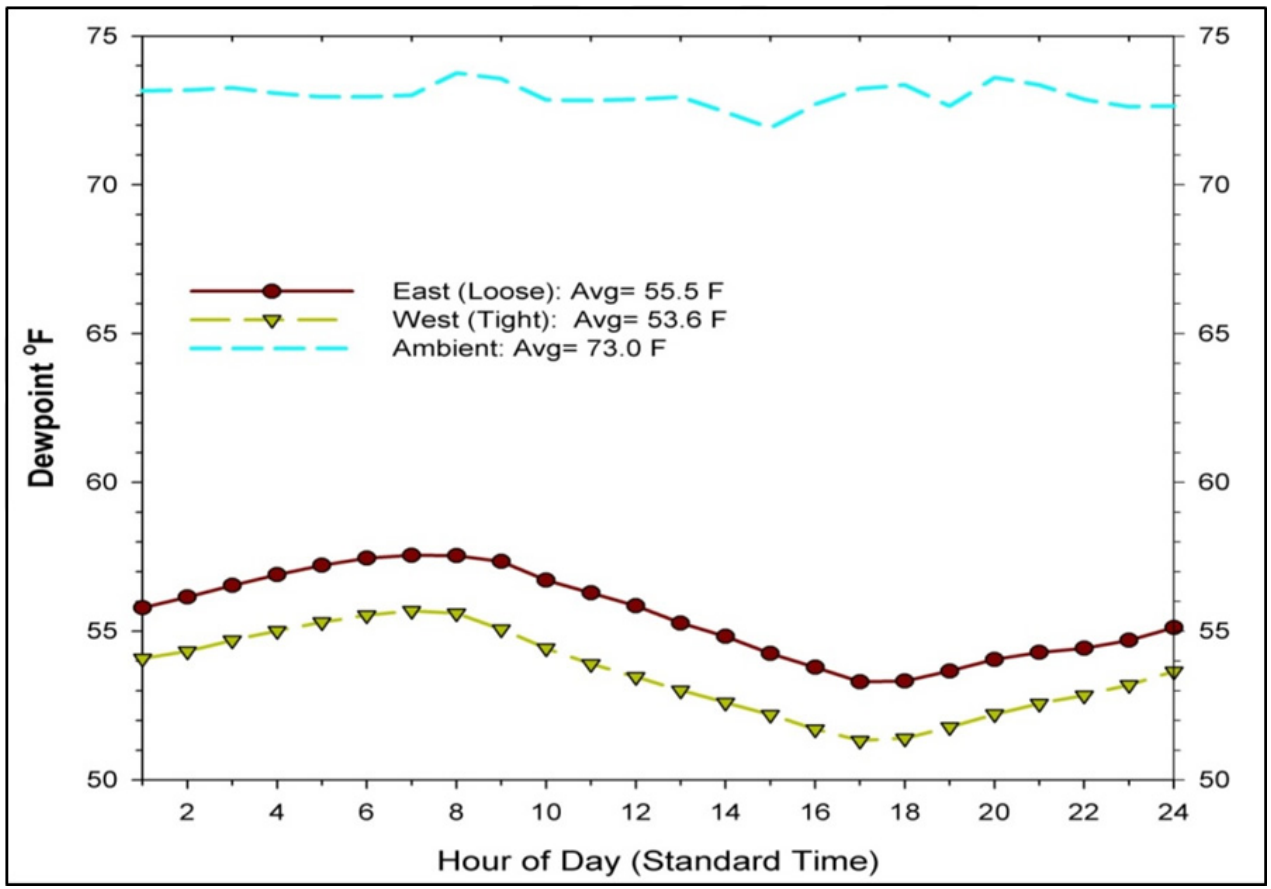

Figure 24. Comparative dew point temperatures, October 2-8, 2012: no ventilation, east building goes to high leakage 


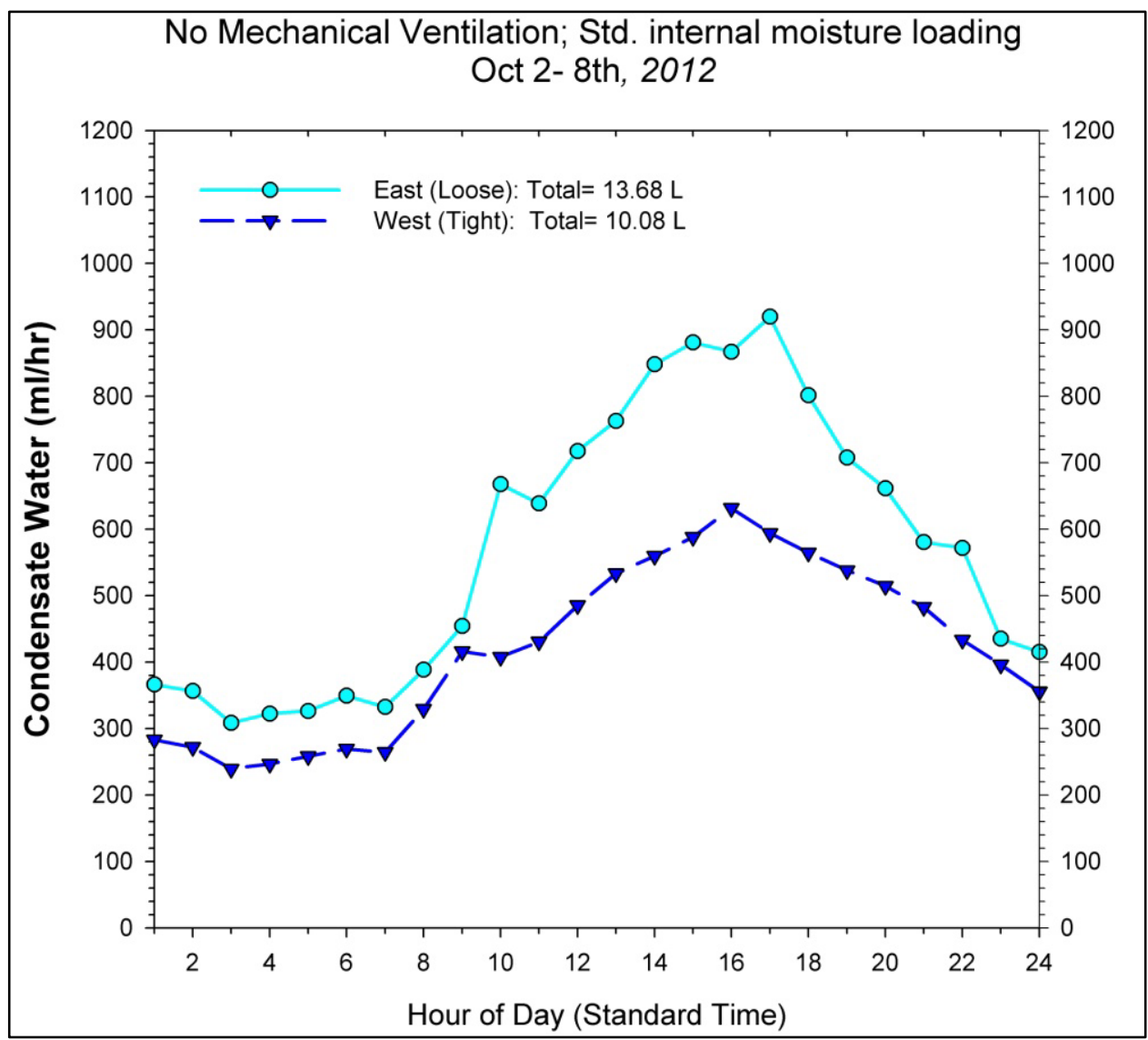

Figure 25. Comparative condensate removal, October 2-8, 2012: no ventilation, east building goes to high leakage

\subsubsection{Test Period V: October 10-20, 2012}

The period from October 10-20 (Table 9) was during a weather pattern when cooling loads were dropping rapidly, while the ventilation system was operated in the tighter west building. While interior temperature conditions were similar in both buildings, the ventilated building had higher moisture levels: $+2.2 \% \mathrm{RH}, \mathrm{a}^{\circ} \mathrm{F}$ higher interior dew point, and $60 \%$ higher condensate removal by the AC system. Combined AC and ventilation system power was $4.7 \mathrm{kWh} /$ day higher than with the leakier east building - an increase of $27 \%$. The various summarized performance indices are shown in Figure 26 through Figure 29.

Table 9. October 10-20, 2012 (West Unit Vented)

\begin{tabular}{|c|c|c|c|c|}
\hline & East & West & $\Delta$ & $\mathbf{\%}$ \\
\hline Thermostat Temperature $\left({ }^{\circ} \mathbf{F}\right)$ & $77.6^{\circ}$ & $77.3^{\circ}$ & -0.3 & -0.4 \\
\hline RH (\%) & $46.9^{\circ}$ & $49.1 \%$ & +2.2 & +4.7 \\
\hline Dew Point $\left({ }^{\circ} \mathbf{F}\right)$ & $55.7^{\circ}$ & $56.6^{\circ}$ & +1.1 & +2.0 \\
\hline Condensate $(\mathbf{L} / \mathbf{d a y})$ & 10.30 & 16.82 & 6.53 & +63.4 \\
\hline Air Conditioner Power (kWh/day) & 17.72 & 22.44 & +4.72 & +26.6 \\
\hline Ambient Temperature ( $\left.{ }^{\circ} \mathbf{F}\right)$ & Average & Minimum & Maximum & \\
\hline Ambient RH (\%) & $76.2^{\circ}$ & $62.2^{\circ}$ & $86.9^{\circ}$ & \\
\hline Ambient Dew Point $\left({ }^{\circ} \mathbf{F}\right)$ & $72.0^{\circ} \%$ & $31.9^{\circ} \%$ & $95.2^{\circ}$ & \\
\hline
\end{tabular}




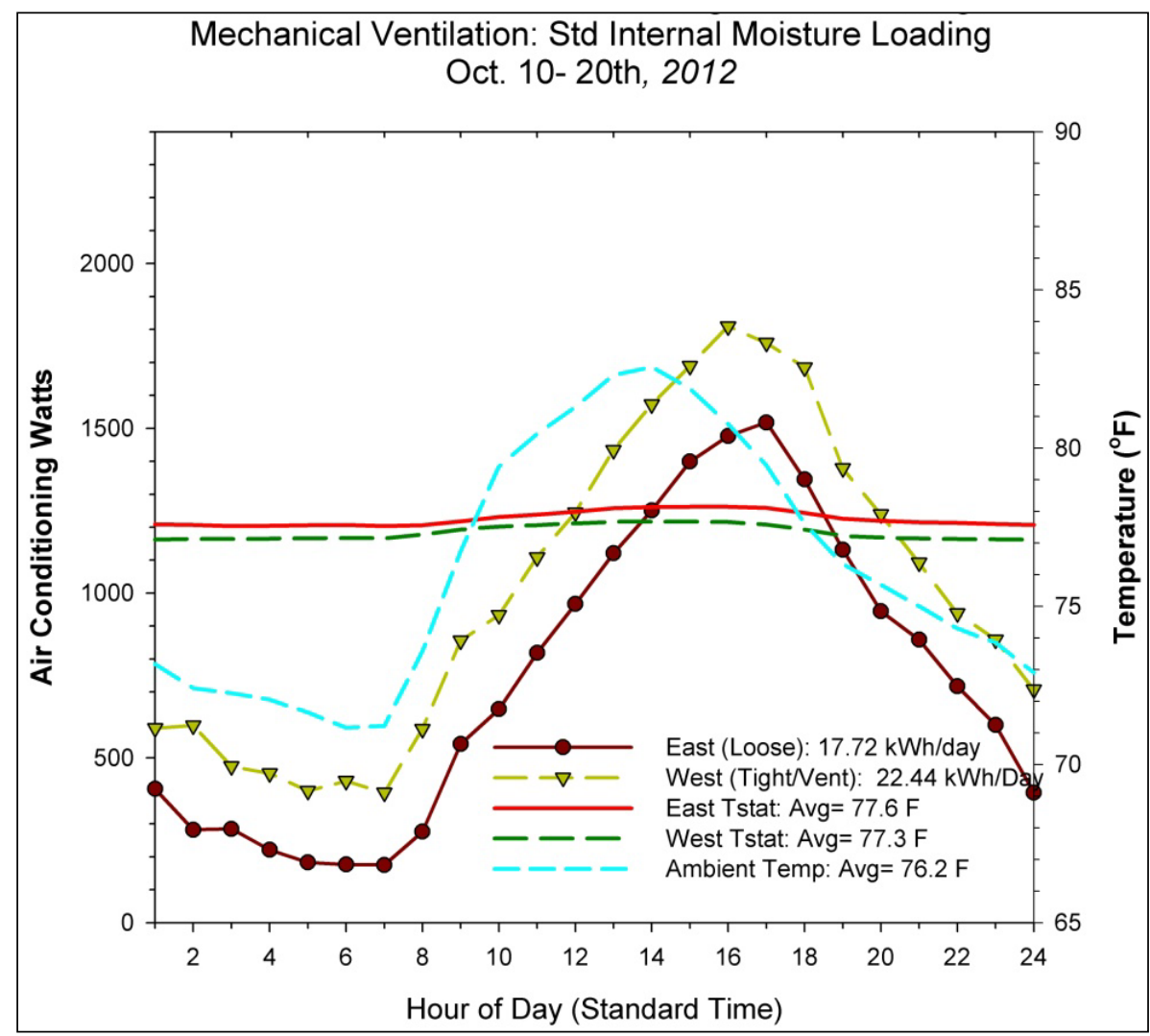

Figure 26. AC energy use, October 10-20, 2012: west unit vented

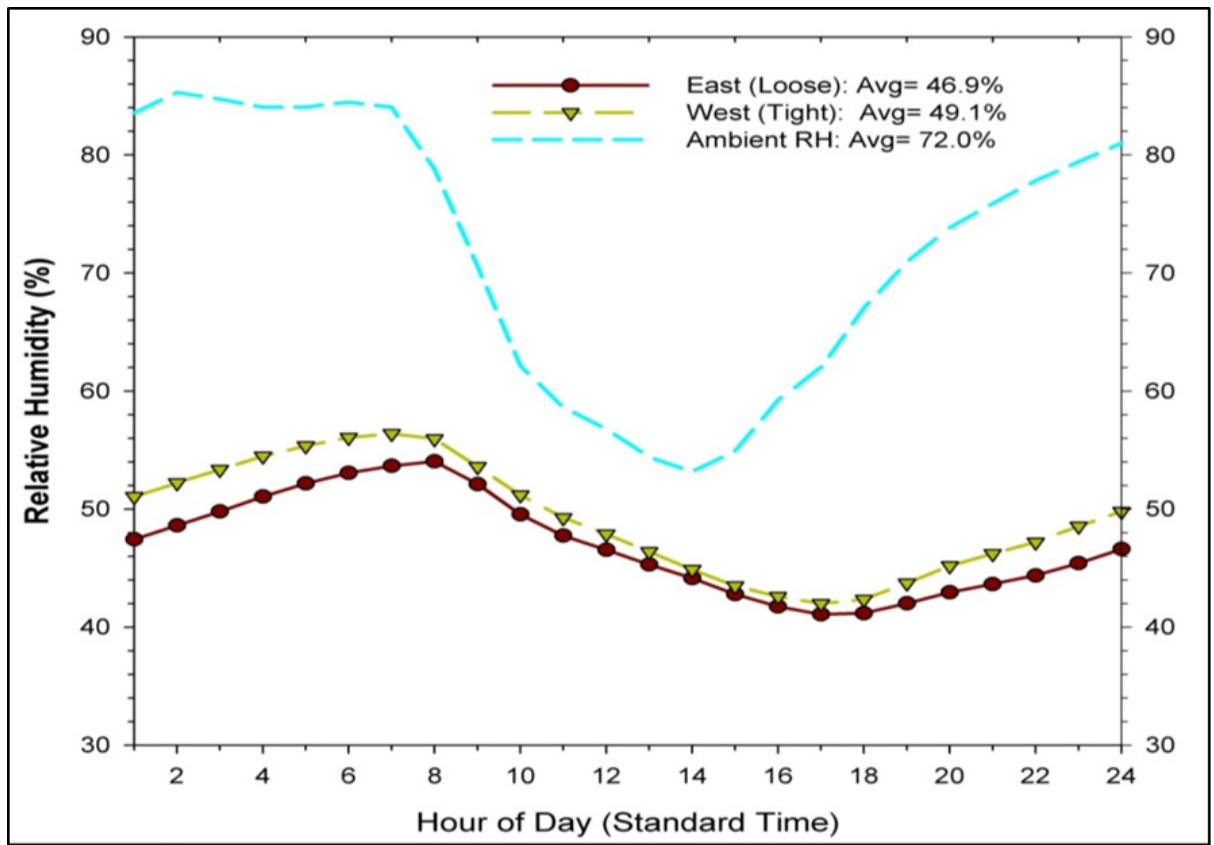

Figure 27. Comparative RH, October 10-20, 2012: west unit vented 


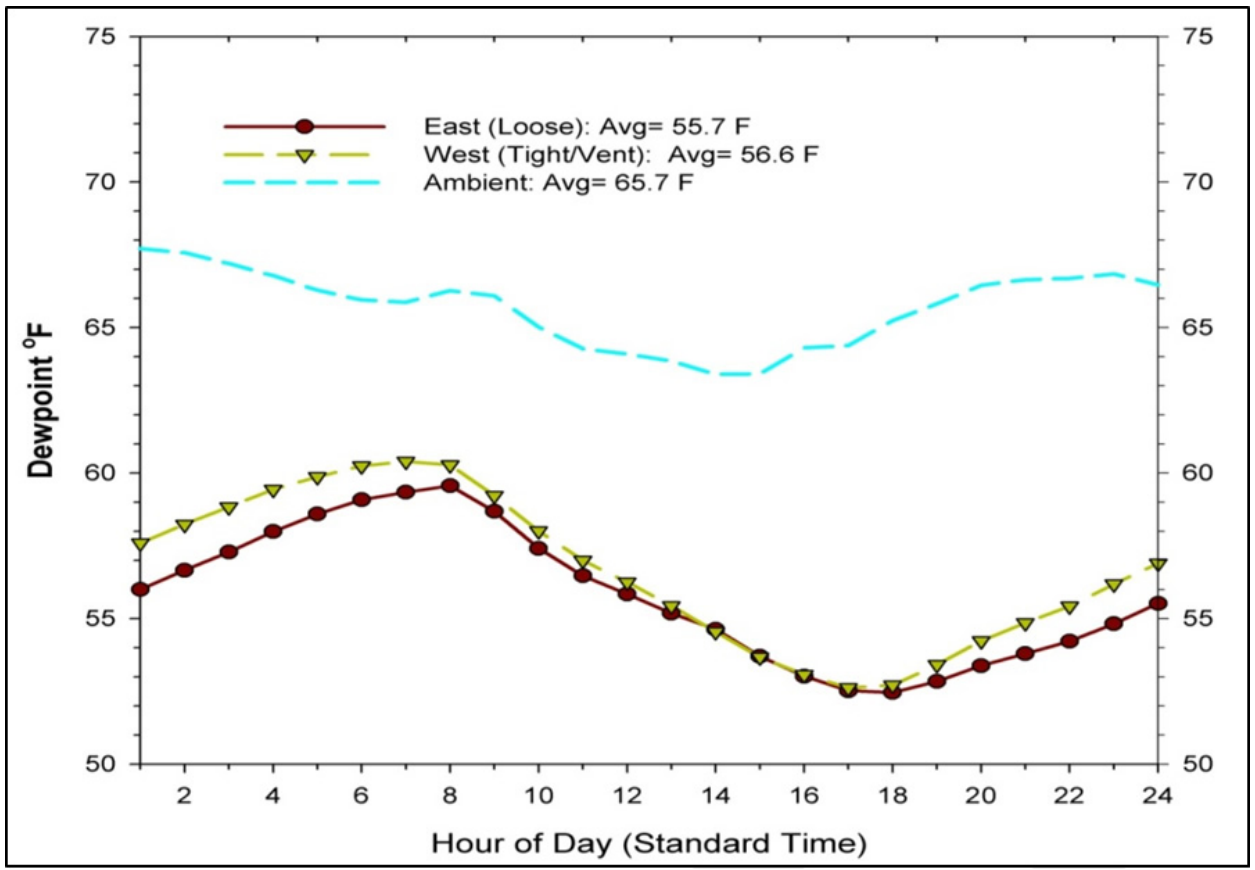

Figure 28. Comparative dew point temperatures, October 10-20, 2012: west unit vented

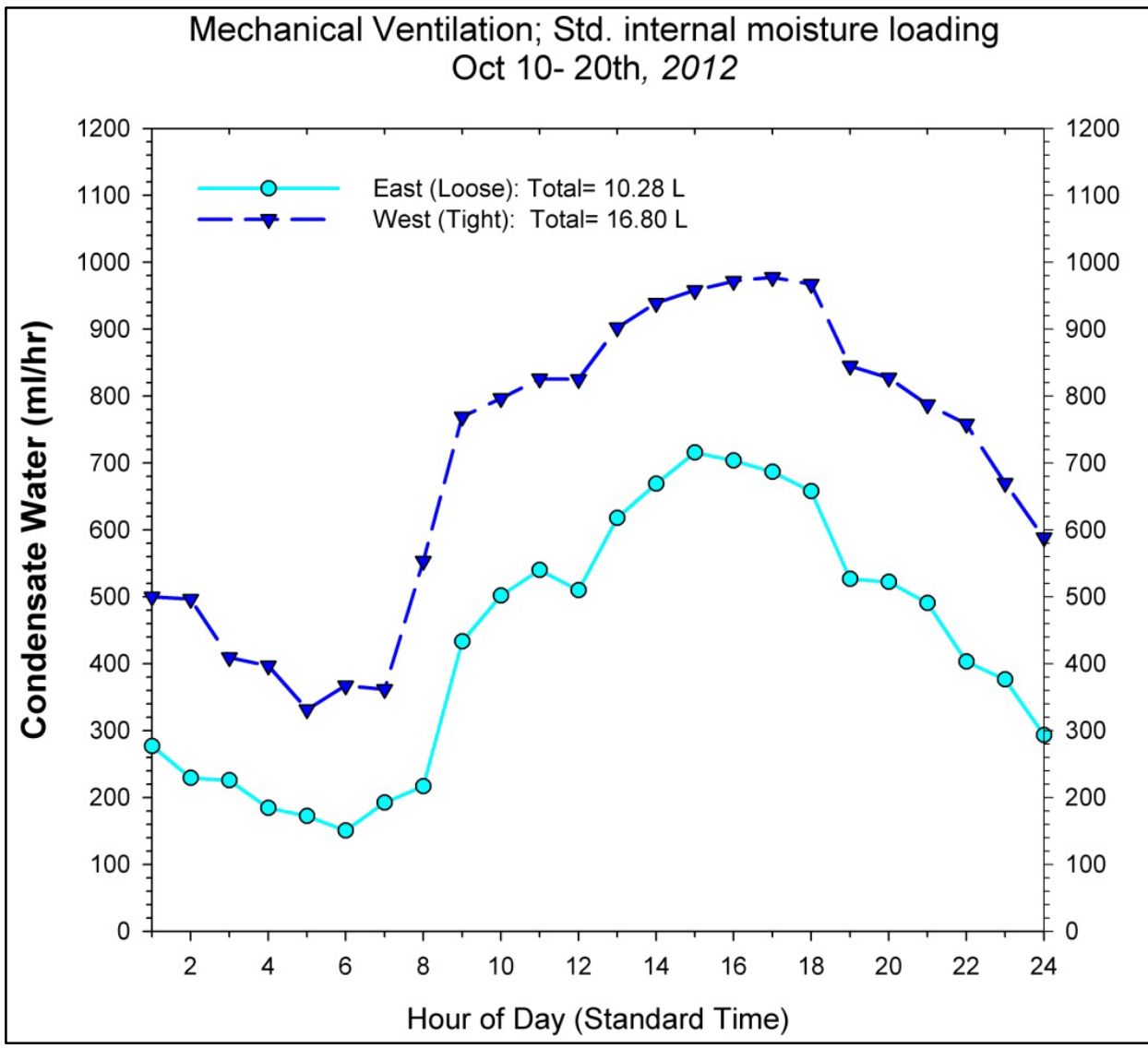

Figure 29. Comparative condensate removal, October 10-20, 2012: west unit vented 


\subsubsection{Test Period VI: October 25 to November 8, 2012}

The final test period came at the end of the cooling season in 2012 (Table 10) ending on November 8 . The ventilation system in the tighter west building was off for the entire time, and AC averaged 1.5 to $1.7 \mathrm{kWh}$ /day in the east and west buildings, respectively. The lower cooling use in the looser building is expected, as it was actually cooler outside than inside during the test. As seen in the testing in winter 2011-2012, the tighter unventilated building had much higher humidity levels: $59 \%$ versus $53 \% \mathrm{RH}$ and a dew point of $60^{\circ} \mathrm{F}$ versus $57^{\circ} \mathrm{F}$. Collected condensate was low, as the AC system seldom operated during this 14-day period. Because it was drier outside than inside, the leakier east building yielded lower internal moisture levels created by natural air infiltration. The summarized performance indices during the period are shown in Figure 30 through Figure 33.

Table 10. October 25 to November 8, 2012 (No Ventilation)

\begin{tabular}{c|c|c|c|c}
\hline & East & West & $\Delta$ & $\%$ \\
\hline Thermostat Temperature $\left({ }^{\circ} \mathbf{F}\right)$ & $75.8^{\circ}$ & $75.4^{\circ}$ & -0.4 & NA \\
RH $(\%)$ & $53.1 \%$ & $59.0 \%$ & +6.9 & +11.1 \\
Dew Point $\left({ }^{\circ} \mathbf{F}\right)$ & $57.3^{\circ}$ & $60.0^{\circ}$ & +2.7 & +4.7 \\
\hline Condensate $(\mathbf{L} /$ day) & 2.57 & 2.84 & +0.27 & +10.6 \\
\hline Air Conditioner Power $(\mathbf{k W h} /$ day) & 2.92 & 3.46 & +0.52 & +18.5 \\
\hline Ambient Temperature $\left({ }^{\circ} \mathbf{F}\right)$ & Average & Minimum & Maximum & \\
Ambient RH $(\%)$ & $65.4^{\circ}$ & $46.1^{\circ}$ & $81.9^{\circ}$ & \\
Ambient Dew Point $\left({ }^{\circ} \mathbf{F}\right)$ & $69.4 \%$ & $26.7^{\circ} \%$ & $95.0^{\circ}$ & \\
\hline
\end{tabular}

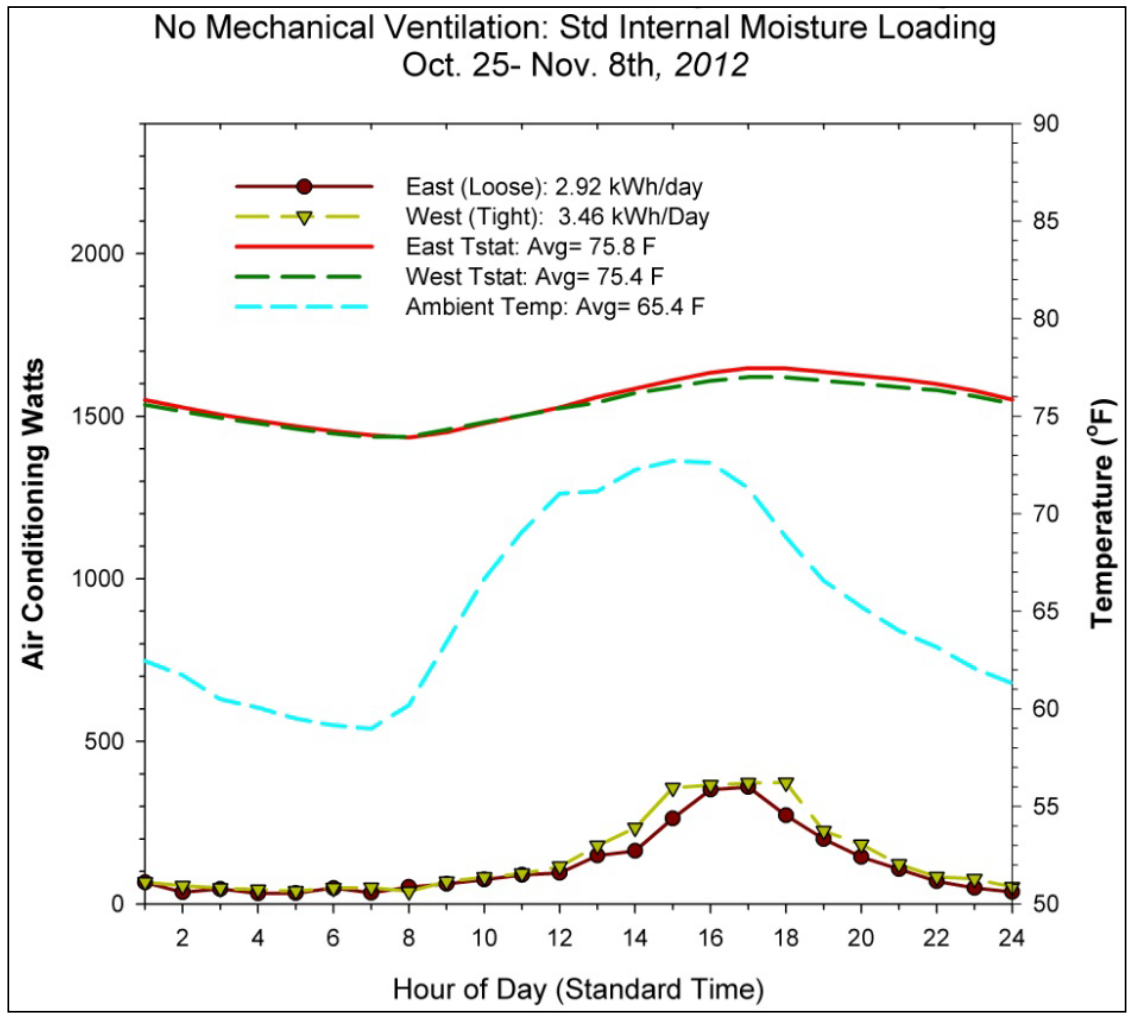

Figure 30. AC energy use, October 25 to November 8, 2012: no ventilation 


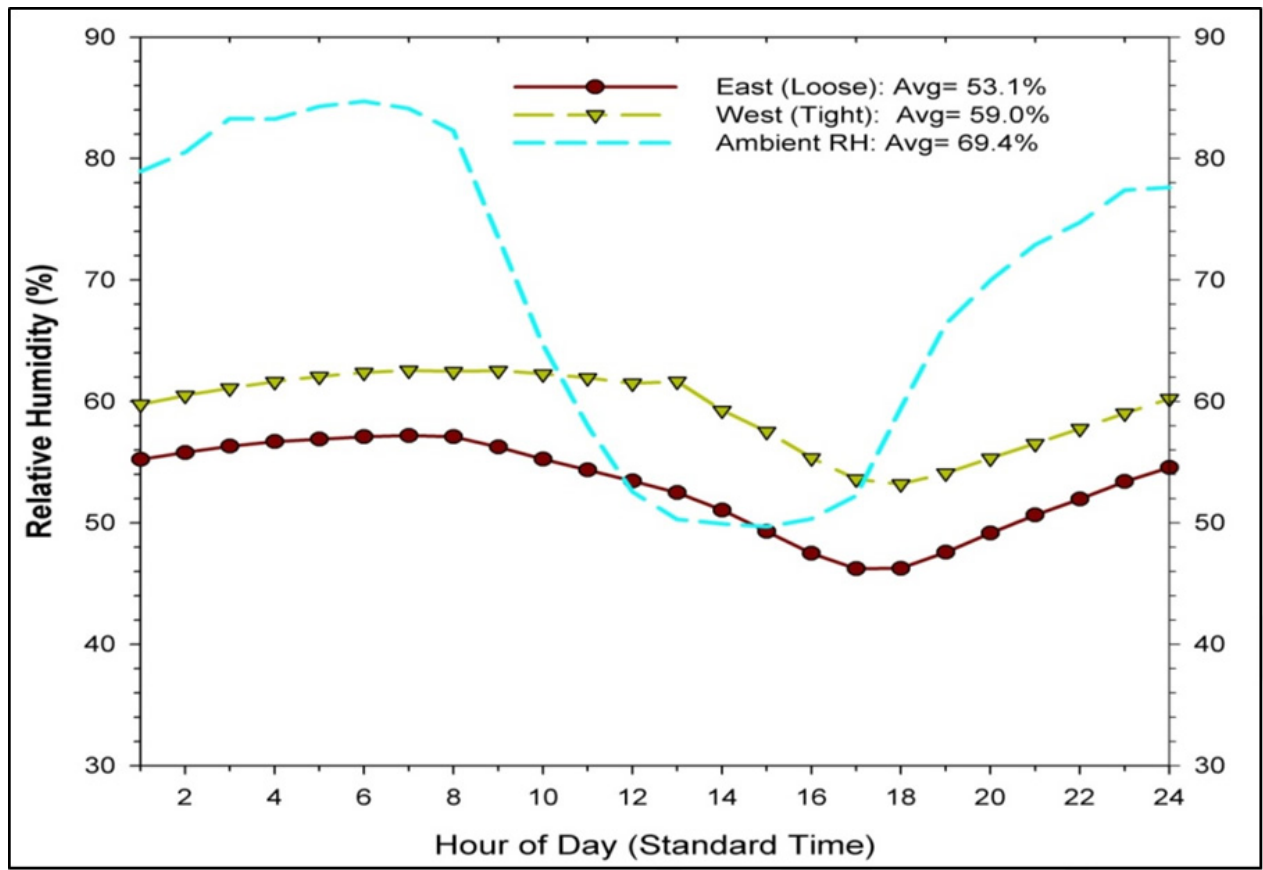

Figure 31. Comparative RH, October 25 to November 8, 2012: no ventilation

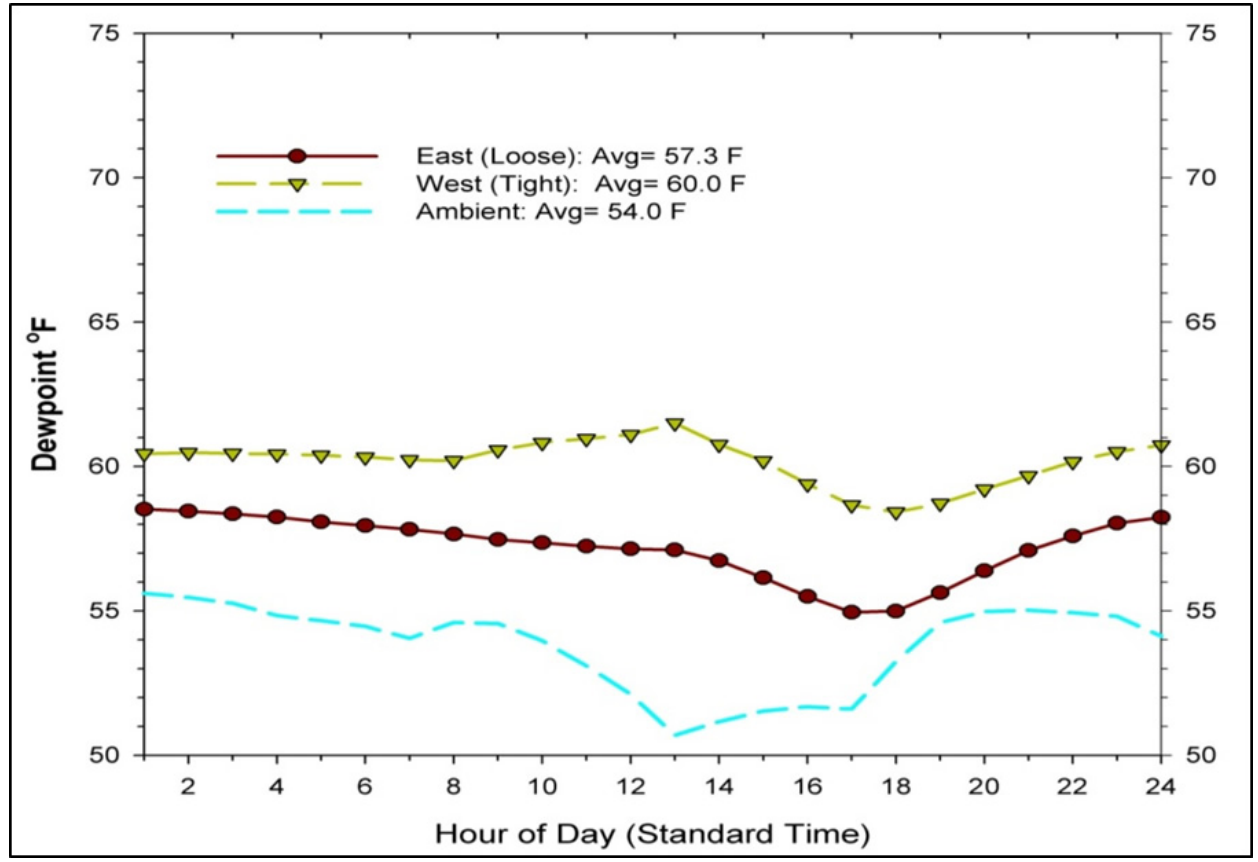

Figure 32. Comparative dew point temperatures, October 25 to November 8, 2012: no ventilation 


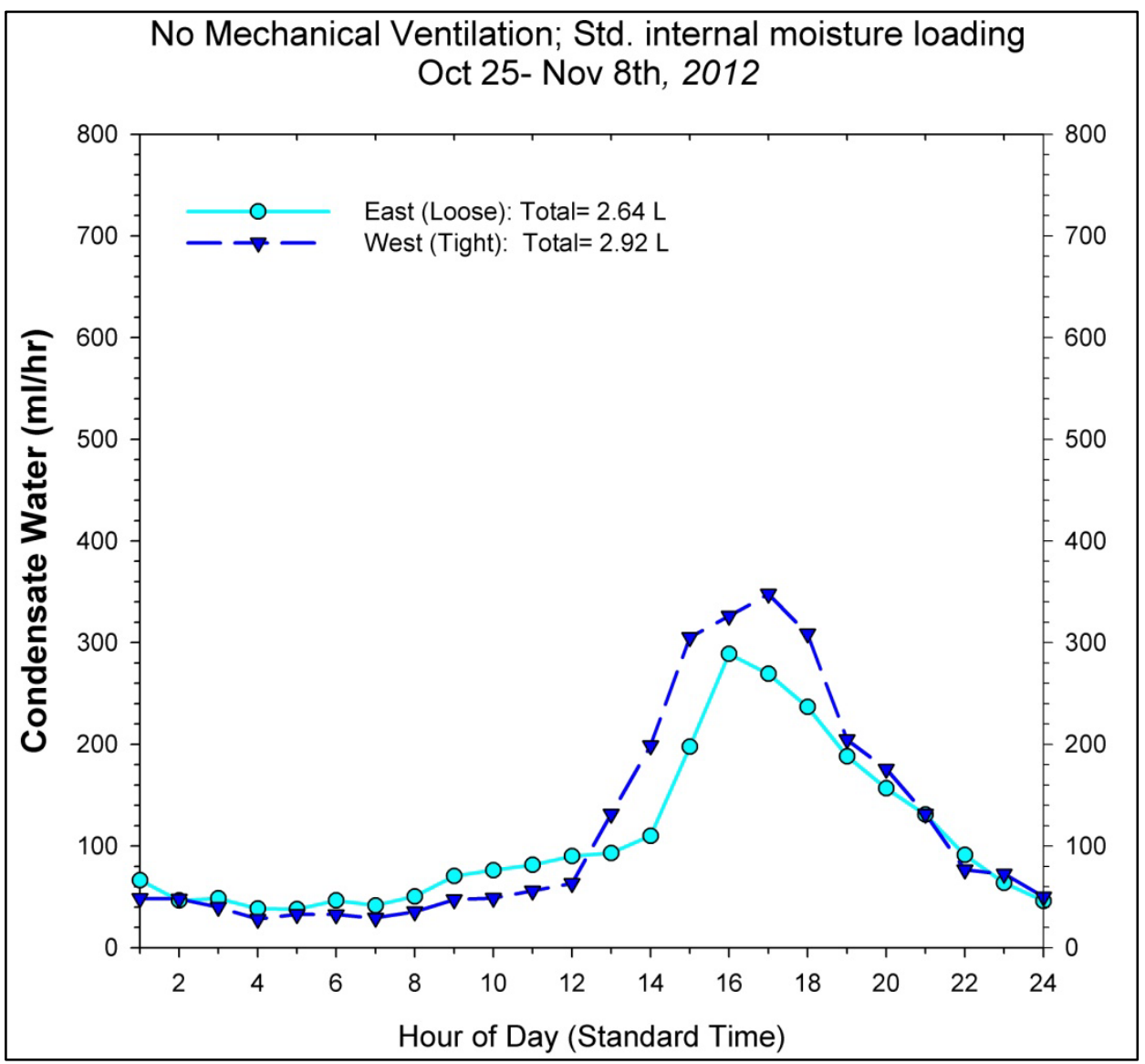

Figure 33. Comparative condensate removal, October 25 to November 8, 2012: no ventilation

\subsection{Tracer Gas Testing of Real-Time Building Infiltration and Ventilation Rates} In October 2012, $\mathrm{CO}_{2}$ dosing and monitoring equipment began to measure $\mathrm{CO}_{2}$ levels for calculating building infiltration rates.

The first plot in Figure 34 shows the measured total infiltration rates and resulting ACH for 8 days in the middle of October 2012. For this test period, the looser east building is in its standard leakage configuration (8 ACH50). The tighter west building (2.2 ACH50) had the supply fan operating for the entire period. Note in the plot that the west building experiences a greater amount of outdoor air as well as a more consistent value. The effective infiltration rate for the east building is only about $40 \mathrm{CFM}$ or $0.18 \mathrm{ACH}$. However, the west building with the mechanical ventilation system saw an average total outdoor air introduction rate of $73 \mathrm{CFM}$ or $0.33 \mathrm{ACH}$. For illustration, a dotted horizontal gray line shown in the plot below represents the outdoor mechanical ventilation rate (63 CFM) recommended by the ASHRAE Standard 62.22013, the air quality standard for a residence of this configuration. A dotted blue horizontal line shows the total ventilation rate (76 CFM) assumed by ASHRAE Standard 62.2-2013 when the estimates for natural infiltration are included. Although the west building comes close to matching this value, the east building falls short. 


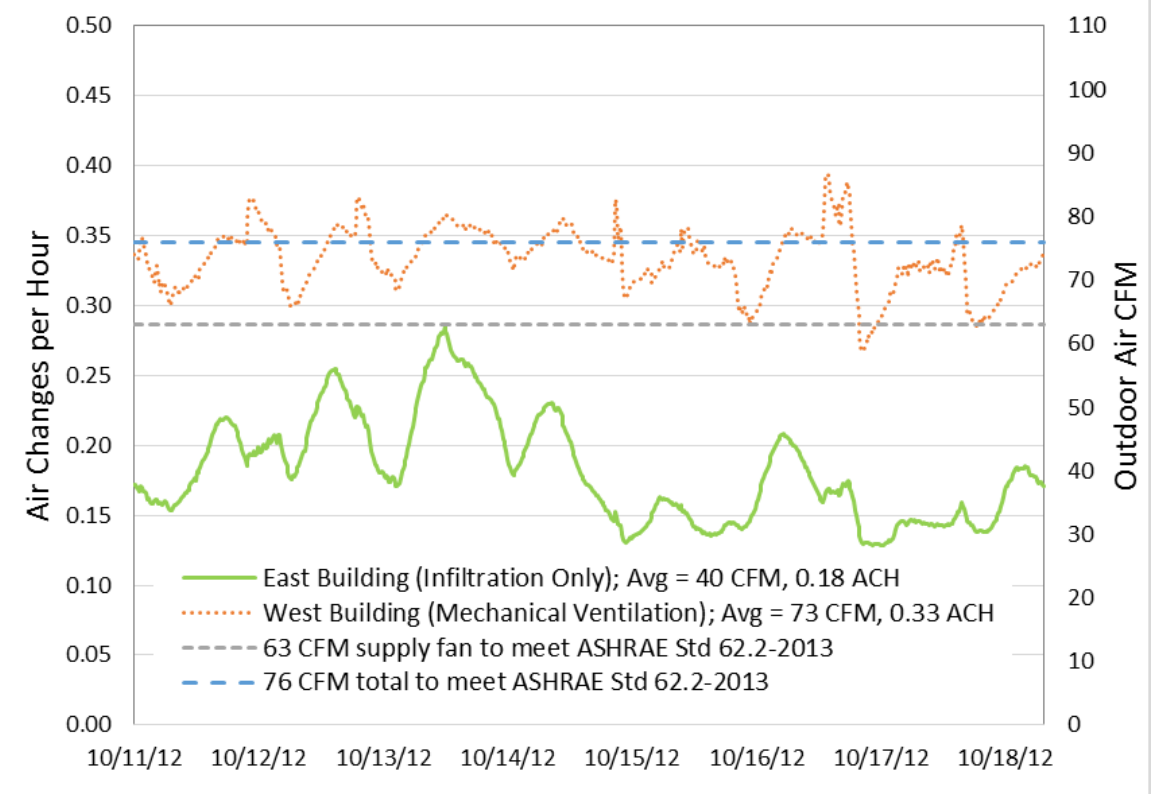

Figure 34. Measured infiltration rate by $\mathrm{CO}_{2}$ tracer, mechanical ventilation in west building

The second plot (Figure 35) shows similar data for an 8-day period when the buildings were in exactly the same configuration but with the supply ventilation fan in the tighter west building turned off. The two periods show a dramatic difference in the achieved ventilation rate. Although the end of October and beginning of November were somewhat cooler and windier, the tighter west building showed very low ventilation rates from natural infiltration: an average 9 CFM or $0.04 \mathrm{ACH}$. On the other hand, the leakier east building showed large response to weather as well as air handling unit operation (which serves to periodically depressurize the holes in the building shell). Some of the time, its infiltration rate was high enough to satisfy the mechanical ventilation rate of Standard 62.2-2013; less frequently, the infiltration satisfied the standard's recommended total ventilation rate. However, the infiltration was still too low during milder conditions. Average outdoor airflow rate was $58 \mathrm{CFM}$ for an average air change rate of 0.27 $\mathrm{ACH}$. 


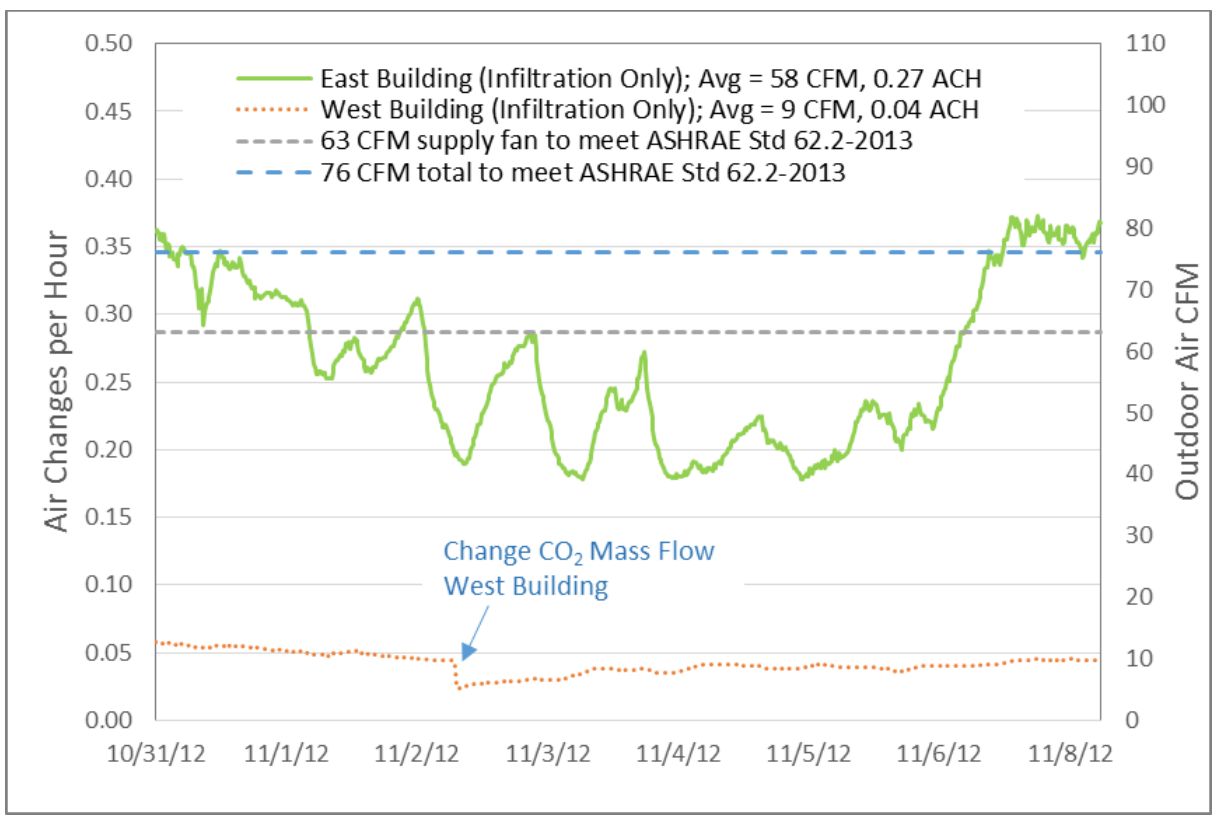

Figure 35. Measured infiltration rate by $\mathrm{CO}_{2}$ tracer, infiltration only in both buildings 


\section{Discussion}

\subsection{Moisture Control}

Reviewing the data taken during the summer test periods, we can conclude the following about relative interior moisture impacts of internal moisture loads, leakage rates, and mechanical ventilation:

\subsubsection{No Mechanical Ventilation}

- Greater internal moisture loads did not lead to significantly higher interior moisture levels when AC is in use and runtime is sufficient to remove the added moisture. As revealed by the comparative test periods in May-June and June-July, much of the possible impact of lower internal moisture generation rates is lost, as the AC equipment simply removes more moisture when the loads are high enough with greater runtime. This is shown by the consistent dew point temperatures during the two periods with much different moisture loading, while the condensate removed was much higher when the internal moisture generation was much higher in the July period. This resulted because the greater AC runtime in the midsummer period was able to effectively remove the added moisture. However, it is very likely that had the moisture generation rate been increased during a period when AC use was declining, the increase in interior moisture would have clearly been seen.

- Tighter envelope leakage with natural air infiltration in summer during AC had only modest impacts on internal moisture levels. Part of this may be due to the ceilingdominated distribution of leakage in the testing, which is consistent with residences in Florida, but may not be similar to other building foundation types. The low impact of building leakage on cooling was shown by comparing the data from May through July, when natural air infiltration only took place. Dew points were slightly lower in the tighter west building $\left(\sim 0.5^{\circ} \mathrm{F}\right)$, and collected air conditioner condensate was also slightly lower. Interior average RHs were low (42-43\%), within $1 \%$ of each other, and were not significantly different.

- An even higher building leakage rate does show some increase in interior moisture levels in summer - particularly under rainy conditions. This is seen by comparing the data for the period from October 2-8, when the east building with higher building leakage had $46 \%$ versus $44 \% \mathrm{RH}$, dew points of $56^{\circ} \mathrm{F}$ versus $54^{\circ} \mathrm{F}$, and much greater collected AC condensate (13.7 L/day versus $10 \mathrm{~L} /$ day).

- Against our inference from observation that air conditioner operation and dehumidification trump changes in natural air infiltration, it must be added that increased moisture loads during periods with a declining AC unit (such as the October data) will evidence greater moisture load impacts.

In summary, we found that building tightness, mechanical ventilation, and infiltration all operate in concert with the outdoor conditions and indoor moisture generation rates to produce indoor moisture conditions. Sometimes low infiltration lowered indoor moisture levels (during moist/rainy periods) and sometimes high infiltration, whether from a leaky envelope or mechanical venting, was beneficial (such as during periods with "free" cooling or dehumidification due to diurnal weather patterns). The issue then becomes, on balance, which 
conditions predominate in a given climate and during which seasons. Also critical is how this interacts with AC operation, which can counteract most moisture variation, even doubling indoor moisture generation rates.

\subsubsection{Mechanical Ventilation}

- When 63 CFM of mechanical supply air ventilation was added to the tighter west building, it experienced higher interior moisture levels with AC. For instance, in the September 1-13 test period, the mechanically-ventilated building had 5\% higher interior $\mathrm{RH}$, a $3^{\circ} \mathrm{F}$ increase in the interior dew point, and a $15 \mathrm{~L} /$ day increase in the collected $\mathrm{AC}$ condensate. This is not a surprising finding, as earlier empirical research by Rudd and Henderson (2007) found that homes with mechanical ventilation in humid climates without supplement dehumidification experienced higher interior moisture levels. We note, however, that no specific moisture-related issues emerged in summer in the lab houses. This was quite different in the winter period when no AC-related dehumidification was available and moisture problems (condensation and mold) were seen.

- Even though the east building had higher building leakage levels, there was still evidence of somewhat higher interior moisture levels under mechanical ventilation. This was evident in the October 10-20 test period. Interior RH was $2 \%$ higher, dew points were $1^{\circ} \mathrm{F}$ higher, and collected condensate was about $2 \mathrm{~L} /$ day higher in the west home. It should be noted, however, that these results were dependent on the prevailing weather when it was wetter outside than inside. In winter conditions in Central Florida, where it is often drier outside, the mechanical ventilation could be expected to result in lower interior moisture levels.

- Although slightly higher moisture and energy use were associated with mechanical ventilation, the $\mathrm{CO}_{2}$ tracer measured ventilation rates indicated that the leaky residential building without mechanical ventilation still fell considerably short of the recommended ASHRAE Standard 62.2-2013 ventilation levels much of the time, and the tighter west building without mechanical ventilation fell far below that rate $(0.04 \mathrm{ACH})$.

In summary, we saw that mechanical venting operates similarly to natural venting, in that under moist outdoor conditions it leads to higher indoor humidity, but this same effect in Florida's winter would operate in reverse with drier outdoor air. We also saw indication that mechanical venting seems to have a slightly different effect than natural ventilation to a similar rate, although such a hypothesis would need more rigorous experimentation.

Another caution is that the evaluation does not include any duct leakage in either of the test buildings, an unusual configuration for a Florida building. It is nearly certain that there would be large interactions with duct system leakage during the summer, which should be investigated. These could easily lead to considerably higher internal moisture levels because running the AC system would both remove and add outdoor moisture. This study also indicates a need for further testing on mechanical ventilation, including enthalpy recovery, to determine if part of the reduced moisture and energy performance of forced ventilation can be ameliorated. Finally, it has been suggested by project reviewers that an exhaust ventilation system might actually function better to address the observed moisture-related increases. 


\subsection{Air Conditioning Energy Use}

The measured air conditioner and air handling unit compressor power was continuously measured during the test period to evaluate how measured cooling energy use was influenced by building air leakage and mechanical ventilation. Average summer AC from May 1 through September 30 averaged $11.7 \mathrm{kWh} /$ day in the east building and $12.2 \mathrm{kWh} /$ day in the west building. This compares to measured AC energy use in average Florida homes of $24.5 \mathrm{kWh} /$ day over the same May-September summer time frame, according to monitoring studies from Florida Power and Light Company (Florida Power and Light Company 1999).

The lower-than-average AC energy use is likely due to several factors. The thermostat settings may be somewhat high $\left(78^{\circ} \mathrm{F}\right)$, and the air conditioners used in this study are newer and more efficient than the air conditioners in the Florida Power and Light study (seasonal energy efficiency ratio $13 \mathrm{Btu} / \mathrm{Wh}$ versus an average seasonal energy efficiency ratio 10 in the Florida Power and Light study). Additionally, the test buildings are operating with almost no duct leakage, which is atypical for existing Florida homes (e.g., Cummings et al. 1990). However, the purpose of this study is to examine the influences of infiltration and ventilation without the complications of duct system interactions.

\subsection{Tracer Gas Testing}

Tracer gas testing in October 2012 reinforced expectations regarding air infiltration and ventilation. It is noteworthy that the indicated ASHRAE Standard 62.2-2013 ventilation rate for the lab buildings is 63 CFM of mechanical ventilation and 76 CFM overall.

- Without mechanical ventilation, the tighter building had a much lower leakage rate than the loose one ( $0.04 \mathrm{ACH}$ versus $0.27 \mathrm{ACH})$. The tighter building was far below the recommended ASHRAE Standard 62.2-2013 total ventilation rate (76 CFM), while at times the leaker building approached this level, but it fell short during milder conditions.

- When mechanical ventilation was added to the tighter building, it exhibited higher ventilation ( $73 \mathrm{CFM}$ versus $40 \mathrm{CFM}$ and $0.33 \mathrm{ACH}$ versus $0.18 \mathrm{ACH}$ ).

- A tighter building with mechanical ventilation tended to remain close to the ventilation target and experience less amplitude in its variation relative to a loose building. The 62.22013 compliant target is 76 CFM of ventilation for the laboratory homes. The east structure, relying solely on natural ventilation saw an average ventilation rate of 39.7 CFM (standard deviation = 8.2 CFM) over a weeklong test period with a range of 28-62 CFM against an average for the tight west building with mechanical ventilation of 72.8 CFM (standard deviation $=4.8 \mathrm{CFM}$ ) with a range of 58-86 CFM. 


\section{Conclusions}

How does the airtightness of a home affect its moisture levels, temperature, and AC loads during the cooling season in a hot-humid climate?

The comparative summer testing showed that the tighter buildings, exemplified by the west structure compared to the leakier east structure, exhibited little if any AC energy savings under natural infiltration. This was largely because the outdoor temperature was nearly as often below as above the desired thermostat set point (as examples, see Figure 11 and Figure 19). Thus, increased air infiltration during nighttime hours when the temperature outside is lower than the desired cooling set point actually reduces the AC load. The same is true of mechanical ventilation, which will act like an economizer during cooler nighttime hours.

During the first part of the summer, the building moisture levels and temperature levels saw only minor changes between the tight and loose structures, mainly because the buildings utilized AC most of the time, and the AC promptly removed any excess heat or moisture.

The only measurable differences seen in increased infiltration between the homes occurred toward the end of the testing period. The first week of October, period V, featured heavy rainfall, while both homes operated with natural infiltration only. The humidity averaged $2.5 \%$ higher, and the dew point averaged nearly $2^{\circ} \mathrm{F}$ higher in the east (loose) home during this time period, while the AC energy was nearly the same. During the last testing period of the study, the AC loads decreased, and the tight west house had much higher moisture levels, with an RH 6\% higher and a dew point $2.7^{\circ} \mathrm{F}$ higher than the loose east house.

How does mechanical ventilation at ASHRAE Standard 62.2-2013 levels affect a home's moisture levels, temperature, and AC loads during the cooling season?

When mechanical ventilation was added to the airtight home, cooling energy use increased by $27 \%-30 \%$, or about $5-7 \mathrm{kWh} /$ day when comparing to the nearby building with natural air infiltration only. Part of this came from the fact that the mechanical ventilation system fan itself added $1.8 \mathrm{kWh}$ /day of energy use. Moreover, as shown in Sections 4.3.3 and 4.3.5, the operation of the mechanical ventilation system also appeared to result in measurable increases to the building moisture levels, whereas a leaky building envelope had only modest increases to interior moisture levels (Section 4.3.4). The reason for this disparity is likely because of low driving forces for air infiltration, as seen in the tracer gas testing, resulting in low overall airflow even in the building with substantial ceiling leakage. This means that the leaky building was resulting in less overall outside air being introduced, and hence less impact to energy and moisture levels. It is also possible there are differences due to enthalpy recovery through the building envelope components during natural air infiltration (e.g., Claridge and Bhattacharyya 1990) as opposed to mechanical ventilation. However, this would need further testing and evaluation. One important point to examine would be whether exhaust-only ventilation might exact less impact on energy and interior moisture conditions. 
How does air infiltration from natural infiltration compare to the ASHRAE Standard 62.2-2013 ventilation requirements?

During periods with no mechanical ventilation, the tight west home showed very low infiltration rates, even on windy days - often less than $0.06 \mathrm{ACH}$. The leakier east home, however, exhibited much higher infiltration rates, and during windy periods, it proved comparable over a daily time period to the ventilation prescribed by ASHRAE Standard 62.2-2013. This was not true during periods of low wind, however; the building experienced air changes rates considerably lower than recommended by Standard 62.2-2013. Meanwhile, the tight building with mechanical ventilation experienced less variation in the effective ventilation rate. The east home had infiltration rates that satisfied Standard 62.2-2013 for some of the time and had an average infiltration rate of 58 CFM during a 9-day period, as shown in Section 4.4.

The tight west home with mechanical ventilation showed a high and more consistent level of air exchange, averaging 73 CFM and hovering around the ASHRAE Standard 62.2-2013 recommended 76 CFM during an 8-day testing period. This period was less windy than the previously mentioned period. The east building was well below Standard 62.2-2013 levels, but it was still significant, at an average of 40 CFM.

According to these data, a leaky home experiences a significant amount of infiltration for a home compared to ASHRAE Standard 62.2-2013 levels of ventilation, especially during windy periods. During the mechanical ventilation period, the leaky home experienced more than half the infiltration than the mechanically-ventilated home experienced. ${ }^{5}$

\section{How does the level of moisture generation within a home affect its moisture levels and AC loads?}

During summer months when a home's air conditioner is running regularly, differences in moisture generation seemed to have little impact on interior moisture levels and only moderate impact on energy use. The two test periods used to compare a standard moisture generation level and a reduced moisture generation level showed little difference between internal temperatures, humidities, and air conditioner power consumption. However, real differences in the impact of moisture generation were likely masked by increased air conditioner runtime during the period with higher moisture release, as this time came during a hotter part of the summer with greater air conditioner operation and hence moisture removal. The major change to the data was an increase in condensate collection from around $6.5 \mathrm{~L} /$ day with lower moisture generation to approximately $10.5 \mathrm{~L} /$ day with standard moisture generation. In the future, this influence could be isolated by introducing more moisture during a series of flip-flop tests that would likely show evidence of larger effect.

\subsection{Key Findings/Lessons Learned}

Overall, this study found that natural air infiltration from a relatively leaky home ( $\sim 8 \mathrm{ACH} 50)$ does not cause a significant increase in cooling energy, but can cause some increase in moisture levels near the end of the summer season when sensible loads fall. It must be added that these

\footnotetext{
${ }^{5}$ One caveat to the collected data is that the lab buildings, while similar to the distribution of leakage in most Florida buildings, may not be similar to other housing in the Southeast - particularly that with crawlspace floors. In Florida slab-on-grade homes, a majority of the leakage is shielded from the wind and located in the ceiling plane due to recessed lighting fixtures and bathroom and kitchen fans making up a preponderance of the leakage sites.
} 
results are true, however, in locations such as Central Florida where the interior to exterior temperature differences under cooling are low and outdoor moisture levels are high. Such results provide further evidence that much of the moisture problem in residences in Central Florida likely occurs during winter when there are no sensible cooling loads and no humidity removal. Unlike natural infiltration in leaky homes, forced ventilation at ASHRAE Standard 62.2-2013 levels caused increases to both moisture and energy use in homes. Cooling energy use increased by $27 \%-30 \%(5-7 \mathrm{kWh} /$ day) and building moisture increased measurably, approaching and occasionally exceeding an interior RH of $60 \%$.

Consistent with past findings and simulation estimates, the introduction of mechanical ventilation will generally increase the energy usage of an airtight home and may affect indoor humidity, but this is necessary because of the highly variable and often insufficient air ventilation rate provided by even a fairly leaky home in a hot-humid climate, which can have limited natural driving forces during the cooling season.

\subsection{Future Work}

The experience with the summer testing suggests that further experimentation be done to examine the potential of enthalpy recovery ventilation systems to address moisture issues and provide more comparable energy performance. Also, as the buildings do not have interior walls or normal furnishings, there are questions about how these factors may influence moisturerelated impacts. This should be examined in future testing. 


\section{References}

American Society of Testing and Materials. (2011). ASTM E-741: Standard Test Method for Determining Air Change in a Single Zone by Means of a Tracer Gas Dilution. Philadelphia, PA: ASTM.

Arundel, A.; Sterling, E.; Biggin, J.; Sterling, T. (1986). "Indirect Health Effects of Relative Humidity in Indoor Environments." Environmental Health Perspectives 65:351-361.

ASHRAE Standard 62.2-2010: Ventilation and Acceptable Indoor Air Quality in Low Rise Residential Buildings. (2010). Atlanta, GA: ASHRAE.

ASHRAE Standard 160-2009. Criteria for Moisture-Control Design Analysis in Buildings. Atlanta, GA: ASHRAE.

Barley, D. (2001). An Overview of Residential Ventilation Activities in the Building America Program. NREL/TP-550-30107. Golden, CO: National Renewable Energy Laboratory.

Baughmann, A.; Arens, E. (1996). "Indoor Humidity and Human Health: Literature Review of Health Effects of Humidity Influenced Indoor Pollutants." ASHRAE Transactions 102, Pt. 1. Atlanta, GA: ASHRAE.

Blondeau, P.; Spérandio, M.; Allard, F. (1997). "Night Ventilation for Building Cooling in Summer." Solar Energy 61(5):327-335.

Claridge, D.; Bhattacharyya, S. (1990). "The Measured Energy Impact of Infiltration in a Test Cell.” Journal of Solar Energy Engineering 112.

Cummings, J.; Tooley, J. (1989). "Infiltration and Pressure Differences Induced by Forced Air Systems in Florida Residences." ASHRAE Transactions 95:2.

Cummings, J.; Tooley, J.; Moyer, N.; Dunsmore, R. (1990). "Impacts of Duct Leakage on Infiltration Rates, Space Conditioning Energy Use, and Peak Electrical Demand in Florida Homes." Proceedings of the ACEEE 1990 Summer Study, August 1990, Pacific Grove, CA.

Emmerich, S.; Persily, A.; McDowell, T. (2005). "Impact of Infiltration on Heating and Cooling Loads in US Office Buildings." Proceedings of the 26th IEA Conference of the Air Infiltration and Ventilation Center.

Fang., X.; Christiansen, D.; Barker, G.; Hancock, E. (2011). Field Test Protocol: Standard Internal Load Generation for Unoccupied Test Homes. NREL/TP-550-51928. Golden, CO: National Renewable Energy Laboratory.

Fisk, W.; Elisseeva, E.; Mendall, M. (2010). "Association of Residential Dampness and Mold with Respiratory Tract Infections and Bronchitis: A Meta Analysis." Environmental Health Journal 9:72.

Florida Power and Light Company. (1999). "Typical Customer Monthly Electricity Usage by DCA Climate and House Type," FPL Gas Hot Water Research Project, Florida Power and Light Company, Miami, FL, May, 1999.

Hekmat, D.; Feustel, H.; Modera, M. (1986). "Impacts of Ventilation Strategies on Energy Consumption and Indoor Air Quality in Single-family Residences." Energy and Buildings 9:239-251. 
Henderson, H.; Rengarahan, K. (1996). "A Model to Predict the Latent Capacity of Air Conditioners and Heat Pump at Part-Load Conditions with Constant Fan Operation." ASHRAE Transactions 102(Pt. 1):266-274. Atlanta, GA: ASHRAE.

Iwashita, G.; Akasaka, H. (1997). "The Effects of Human Behavior on Natural Ventilation Rate and Indoor Air Environment in Summer - A Field Study in Southern Japan." Energy and Buildings 25(3):195-205.

"Lighting, Appliance and Miscellaneous Energy Usage Profile Amendment." (2011). RESNET. Accessed June 2013: www.resnet.us/standards/PropStdsRevision-01-11_Revised FINAL.pdf.

Robertson, J.; Brown, E.; Koomey, J.; Greenberg, S. (1998). Recommended Ventilation Strategies for Energy-Efficient Production Homes. LBNL-40478. Berkeley, CA: Lawrence Berkeley National Laboratory.

Rudd, A.; Henderson, H. (2007). "Monitored Interior Moisture and Temperature Conditions in Humid Climate Homes.” ASHRAE Transactions 113, Pt. 1. Atlanta, GA: ASHRAE.

Sherman, M.; Grimsrud, D.; Condon, P.; Smith, B. (1980). "Air infiltration Measurement Techniques.” First International Energy Agency Symposium of the Air Infiltration Center; October 1980, Windsor, England. LBNL-10705. Berkeley, CA: Lawrence Berkeley National Laboratory.

Sherman, M.; Wilson, D.; Kiel, D. (1986). "Variability in Residential Air Leakage.” Measured Air Leakage of Buildings, ASTM STP 904, H.R. Trechsel and P.L. Lagus, Eds. American Society for Testing and Materials, Philadelphia, pp. 349-364.

Vieira, R.; Sherwin, J. (2012). Flexible Residential Test Facility Instrumentation Plan. Report to the Building America Building Technologies Program, Office of Energy Efficiency and Renewable Energy, U.S. Department of Energy.

Walker, I.; Sherman, M. (2003). Heat Recovery in Building Envelopes. LBNL-53484. Berkeley, CA: Lawrence Berkeley National Laboratory.

Walker, I.; Sherman, M. (2007). "Humidity Implications for Meeting Residential Ventilation Requirements." ASHRAE Transactions 113, Pt. 1. Atlanta, GA: ASHRAE.

Walker, I.; Wilson, D. (1998), "Field Validation of Equations for Stack and Wind Driven Air Infiltration Calculations." ASHRAE HVAC\&R Research Journal 4(2):119-140.

Wray, C.P.; Matson, N.E.; Sherman, M.H. (2000). "Selecting Whole House Ventilation Strategies to Meet Proposed ASHRAE Standard 62.2: Energy Cost Considerations." ASHRAE Transactions 106, Part II. Also (1998) Berkeley, CA: Lawrence Berkeley, National Laboratory; LBNL-44479. 


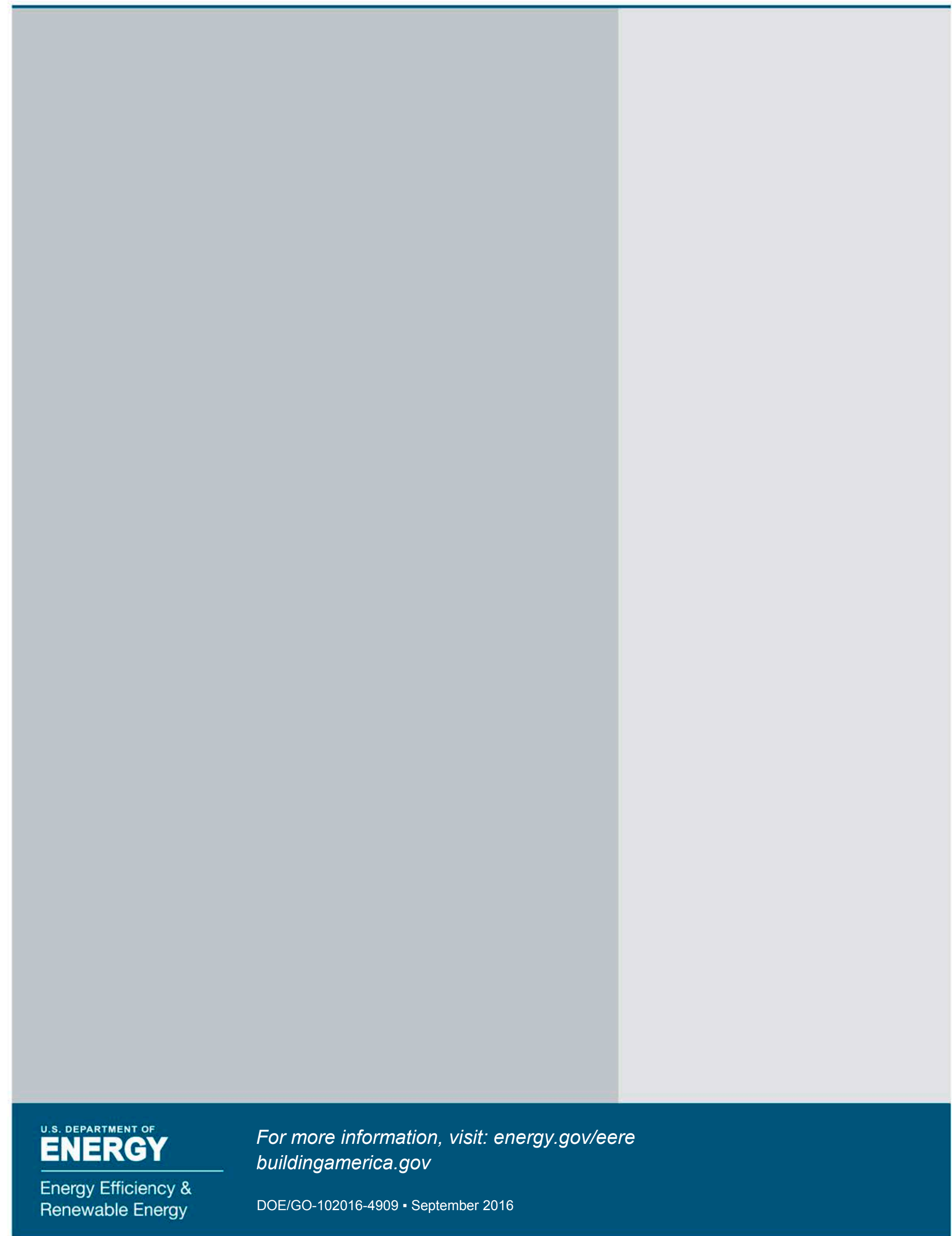

